\title{
Title: A piperidinium salt stabilizes efficient metal-halide perovskite solar cells
}

Authors: Yen-Hung $\mathrm{Lin}^{1}{ }^{*}$, Nobuya Sakai ${ }^{1}$, Peimei $\mathrm{Da}^{1}$, Jiaying $\mathrm{Wu}^{2}$, Harry C. Sansom ${ }^{1}$, Alexandra J. Ramadan ${ }^{1}$, Suhas Mahesh ${ }^{1}$, Junliang Liu ${ }^{3}$, Robert D. J. Oliver ${ }^{1}$, Jongchul Lim ${ }^{1 \#, ~}$ Lee Aspitarte ${ }^{4}$, Kshama Sharma ${ }^{5}$, P. K. Madhu ${ }^{5}$, Anna B. Morales-Vilches ${ }^{6}$, Pabitra K. Nayak ${ }^{1,5}$, Sai Bai ${ }^{7}$, Feng Gao ${ }^{7}$, Chris R. M. Grovenor ${ }^{3}$, Michael B. Johnston ${ }^{1}$, John G. Labram ${ }^{4}$, James R. Durrant $^{2,8}$, James M. Ball ${ }^{1}$, Bernard Wenger ${ }^{1}$, Bernd Stannowski ${ }^{6}$, Henry J. Snaith ${ }^{1 *}$

\section{Affiliations:}

${ }^{1}$ Clarendon Laboratory, Department of Physics, University of Oxford, Parks Road, Oxford OX1 3PU, United Kingdom.

${ }^{2}$ Department of Chemistry and Centre for Plastic Electronics, Imperial College London, London W12 0BZ, United Kingdom.

${ }^{3}$ Department of Materials, University of Oxford, Parks Road, Oxford OX1 3PH, United Kingdom.

${ }^{4}$ School of Electrical Engineering and Computer Science, Oregon State University, Corvallis, OR 97331, USA.

${ }^{5}$ TIFR Centre for Interdisciplinary Sciences, Tata Institute of Fundamental Research, Hyderabad 500107, India.

${ }^{6}$ PVcomB, Helmholtz-Zentrum Berlin für Materialien und Energie GmbH, Schwarzschildstr. 3, 12489 Berlin, Germany.

${ }^{7}$ Department of Physics, Chemistry and Biology (IFM), Linköping University, Linköping, Sweden.

${ }^{8}$ SPECIFIC, College of Engineering, Swansea University, Bay Campus, Swansea SA1 8EN, United Kingdom.

\#Present address: Graduate School of Energy Science and Technology, Chungnam National University, 99 Daehak-ro, Yuseong-gu, Daejeon, 34134, Republic of Korea.

*Correspondence to: yen-hung.lin@physics.ox.ac.uk, henry.snaith@physics.ox.ac.uk

\begin{abstract}
:
Longevity has been a long-standing concern for hybrid perovskite photovoltaics. We demonstrate high-resilience positive-intrinsic-negative perovskite solar cells by incorporating a piperidiniumbased ionic-compound into the formamidinium-cesium lead-trihalide perovskite absorber. With the band gap tuned to be well suited for perovskite-on-silicon tandem cells, this piperidinium additive enhances the open-circuit voltage and cell efficiency. This additive also retards compositional segregation into impurity phases and pinhole formation in the perovskite absorber layer during aggressive aging. Under full-spectrum simulated sunlight in ambient atmosphere, our
\end{abstract}


unencapsulated and encapsulated cells retain $80 \%$ and $95 \%$ of their peak and "post-burn-in" efficiencies for 1010 and 1200 hours at 60 and 85 degree Celsius, respectively. Our analysis reveals detailed degradation routes that contribute to the failure of aged cells.

One Sentence Summary: Molecular additives enable exceptional longevity for perovskite solar cells by effectively inhibiting the generation of degradation products.

\section{Main Text:}

Two-terminal monolithic perovskite-on-silicon tandem cells appear to be one of the most promising photovoltaic technologies for a near-term commercial-scale deployment $(1,2)$. They feature a wide band-gap perovskite "top-cell" which absorbs in a complementary region of the solar spectrum, in comparison to the silicon "bottom-cell", and such solar cells with a certified PCE reaching $29.1 \%$ have been demonstrated (3).

There is often a compromise between achieving high efficiency and long-term stability. The presence of methylammonium (MA) as the A-site cation in the perovskite absorber, which leads to more rapid decomposition under elevated temperature, light exposure, and atmosphere (4), can be alleviated by substitution with formamidinium (FA) or compositions of FA and cesium (Cs) (5-7). However, the use of MA persists in many recent reports on the highest efficiency perovskite cells in the form of the mixed cation MA/FA/Cs or FA/MA perovskites $(8,9)$. Also, the organic hole-conductor 2,2',7,7'-tetrakis[ $N, N$-di(4-methoxyphenyl)amino]-9,9'spirobifluorene (Spiro-OMeTAD) and the "additives" required to deliver high efficiency are detrimental to the stability of perovskite cells (10-12), but often used in the highest PCE singlejunction perovskite cells $(9,12)$. Finally, molecular passivation of defects in the perovskite absorber (13), in order to deliver solar cells approaching the "radiative" efficiency limit, are often thermally unstable. The absorber layers and cells reverting to their "unpassivated" state, after thermal treatment at temperatures as low as $60^{\circ}$ to $85^{\circ} \mathrm{C}(9)$.

Efforts hence are required to deliver efficiency enhancements and improve long-term stability. We recently reported that incorporation of an imidazolium-based ionic liquid into positive-intrinsic-negative ( $\mathrm{p}-\mathrm{i}-\mathrm{n})$ perovskite solar cells, which use the triple cation perovskite as the absorber layer and nickel oxide $(\mathrm{NiO})$ as the p-type layer, can improve both efficiency and long term stability (14). However, the best-quality $\mathrm{NiO}$ p-layers require annealing at $\sim 400^{\circ} \mathrm{C}$, which makes them challenging for integration with Si heterojunction (SHJ) bottom cells, which cannot be processed above $200^{\circ} \mathrm{C}$ because of the sensitivity of the amorphous silicon passivation and charge extraction layers. We also found that this imidazolium-based ionic liquid is incompatible with the use of low-temperature processible organic p-type layers. Moreover, we carried out thermal-stability test in nitrogen at $85^{\circ} \mathrm{C}$, and found that when using $\mathrm{NiO}$ p-layers, the cells were significantly less stable, in comparison with cells that employ poly(4-butylphenyldiphenyl-amine) (polyTPD) as the hole-transport material, which we show in Fig. S1.

Here, we demonstrate high-performance p-i-n perovskite solar cells using "thermallystable" Cs/FA-based lead-halide perovskite absorber layers, low-temperature processed organic charge extraction layers, and an organic ionic solid additive, 1-butyl-1-methylpiperidinium tetrafluoroborate $\left([\mathrm{BMP}]^{+}\left[\mathrm{BF}_{4}\right]^{-}\right)$. The incorporation of $[\mathrm{BMP}]^{+}\left[\mathrm{BF}_{4}\right]^{-}$into the perovskite absorber 
suppressed deep trap states improved performance and enhanced the operational stability of cells stressed under full spectrum sunlight at elevated temperatures up to $85^{\circ} \mathrm{C}$.

\section{Perovskite solar cells with a piperidinium additive}

We screened a number of ionic salts as additives for improving the efficiency of perovskite solar cells, with the commonality of having a large chemically stable organic cation and $\left[\mathrm{BF}_{4}\right]^{-}$ anion. At low concentrations, $[\mathrm{BMP}]^{+}\left[\mathrm{BF}_{4}\right]^{-}$(see Fig. 1A for the chemical structure) resulted in a particularly positive influence in photovoltaic performance. We depict the device architecture in Fig. 1A, where polyTPD and [6,6]-phenyl- $\mathrm{C}_{61}$-butyric acid methyl ester $\left(\mathrm{PC}_{61} \mathrm{BM}\right)$ were used as the hole-transporting and electron-transporting layers, respectively. The scanning electron microscopy (SEM) image for a representative $\mathrm{p}$-i-n cell based on a perovskite composition of $\mathrm{Cs}_{0.17} \mathrm{FA}_{0.83} \mathrm{~Pb}\left(\mathrm{I}_{0.77} \mathrm{Br}_{0.23}\right)_{3}$ and $0.25 \mathrm{~mol} \%[\mathrm{BMP}]^{+}\left[\mathrm{BF}_{4}\right]^{-}$(with respect to the $\mathrm{Pb}$ content) is shown in Fig. $1 B$.

To demonstrate the potential of $[\mathrm{BMP}]^{+}\left[\mathrm{BF}_{4}\right]^{-}$for the performance enhancement, we fabricated mixed halide perovskites with a low $\mathrm{Br}$ content $\mathrm{Cs}_{0.17} \mathrm{FA}_{0.83} \mathrm{~Pb}\left(\mathrm{I}_{0.90} \mathrm{Br}_{0.10}\right)_{3}$, which we have found to be the best composition for maximum efficiency of single-junction cells. In Fig. 1C and Fig. S2 we show typical current density-voltage $(J-V)$ characteristics for the $0.25 \mathrm{~mol} \%$ $[\mathrm{BMP}]^{+}\left[\mathrm{BF}_{4}\right]^{-}$modified and control devices with the statistical results of the device performance parameters shown in Fig. 1D. A champion $[\mathrm{BMP}]^{+}\left[\mathrm{BF}_{4}\right]^{-}$device (Fig. 1E) exhibited an opencircuit voltage $\left(V_{\mathrm{OC}}\right)$ of $1.12 \mathrm{~V}$, a short-circuit current density $\left(J_{\mathrm{SC}}\right)$ of $22.8 \mathrm{~mA} \cdot \mathrm{cm}^{-2}$ and a fill factor (FF) of 0.79 , resulting in a PCE of $20.1 \%$ and a steady-state power output (SPO) of $20.1 \%$. The corresponding external-quantum efficiency (EQE) (Fig. S3) yielded an integrated $J_{\mathrm{SC}}$ with a negligible variation $(\sim 2.5 \%)$ from the measured $J_{\mathrm{SC}}$. The addition of $[\mathrm{BMP}]^{+}[\mathrm{BF} 4]^{-}$in the perovskite light absorber led to very high performance for "MA-free" single-junction p-i-n perovskite solar cells compared to reports to date $(5,15)$.

For a perovskite-on-silicon tandem solar cell, balancing the light absorption between the constituent subcells is key to achieve current matching to maximize PCE $(16,17)$. Following ref. (17) we simulated the evolution of subcell $J_{\mathrm{SC}}$ values in perovskite-on-silicon tandem cells as a function of absorber layer thickness for perovskite band gaps of 1.56, 1.66, and $1.76 \mathrm{eV}$ (Fig. 1F). This ideal thickness needed for a $1.66 \mathrm{eV}$ band gap was $\sim 500 \mathrm{~nm}$, which falls into a common perovskite processing window (15). We also modeled the subcell $J_{\mathrm{SC}}$ with various band gaps for a 500-nm perovskite layer (Fig. S4), and a $1.66 \mathrm{eV}$ band gap was also nearly ideal for maximizing energy yield for monolithic perovskite-on-silicon tandem cells deployed in real-world locations (18).

By tuning the $\mathrm{I} / \mathrm{Br}$ composition, we found that $\mathrm{Cs}_{0.17} \mathrm{FA}_{0.83} \mathrm{~Pb}\left(\mathrm{I}_{0.77} \mathrm{Br}_{0.23}\right)_{3}$ perovskite delivered the desired $1.66 \mathrm{eV}$ band gap, as determined from the derivative of the EQE spectrum, (Fig. S5). We optimized the single-junction cells using different $[\mathrm{BMP}]^{+}\left[\mathrm{BF}_{4}\right]^{-}$concentrations ranging from 0.0 (control) to $0.3 \mathrm{~mol} \%$, and summarize the device performance parameters from a large batch of cells in Fig. S6. With increasing concentrations of $[\mathrm{BMP}]^{+}\left[\mathrm{BF}_{4}\right]^{-}$, we observed that $V_{\mathrm{OC}}$ rose from an average of $1.11 \mathrm{~V}$ for the control device to $>1.16 \mathrm{~V}$ for the $0.3 \mathrm{~mol} \%$ $[\mathrm{BMP}]^{+}\left[\mathrm{BF}_{4}\right]^{-}$modified device; $J_{\mathrm{SC}}$ did not vary appreciably relative to the control. However, on average, the FF increased at low concentrations but tended to decrease at higher concentrations of $[\mathrm{BMP}]^{+}\left[\mathrm{BF}_{4}\right]^{-}$. Thus, devices with $0.25 \mathrm{~mol} \% \quad[\mathrm{BMP}]^{+}\left[\mathrm{BF}_{4}\right]^{-}$exhibited the highest PCEs. Characteristic $J-V$ curves for an optimized $0.25 \mathrm{~mol} \%[\mathrm{BMP}]^{+}\left[\mathrm{BF}_{4}\right]^{-}$modified perovskite solar cell 
and a control device are shown in Fig. 1G, and the corresponding SPOs are shown in Fig. 1H. The corresponding forward and reverse direction $J-V$ scans are shown in Fig. S7. The device comprising $0.25 \mathrm{~mol} \%[\mathrm{BMP}]^{+}\left[\mathrm{BF}_{4}\right]^{-}$exhibited a $V_{\mathrm{OC}}$ of $1.16 \mathrm{~V}$, a $J_{\mathrm{SC}}$ of $19.5 \mathrm{~mA} \cdot \mathrm{cm}^{-2}$ and a FF of 0.77 , yielding a PCE of $17.3 \%$. The control device, which exhibited a lower PCE of $16.6 \%$, had a $V_{\mathrm{OC}}$ of $1.11 \mathrm{~V}$ and a FF of 0.75 . The corresponding SPOs were $16.5 \%$ and $15.7 \%$ for the modified and control devices, respectively. We show a set of the statistical results obtained from 15 individual cells of each type in Fig. 1I. The external quantum efficiency (EQE) (the inset of Fig. 1H) was in good agreement with the $J_{\mathrm{SC}}$ measured from the $J$ - $V$ scans (Fig. 1G). With the addition of $[\mathrm{BMP}]^{+}\left[\mathrm{BF}_{4}\right]^{-}$, the cells generally exhibited an increase in $V_{\mathrm{OC}}, \mathrm{FF}$ and PCE. The $J_{\mathrm{SC}}$ was similar or slightly higher with the optimum piperidinium content for all perovskite compositions.

\section{Optoelectronic and material analyses of fresh and aged perovskites}

To understand the impact upon the optoelectronic characteristics of the perovskite films with the addition $[\mathrm{BMP}]^{+}\left[\mathrm{BF}_{4}\right]^{-}$, we carried out a series of spectroscopic measurements, including transient photovoltage (TPV, Fig. S8A), charge extraction (Fig. S8B), time-resolved photoluminescence (TRPL, Fig. S9A), steady-state photoluminescence (SSPL, Fig. S9B), and transient photoconductivity (TPC, Fig. S10) on half-complete or complete device structures, and time-resolved microwave conductivity (TRMC, Figs. S11-S12) and in-plane transient photoconductivity (ip-TPC, Fig. S13) on isolated perovskite films. We found that adding $[\mathrm{BMP}]^{+}\left[\mathrm{BF}_{4}\right]^{-}$did not compromise charge carrier mobilities (Figs. S10B, S12 and S13A). More importantly, from light-intensity dependent $V_{\mathrm{OC}}$ and charge-extraction measurements of complete devices, we observed a reduced ideality factor and capacitance (or reduced total stored charge density) for the $[\mathrm{BMP}]^{+}[\mathrm{BF} 4]^{-}$modified devices under low-light intensity (Fig. S8B). We also observed a slower TRPL decay and more than doubling of the SSPL intensity in the $[\mathrm{BMP}]^{+}[\mathrm{BF}]_{4}^{-}$ film (Fig. S9). These results were consistent with a reduced density of deep trap sites in the $[\mathrm{BMP}]^{+}[\mathrm{BF} 4]^{-}$modified devices. Further analysis of the optoelectronic and spectroscopic characterizations is provided in the Supplementary Text.

To reveal how $[\mathrm{BMP}]^{+}[\mathrm{BF} 4]^{-}$was distributed within the perovskite layer, we used highresolution secondary-ion mass spectrometry (NanoSIMS). We present the secondary electron and elemental mapping for the ${ }^{19} \mathrm{~F}^{-}$and ${ }^{11} \mathrm{~B}^{16} \mathrm{O}_{2}{ }^{-}$distributions in a $\mathrm{Cs}_{0.17} \mathrm{FA}_{0.83} \mathrm{~Pb}_{\left(\mathrm{I}_{0.77} \mathrm{Br}_{0.23}\right)_{3}}$ perovskite film in Fig. 2, A to C. In Fig. 2A, the ${ }^{19} \mathrm{~F}^{-}$signals show agglomeration and despite yielding much lower intensities, the ${ }^{11} \mathrm{~B}^{16} \mathrm{O}_{2}{ }^{-}$intensity map (Fig. 2B) coincided reasonably well with the ${ }^{19} \mathrm{~F}^{-}$map. We show the three-dimensional (3D) visualization of the entire ${ }^{19} \mathrm{~F}^{-}$dataset in Fig. 2D, where we observed that the ${ }^{19} \mathrm{~F}^{-}$signal originated from roughly spherical regions a few hundred nanometers in diameter that were evenly distributed over the surveyed volume. Both the depth (Fig. S14A) and line (Fig. S14B) profiles revealed that a small amount of F could be detected throughout the perovskite, in addition to the agglomerates.

From this NanoSIMS characterisation we deduce that most of the $[\mathrm{BMP}]^{+}\left[\mathrm{BF}_{4}\right]^{-}$molecules were localized in isolated aggregates that presumably accumulated between the perovskite domains, but small amounts penetrated the entire volume of the film. This distribution is in contrast to the imidazolium-based ionic liquid, which we have previously used with $\mathrm{NiO}$ p-type layers. For that material, the predominant accumulation of $\left[\mathrm{BF}_{4}\right]^{-}$was at the buried NiO-perovskite interface (14). Presumably, the distribution throughout the entire volume of the perovskite film helped the $[\mathrm{BMP}]^{+}\left[\mathrm{BF}_{4}\right]^{-}$ionic salt enhance the performance of the cells when we used the poly-TPD organic 
hole-conductor. We attempted to observe interactions between the $[\mathrm{BMP}]^{+}[\mathrm{BF}]^{-}$and the perovskites via solid-state nuclear magnetic resonance (ssNMR) and X-ray photoemission spectroscopy (XPS), which we show in the Supplementary Text and Figs. S15 and S16, respectively. However, we observed no discernible differences.

We also carried out characterizations to assess the stability of the Cs/FA perovskite compounds upon the addition of $[\mathrm{BMP}]^{+}\left[\mathrm{BF}_{4}\right]^{-}$. Ultraviolet-visible (UV-vis) absorption spectra (Fig. S17) and X-ray diffraction (XRD) patterns (Fig. 2, E and F) were obtained of the $[\mathrm{BMP}]^{+}\left[\mathrm{BF}_{4}\right]^{-}$modified and control $\mathrm{Cs}_{0.17} \mathrm{FA}_{0.83} \mathrm{~Pb}\left(\mathrm{I}_{0.77} \mathrm{Br}_{0.23}\right)_{3}$ perovskite films aged under simulated full-spectrum sunlight at $60^{\circ} \mathrm{C}$ in ambient air (relative humidity in the laboratory $~ 50 \%$ ). The absorption edge of the $[\mathrm{BMP}]^{+}\left[\mathrm{BF}_{4}\right]^{-}$modified sample exhibited a minor change for the first 264 h (Fig. S17A), while the control sample exhibited a clear redshift in the absorption edge, which moved from $\sim 750 \mathrm{~nm}$ to $>775 \mathrm{~nm}$ (Fig. S17B). This redshift in absorption, also coincides with a redshift in the EQE spectrum of complete solar cells aged in a similar manner (Fig. S18), indicating that a similar change is occurring, albeit at a slower rate, in the complete devices. The XRD measurements did not reveal any noticeable formation of lead halide $\left(\sim 12.7^{\circ}\right)$ with aging time for both the control (Fig. 2E) and modified (Fig. 2F) samples, which is usually observed during degradation of MA containing perovskites due to the loss of MAI (4). Conversely, a small $\mathrm{PbI}_{2}$ peak present at $12.7^{\circ}$ in both the control and modified films at early time, disappeared during aging. During the time series, the main perovskite phase peaks broadened (Fig. S19) and decreased in intensity, and additional peaks at $14.6^{\circ}$ and $20.7^{\circ}$, as well as a low-angle peak at $11.3^{\circ}$, appeared for long aging in the control film.

The broadening of the main phase can be explained by orthorhombic strain. Before aging, we fit the main perovskite phase to an orthorhombic cell in space group Pnma, with lattice parameters of $\mathrm{a}=8.801(1) \AA, \mathrm{b}=8.8329(3) \AA, \mathrm{c}=12.4940(5) \AA$, vol $=971.3(2) \AA^{3}$ for the control film, and $\mathrm{a}=8.8146(3) \AA, \mathrm{b}=8.8333(9) \AA, \mathrm{c}=12.4892(9) \AA$ for the modified film with a larger volume of $972.4(1) \AA^{3}$. Both are larger than the orthorhombic perovskite $\gamma-\mathrm{CsPbI}_{3}(\mathrm{vol}=947.33(5)$ $\AA^{3}$ ) (19), indicating the mixed Cs/FA phase. The lowering of symmetry from cubic to orthorhombic was needed to fit the XRD data well (Fig. S20). We refined the orthorhombic unit cell across the aging series, and define the orthorhombic strain as $S(\%)=100 \times$ $\sqrt{\left(\frac{\sqrt{2} a}{\sqrt{2} b}-1\right)^{2}+\left(\frac{\sqrt{2} b}{c}-1\right)^{2}+\left(\frac{\sqrt{2} a}{c}-1\right)^{2}}$, which we show in Fig. S21A. The orthorhombic strain in the control and modified films increased at a similar rate; however, the control sample started with a slightly more orthorhombic phase.

The orthorhombic strain was the only sign of change in the XRD pattern for the $[\mathrm{BMP}]^{+}\left[\mathrm{BF}_{4}\right]^{-}$modified samples at aging times less than $360 \mathrm{~h}$. Comparison of spectra showed that the orthorhombic strain did not have a large effect on the absorption. The additional peaks at $14.6^{\circ}$ and $20.7^{\circ}$ appeared for the control sample after the first aging step of $168 \mathrm{~h}$ and for the modified sample between the 264 and $360 \mathrm{~h}$ aging. These peaks were fitted to a cubic unit cell in the Pm $\overline{3} \mathrm{~m}$ space group and could not be fitted with the unit cells of any of the relevant binary halide salts. For the modified sample aged at $360 \mathrm{~h}$ the cubic unit cell has a volume of 217(1) $\AA^{3}$, which is within error of the reported volume of $\operatorname{FAPbBr}_{3}\left(217.45(2) \AA^{3}\right)(20)$. We indicate the XRD peaks associated with this second phase by (₹) in Figs. 2E, 2F and S22.

Segregation of $\mathrm{FAPbBr}_{3}$, would leave the main phase Cs and I rich. Iodide enrichment was consistent with the redshift seen in absorption spectra (Fig. S17), and the time at which these phases emerged in the XRD patterns coincide with the timing for the redshift. The volume of the 
main orthorhombic perovskite phase and the secondary $\mathrm{FAPbBr}_{3}$ perovskite phase both initially increased over time but started to decrease for the control after the 264-h aging (Fig. S21, B and C). This decrease suggests that after the initial separation of $\mathrm{FAPbBr}_{3}$, other compositional changes continued, either because of mixing of the halides or external factors. At the same time, the intensity of the main phase peaks decreased, and the decrease was faster in the control sample. The peak at $11.3^{\circ}$, which appeared in the control sample after $456 \mathrm{~h}$ (Fig. S23) but was suppressed in the modified sample, was previously ascribed to the non-perovskite yellow hexagonal $\delta$-FAPbI $\mathrm{I}_{3}$ phase $(21,22)$, that can form in the perovskite film when the Cs or FA content is strongly unbalanced $(7,21,23)$.

In an attempt to visualize the impurity phases generated during aging, we performed optical microscopy measurements on the fresh and aged control (Fig. S24) and $[\mathrm{BMP}]^{+}\left[\mathrm{BF}_{4}\right]^{-}$modified (Fig. S25) $\mathrm{Cs}_{0.17} \mathrm{FA}_{0.83} \mathrm{~Pb}\left(\mathrm{I}_{0.77} \mathrm{Br}_{0.23}\right)_{3}$ perovskite films grown on $\mathrm{FTO}$ glass. The aged samples were subjected to the same aging environmental parameters as applied to the XRD samples for 500 hours. The microscope was backlit with a halogen lamp, with the optional additional photoexcitation from the front with a 375-nm UV light-emitting diode (LED), in order to induce PL. Both the fresh control and $[\mathrm{BMP}]^{+}\left[\mathrm{BF}_{4}\right]^{-}$modified films appeared orange-red in color and had wrinkled surface characteristic of the antisolvent quenching spin-coating fabrication method (24), and showed no clear difference with and without the UV illumination. After aging, the $[\mathrm{BMP}]^{+}\left[\mathrm{BF}_{4}\right]^{-}$modified films appeared to be predominantly unchanged.

In contrast, for the control films, we observed a strong darkening in color and the appearance of large dark domains. Upon UV illumination, these dark domains emitted blue light. The blue emission was consistent with these regions containing some wider gap impurity phase material, most likely the non-perovskite hexagonal $\delta-\mathrm{FAPbI}_{3}$ phase $(21,22)$. In addition to these coarse features, we observed numerous white/yellow bright spots in images of the aged control samples (Fig. S24, C to F). From SEM images on the same samples, which we present in (Fig. S26), we confirmed that these "bright spots" were pinholes in the film. The presence of these pinholes in the aged control films, which were absent from the $[\mathrm{BMP}]^{+}[\mathrm{BF} 4]^{-}$modified films, was a key difference. The addition of $[\mathrm{BMP}]^{+}\left[\mathrm{BF}_{4}\right]^{-}$appeared to have inhibited the formation of the blue emitting impurity phase, $\mathrm{FAPbBr}_{3}$ impurity phase growth, and importantly, strongly suppressed pinhole formation (Fig. S26D).

\section{Long-term stability of perovskite solar cells}

We investigated the operational stability of $\mathrm{Cs}_{0.17} \mathrm{FA}_{0.83} \mathrm{~Pb}\left(\mathrm{I}_{0.77} \mathrm{Br}_{0.23}\right)_{3}$ based perovskite solar cells aged at open-circuit condition under full-spectrum sunlight at elevated temperatures in ambient air (relative humidity in the laboratory $~ 50 \%$ ). We first examined the stability of unencapsulated devices aged at $60^{\circ} \mathrm{C}$. The average SPOs and PCEs obtained from 8 individual devices for each condition are shown in Fig. 3, A and B, respectively, and the evolution of the device parameters is plotted in Fig. S27. For both the $[\mathrm{BMP}]^{+}\left[\mathrm{BF}_{4}\right]^{-}$modified and control devices, we observed a positive light-soaking effect that enhanced the SPO and PCE values by $~ 2 \%$ absolute during the first few days of aging, whereas the average SPO and PCE of the control devices dropped below the initial performance after $72 \mathrm{~h}$ and continuously decrease to $~ 5 \%$ absolute efficiency after $216 \mathrm{~h}$. The efficiency of the $[\mathrm{BMP}]^{+}\left[\mathrm{BF}_{4}\right]^{-}$modified devices improved over the first few hundred hours, likely to be due to the "photo-brightening" effect (25) resulting 
from passivation of defects in the perovskite film, via reaction with photo-generated superoxide and peroxide species (26).

Our $[\mathrm{BMP}]^{+}\left[\mathrm{BF}_{4}\right]^{-}$modified devices remained highly operational, with average times to decrease to $80 \%$ of the peak SPO and PCE ( $\mathrm{T}_{80}$, ave $)$ of $944 \mathrm{~h}$ and $975 \mathrm{~h}$, respectively. We observed that the $V_{\mathrm{OC}}$ remained beyond its initial level for $>1000 \mathrm{~h}$ at close to $1.2 \mathrm{~V}$ (Fig. S27A). We note that the unencapsulated devices appear to be much more stable than the isolated perovskite films aged under the same conditions. This is likely to be due to the $\mathrm{PC}_{61} \mathrm{BM} / \mathrm{BCP}$ electron extraction layer and the $\mathrm{Cr} / \mathrm{Au}$ electrode partially encapsulating the perovskite film, by inhibiting ingress of atmosphere and loss of degradation products $(10,27-29)$. To benchmark our stability results against the long-term stability data from the literature (Table S1), our champion $[\mathrm{BMP}]^{+}[\mathrm{BF}]^{-}$ device exhibited the measured and estimated lifetimes through a linear extrapolation for $80 \%$ of the peak SPO and PCE (i.e., $\mathrm{T}_{80 \text {, champ }}$ ) of $1010 \mathrm{~h}$ and $2630 \mathrm{~h}$, respectively (30). The difference in

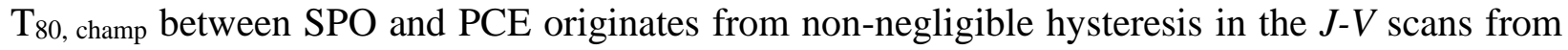
the aged samples (Fig. S28). Notably, most stability studies are performed on encapsulated cells, or cells in an inert atmosphere. Previous reports from unencapsulated cells in ambient atmosphere have delivered $\mathrm{T}_{80}$ of $\sim 100$ hours under similar aging conditions (14), or similar $\mathrm{T}_{80}$ lifetimes, but at $25^{\circ} \mathrm{C}$ in Colorado at a relative humidity of $15 \%$, dropping to $\sim 30$ hours at $70^{\circ} \mathrm{C}(12)$.

In order to explore the stability of our cells under higher elevated temperatures, we sealed our cells in a nitrogen atmosphere with glass cover slides and UV-cured epoxy resin and aged the encapsulated devices under full spectrum sun light at $85^{\circ} \mathrm{C}$ in air. Fig. S29 shows the evolution of the device parameters. The $J-V$ scans for the champion $[\mathrm{BMP}]^{+}\left[\mathrm{BF}_{4}\right]^{-}$device at different aging stages are shown in Fig. S30. At this temperature, a clear "burn-in" effect was observed in the SPOs (Fig. 3C) and PCEs (Fig. 3D) for both the $[\mathrm{BMP}]^{+}\left[\mathrm{BF}_{4}\right]^{-}$modified and control devices. The SPO of the control devices decreased rapidly to $<6 \%$ absolute efficiency after $264 \mathrm{~h}$, while the modified devices retain an operational SPO of $\sim 12 \%$ absolute over the aging period. We estimated the lifetime to $95 \%$ of the "post-burn-in" efficiency (T95, ave) of $1200 \mathrm{~h}$, using a linear extrapolation of the post-burn-in SPO (Fig. 3C) $(14,30)$.

Much variation in aging conditions for perovskite solar cells occur between laboratories, so it is not directly feasible to compare results. With respect to our previous "best-in-class", the $\mathrm{T}_{80}$ lifetime of our unencapsulated cells at $60{ }^{\circ} \mathrm{C}$ here is approximately 7 times longer (14). The post-burn-in $\mathrm{T}_{95}$, ave $\mathrm{SPO}$ lifetime of our encapsulated cells at $85^{\circ} \mathrm{C}$ was 1200 hours, three times longer than our previous best-in-class cells which were stressed at $75^{\circ} \mathrm{C}$ and gave a $\mathrm{T}_{95}$, ave of $\sim 360$ $\mathrm{h}(14)$. Considering that we would expect about a twofold increase in the degradation rate with $10^{\circ} \mathrm{C}$ increase in temperature $(31)$, our cells here appear to degrade approximately six times as slowly.

\section{Degradation mechanism and failure analysis of aged cells}

To elucidate the degradation mechanism in complete cells, we carried out XPS analysis on the unencapsulated device stacks, absent of electrodes, before and after a $60^{\circ} \mathrm{C}$ light soaking 300 $\mathrm{h}$ aging process. The XPS spectra of the core levels relevant to the perovskite elements were measured, and full peak positions, spectra and fittings can be found in Figs. S31-S33 and Table S2. Subtle differences between the $[\mathrm{BMP}]^{+}\left[\mathrm{BF}_{4}\right]^{-}$and control devices were observed in the $\mathrm{C} 1 \mathrm{~s}$, $\mathrm{N} 1 s$ core levels, but these additional peaks correspond to the presence of $[\mathrm{BMP}]^{+}\left[\mathrm{BF}_{4}\right]^{-}$. The I $3 d_{5 / 2}$ core levels for both the $[\mathrm{BMP}]^{+}\left[\mathrm{BF}_{4}\right]^{-}$and control devices show that aging resulted in the 
emergence of an additional peak at $\sim 620 \mathrm{eV}$ next to the main peak at $\sim 618 \mathrm{eV}$, which is attributed to $\mathrm{I}^{-}$. This peak at the higher binding energy could correspond to either the formation of $\mathrm{IO}_{2}{ }^{-}$, which has been previously observed in methylammonium lead iodide perovskite (32), or to the formation of methyl iodide (33).

$\mathrm{The} \mathrm{Pb} 4 f$ core level spectra demonstrated a clear difference between the aged devices with and without $[\mathrm{BMP}]^{+}\left[\mathrm{BF}_{4}\right]^{-}$. In the aged control devices, we observed two peaks at 138.0 and 139.1 $\mathrm{eV}\left(\mathrm{Pb} 4 f_{7 / 2}\right)$ whereas in the devices with $[\mathrm{BMP}]^{+}\left[\mathrm{BF}_{4}\right]^{-}$we only observed one peak at $137.8 \mathrm{eV}$. The peaks at $\sim 138 \mathrm{eV}$ correspond to the presence of $\mathrm{Pb}^{2+}$ while the peak at $139.1 \mathrm{eV}$ corresponds to $\mathrm{PbO}_{\mathrm{x}}$. This result suggest that when aged, the control devices formed lead oxide, which is a product formed from a photo-oxidative degradation process $(34)$. The addition of $[\mathrm{BMP}]^{+}[\mathrm{BF}]^{-}$ inhibited lead oxidation.

In order to understand how $[\mathrm{BMP}]^{+}\left[\mathrm{BF}_{4}\right]^{-}$can improve the stability of the perovskite film, we first review the mechanisms that have been proposed to explain the photoinduced degradation processes of metal halide perovskites. The role of oxygen and moisture has been extensively discussed, in particular for methylammonium containing perovskites. (35-37). However, for perovskite films prepared in inert atmosphere and encapsulated, photodegradation is still observed. A key factor in the photodegradation is the generation of $I_{2}$ under illumination, which has been observed experimentally via a range of analytic methods including electrochemistry (38), optical absorption (38) and mass spectrometry (39). The detrimental role of $\mathrm{I}_{2}$ has been established for silver electrodes (40) but also directly upon the perovskite (41).

Several mechanisms have been proposed to explain the generation of $\mathrm{I}_{2}$. They have in common the capture of a hole by an iodide ion $\left(I^{-}\right)$, with $I^{-}$being either in its lattice site $\left(I_{I}^{x}+\right.$ $h^{\bullet} \rightarrow I_{I}^{\bullet}$ in Kröger-Vink notation) $(26,42)$, as an interstitial ion from a Frenkel pair $\left(I_{i}^{\prime}+h^{\bullet} \rightarrow I_{i}^{x}\right)$ (43), or becoming interstitial upon hole capture $\left(I_{I}^{x}+h^{\bullet} \rightarrow I_{i}^{x}+V_{I}^{\bullet}\right)$ (38). To generate gaseous iodine $\left(I_{2}\right)$, two neutral atoms $\left(I_{i}^{x}\right.$ or $\left.I_{I}^{*}\right)$ need to diffuse and combine. Due to the ability to release iodine from the surface of the film, and the likelihood of a higher vacancy density at the surface than in the bulk of the grains, this process is more likely to happen at the surface of the grains, leading to the release of iodine and the generation of a pair of iodide vacancies $\left(2 V_{I}^{*}\right)$.

The exact nature of the detrimental effect of $I_{2}$ on the perovskite is still under debate $(41)$. Fu et al. investigated these effects in detail and found that $\mathrm{PbI}_{2}$ was more prone to degradation than the perovskite itself, and that voids were left in the films of $\mathrm{PbI}_{2}$ upon prolonged exposure to light and heat (44). We repeated Fu's experiments for the photodegradation of $\mathrm{PbI}_{2}$ at elevated temperatures under light in a nitrogen atmosphere (Figs. S34 and S35) and confirmed the observed generation of lead (Fig. S36) and pinholes in the films (Fig. 4, A and B). Although slower than for $\mathrm{MA}^{+}$containing perovskites, this degradation pathway was also observed in FACs perovskites, indicating that the $\mathrm{I}_{2}$ generation process is related to the lead-halide framework.

We confirmed a faster release of $I_{2}$ from our control perovskite films versus the $[\mathrm{BMP}]^{+}\left[\mathrm{BF}_{4}\right]^{-}$modified films during light soaking, from UV-vis absorption spectrum of toluene, after exposing toluene-submersed films to light and heat (Fig. 4, $\mathbf{C}$ to $\mathbf{G})(38,41)$. The presence of voids (or pinholes, Fig. 4B) in the $\mathrm{PbI}_{2}$ films (and control perovskite films, Fig. S26) after aging can be explained by the loss of volume during $\mathrm{I}_{2}$ release, upon conversion to metallic lead. The presence of $\mathrm{PbO}_{\mathrm{x}}$, which we observed in the degraded unencapsulated devices (Fig. S32), is also consistent with the formation of metallic lead, which is subsequently oxidized to $\mathrm{PbO}_{\mathrm{x}}$ or $\mathrm{Pb}(\mathrm{OH})_{2}$ in ambient air, which notably have a much higher density than perovskite. 
In the light of this degradation mechanism, we discuss the stabilization induced by the ionic additive. For degradation to occur hole-trapping is likely to require interstitial $I^{-}$(43), and two neutral interstitial iodine atoms need to diffuse together and combine to form $\mathrm{I}_{2}$. Therefore, this reaction could be slowed down by either reducing the overall density of Frenkel defects (iodide vacancies/interstitial pairs), or by reducing the diffusivity of interstitials. As with most crystalline materials, defect densities are usually highest on the crystal surface (45). Therefore, we would expect the interstitials or Frenkel defects to mostly diffuse around the surfaces of the polycrystalline domains, where there exists the highest density of defects.

If the crystallisation in the presence of $[\mathrm{BMP}]^{+}\left[\mathrm{BF}_{4}\right]^{-}$leads to reduced Frenkel defect densities, then this would have the effect of reducing the number of sites available for iodide oxidation. Furthermore, if the $[\mathrm{BMP}]^{+}\left[\mathrm{BF}_{4}\right]^{-}$adsorbs to these surface defects, it is likely to block or inhibit the further migration of such defects, slowing down the diffusivity of interstitial iodide or neutral iodine interstitials, reducing the rate of $\mathrm{I}_{2}$ formation. Finally, $[\mathrm{BMP}]^{+}\left[\mathrm{BF}_{4}\right]^{-}$does appear to reduce the amount of residual $\mathrm{PbI}_{2}$ in the films, by improving the crystallisation (as indicated in Fig. 2). Since the $\mathrm{I}_{2}$ generation occurs preferentially at $\mathrm{PbI}_{2}$ sites (44), minimizing the amount of residual $\mathrm{PbI}_{2}$ may play a crucial role. 


\section{References and Notes:}

1. C. Wei et al., Molecule-Doped Nickel Oxide: Verified Charge Transfer and Planar Inverted Mixed Cation Perovskite Solar Cell. Adv. Mater. 30, 1800515 (2018).

2. T. Leijtens, K. A. Bush, R. Prasanna, M. D. McGehee, Opportunities and challenges for tandem solar cells using metal halide perovskite semiconductors. Nat. Energy 3, 828-838 (2018).

3. NREL, Best Research-Cell Efficiency Chart. https://www.nrel.gov/pv/cell-efficiency.html (2020).

4. S. N. Habisreutinger, D. P. McMeekin, H. J. Snaith, R. J. Nicholas, Research Update: Strategies for improving the stability of perovskite solar cells. APL Mater. 4, 091503 (2016).

5. D. P. McMeekin et al., A mixed-cation lead mixed-halide perovskite absorber for tandem solar cells. Science 351, 151-155 (2016).

6. G. E. Eperon et al., Formamidinium lead trihalide: a broadly tunable perovskite for efficient planar heterojunction solar cells. Energy. Environ. Sci. 7, 982-988 (2014).

7. J.-W. Lee et al., Formamidinium and Cesium Hybridization for Photo- and Moisture-Stable Perovskite Solar Cell. Adv. Energy Mater. 5, 1501310 (2015).

8. M. Saliba et al., Cesium-containing triple cation perovskite solar cells: improved stability, reproducibility and high efficiency. Energy. Environ. Sci. 9, 1989-1997 (2016).

9. Q. Jiang et al., Surface passivation of perovskite film for efficient solar cells. Nat. Photon. 13, 460-466 (2019).

10. S. N. Habisreutinger et al., Carbon nanotube/polymer composites as a highly stable hole collection layer in perovskite solar cells. Nano Lett. 14, 5561-5568 (2014).

11. Y. Hou et al., A generic interface to reduce the efficiency-stability-cost gap of perovskite solar cells. Science 358, 1192-1197 (2017).

12. J. A. Christians et al., Tailored interfaces of unencapsulated perovskite solar cells for $>1,000$ hour operational stability. Nat. Energy 3, 68-74 (2018).

13. S. N. Habisreutinger, N. K. Noel, H. J. Snaith, R. J. Nicholas, Investigating the Role of 4Tert Butylpyridine in Perovskite Solar Cells. Adv. Energy Mater. 7, 1601079 (2017).

14. S. Bai et al., Planar perovskite solar cells with long-term stability using ionic liquid additives. Nature 571, 245-250 (2019).

15. S. H. Turren-Cruz, A. Hagfeldt, M. Saliba, Methylammonium-free, high-performance, and stable perovskite solar cells on a planar architecture. Science 362, 449-453 (2018).

16. E. Köhnen et al., Highly efficient monolithic perovskite silicon tandem solar cells: analyzing the influence of current mismatch on device performance. Sustain. Energy Fuels 3, 1995-

17. L. Mazzarella et al., Infrared Light Management Using a Nanocrystalline Silicon Oxide Interlayer in Monolithic Perovskite/Silicon Heterojunction Tandem Solar Cells with Efficiency above 25\%. Adv. Energy Mater. 9, 1803241 (2019).

18. M. T. Hörantner, H. J. Snaith, Predicting and optimising the energy yield of perovskite-onsilicon tandem solar cells under real world conditions. Energy. Environ. Sci. 10, 1983-1993 (2017).

19. R. J. Sutton et al., Cubic or Orthorhombic? Revealing the Crystal Structure of Metastable Black-Phase CsPbI3 by Theory and Experiment. ACS Energy Lett. 3, 1787-1794 (2018).

20. S. Govinda et al., Critical Comparison of FAPbX3 and MAPbX3 (X = Br and $\mathrm{Cl}$ ): How Do They Differ? J. Phys. Chem. C 122, 13758-13766 (2018). 
21. W. Rehman et al., Photovoltaic mixed-cation lead mixed-halide perovskites: links between crystallinity, photo-stability and electronic properties. Energy. Environ. Sci. 10, 361-369 (2017).

22. Z. Li et al., Stabilizing Perovskite Structures by Tuning Tolerance Factor: Formation of Formamidinium and Cesium Lead Iodide Solid-State Alloys. Chem. Mater. 28, 284-292 (2016).

23. C. Yi et al., Entropic stabilization of mixed A-cation ABX3 metal halide perovskites for high performance perovskite solar cells. Energy. Environ. Sci. 9, 656-662 (2016).

24. K. A. Bush et al., Controlling Thin-Film Stress and Wrinkling during Perovskite Film Formation. ACS Energy Lett. 3, 1225-1232 (2018).

25. D. W. deQuilettes et al., Photo-induced halide redistribution in organic-inorganic perovskite films. Nat. Commun. 7, 11683 (2016).

26. J. S. W. Godding et al., Oxidative Passivation of Metal Halide Perovskites. Joule 3, 27162731 (2019).

27. K. A. Bush et al., 23.6\%-efficient monolithic perovskite/silicon tandem solar cells with improved stability. Nat. Energy 2, 17009 (2017).

28. M. Kaltenbrunner et al., Flexible high power-per-weight perovskite solar cells with chromium oxide-metal contacts for improved stability in air. Nat. Mater. 14, 1032-1039 (2015).

29. R. Prasanna et al., Design of low bandgap tin-lead halide perovskite solar cells to achieve thermal, atmospheric and operational stability. Nat. Energy 4, 939-947 (2019).

30. M. V. Khenkin et al., Consensus statement for stability assessment and reporting for perovskite photovoltaics based on ISOS procedures. Nat. Energy 5, 35-49 (2020).

31. H. J. Snaith, P. Hacke, Enabling reliability assessments of pre-commercial perovskite photovoltaics with lessons learned from industrial standards. Nat. Energy 3, 459-465 (2018).

32. G. Rajendra Kumar et al., Phase transition kinetics and surface binding states of methylammonium lead iodide perovskite. Phys. Chem. Chem. Phys. 18, 7284-7292 (2016).

33. X. L. Zhou, F. Solymosi, P. M. Blass, K. C. Cannon, J. M. White, Interactions of Methyl Halides (Cl, Br and I) with Ag(111). Surf. Sci. 219, 294-316 (1989).

34. Y. X. Ouyang et al., Photo-oxidative degradation of methylammonium lead iodide perovskite: mechanism and protection. J. Mater. Chem. A 7, 2275-2282 (2019).

35. R. Brenes, C. Eames, V. Bulovic, M. S. Islam, S. D. Stranks, The Impact of Atmosphere on the Local Luminescence Properties of Metal Halide Perovskite Grains. Adv. Mater. 30, 1706208 (2018).

36. Z. Andaji-Garmaroudi, M. Anaya, A. J. Pearson, S. D. Stranks, Photobrightening in Lead Halide Perovskites: Observations, Mechanisms, and Future Potential. Adv. Energy Mater., 1903109 (2019).

37. N. Aristidou et al., Fast oxygen diffusion and iodide defects mediate oxygen-induced degradation of perovskite solar cells. Nat. Commun. 8, 15218 (2017).

38. G. Y. Kim et al., Large tunable photoeffect on ion conduction in halide perovskites and implications for photodecomposition. Nat. Mater. 17, 445-449 (2018).

39. Z. N. Song et al., Probing the origins of photodegradation in organic-inorganic metal halide perovskites with time-resolved mass spectrometry. Sustain. Energy Fuels 2, 2460-2467 (2018).

40. Y. Kato et al., Silver Iodide Formation in Methyl Ammonium Lead Iodide Perovskite Solar Cells with Silver Top Electrodes. Adv. Mater. Interfaces 2, 1500195 (2015). 
41. S. Wang, Y. Jiang, Emilio J. Juarez-Perez, Luis K. Ono, Y. Qi, Accelerated degradation of methylammonium lead iodide perovskites induced by exposure to iodine vapour. Nat. Energy 2, 16195 (2016).

42. J. Verwey, J. Schoonman, Crystal growth, ionic conductivity, and photolysis of pure and impurity-doped lead bromide single crystals. Physica 35, 386-394 (1967).

43. S. G. Motti et al., Controlling competing photochemical reactions stabilizes perovskite solar cells. Nat. Photon. 13, 532-539 (2019).

44. F. Fu et al., I2 vapor-induced degradation of formamidinium lead iodide based perovskite solar cells under heat-light soaking conditions. Energy. Environ. Sci. 12, 3074-3088 (2019). 45. A. Pimpinelli, J. Villain, Physics of Crystal Growth. (Cambridge University Press, 2010).

\section{Acknowledgements}

Y.-H.L. thanks Dr. N. Noel and Dr. W. Li from the University of Oxford (UK) for the discussion on the effect of ionic molecules on perovskites, and for assisting ssNMR sample preparation and optical microscopic imaging, respectively. Junliang L. acknowledges the assistance of Prof. J. Marrow from the University of Oxford (UK), with access to the Avizo software packages to perform 3D virtualization of the NanoSIMS data. Funding: This work was supported by the UK Engineering and Physical Sciences Research Council (EPSRC) grants EP/S004947/1 and EP/P006329/1. Junliang L. and C.R.M.G. are grateful for support for the NanoSIMS facility from EPSRC under grant EP/M018237/1. S.M. is grateful for the support of the Rhodes Scholarship (India \& Worcester). R.D.J.O. gratefully acknowledges the Penrose Scholarship for funding his studentship. Author contributions: Y.-H.L. and H.J.S. conceived the concept, designed the experiments, analyzed the data and wrote the manuscript. H.J.S. supervised and guided the project. Y.-H.L. performed the fabrication, optimization and characterization of the perovskite films and solar cells. Y.-H.L. conducted OM measurements. Y.-H.L. and N.S. conducted UV-vis, XRD and FTIR characterization and analysis. N.S. performed SEM characterization and material analysis. P.D. and S.B. screened ionic additives and conducted early assessments for single-junction cells. Y.-H.L. and P.D. performed cell thermal-stability measurement on p-type layers. J.W. conducted CE, TPV and TPC and analyzed the data with J.R.D. H.C.S. conducted analysis on XRD results to deduce degradation mechanism with Y.-H.L. and N.S. A.J.R. performed XPS characterization and analyzed the data with Y.-H.L. and N.S. S.M. performed numerical modelling. Junliang L. conducted NanoSIMS characterization and analyzed the results with Y.-H.L., P.K.N. and C.R.M.G. R.D.J.O. conducted EQE measurement and analyzed the data with M.B.J. Jongchul L. conducted ip-TPC characterization. L.A. and J.G.L. performed TRMC characterization. K.S. and P.K.M. performed ssNMR and analyzed the data with P.K.N. A.B.M.-V. and B.S. contributed to the planning of the experiments to tune the band gap of the perovskite solar cells and optical modeling. B.W. contributed to degradation mechanism analysis. J.M.B. set up $\mathrm{N}_{2}$ aging system, characterized the EQE spectrum of aged devices and evaluated spectrum mismatch factors. Y.H.L. analyzed the data with H.J.S. F.G. provided suggestions for ionic additives. All authors discussed the results and contributed to the writing of the paper. Competing interests: H.J.S. is a co-founder, Chief Scientific Officer and a director of Oxford PV Ltd. Oxford University has filed a patent related to the subject matter of this manuscript. Data and materials availability: All data needed to evaluate the conclusions of the paper are present in the paper or the supplementary materials.

\section{Supplementary Materials}


Materials and Methods

Supplementary Text

Figs. S1 to S36

Tables S1 to S2

5

References (46-80) 
A
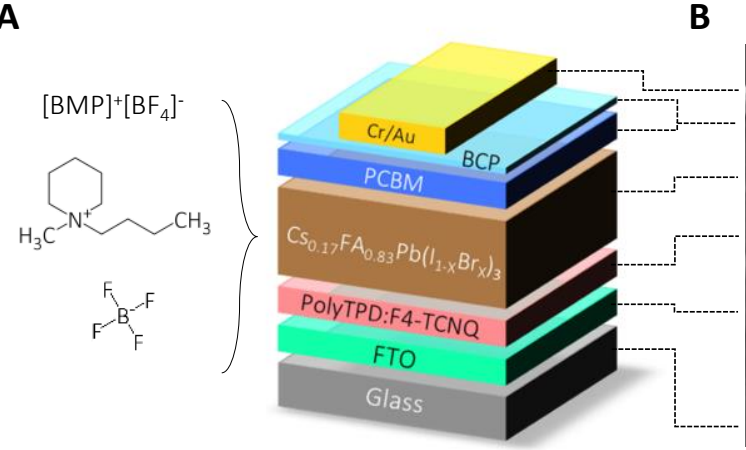

D

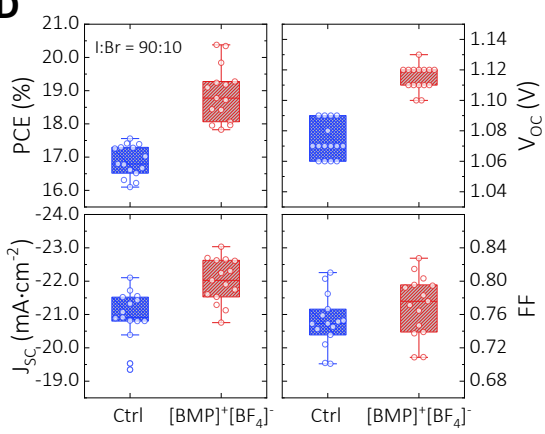

G

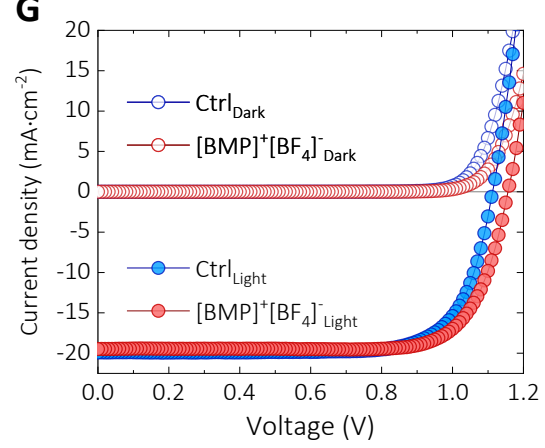

E

B
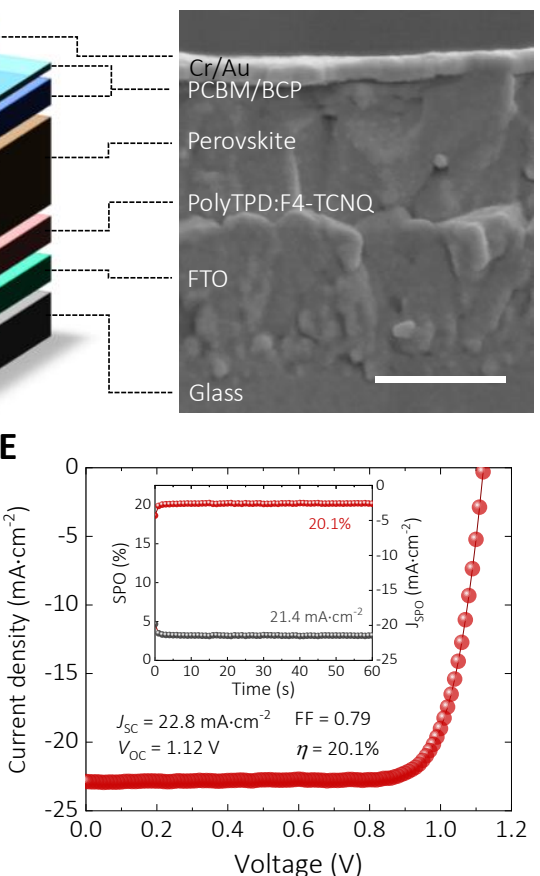

H

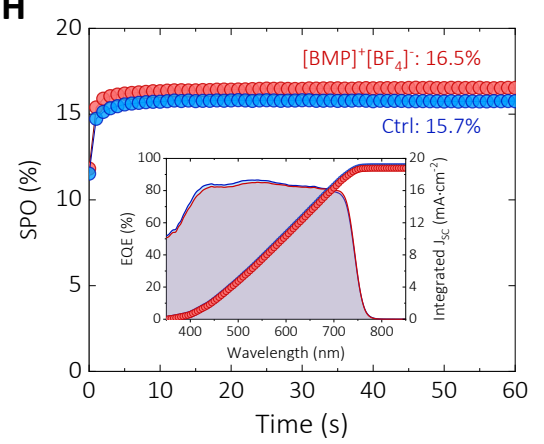

C

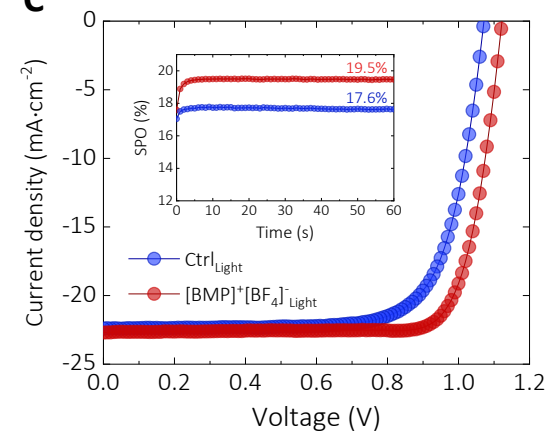

F

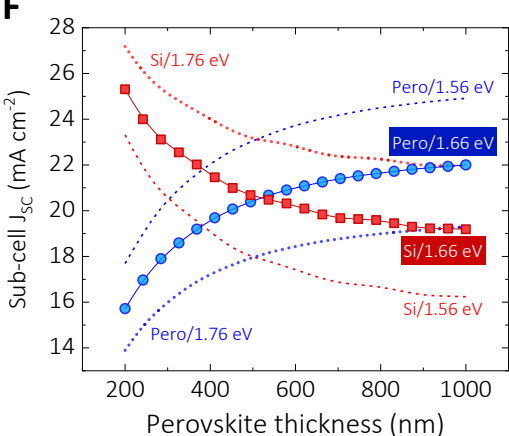

I

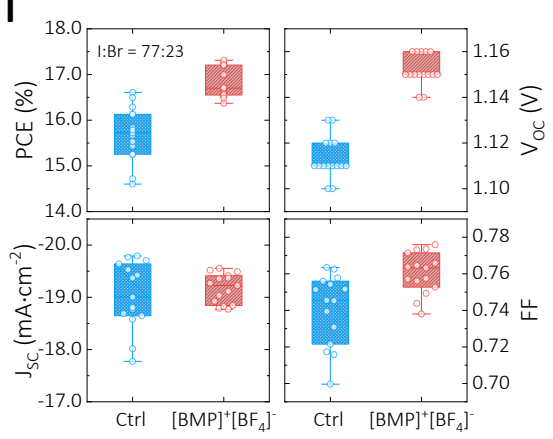

Fig. 1. Perovskite solar cell characterization. (A) Schematic of the p-i-n perovskite solar cell and the chemical structure of $[\mathrm{BMP}]^{+}\left[\mathrm{BF}_{4}\right]^{-}$. (B) Scanning electron microscopic image of the full device stack made from $\mathrm{Cs}_{0.17} \mathrm{FA}_{0.83} \mathrm{~Pb}\left(\mathrm{I}_{0.77} \mathrm{Br}_{0.23}\right)_{3}$ with $0.25 \mathrm{~mol} \%[\mathrm{BMP}]^{+}\left[\mathrm{BF}_{4}\right]^{-}$(the scale bar is $500 \mathrm{~nm}$ ). (C) $J-V$ characteristics of the representative $0.25 \mathrm{~mol} \%[\mathrm{BMP}]^{+}\left[\mathrm{BF}_{4}\right]^{-}$modified $\mathrm{Cs}_{0.17} \mathrm{FAA}_{0.83} \mathrm{~Pb}\left(\mathrm{I}_{0.90} \mathrm{Br}_{0.10}\right)_{3}$ and control devices measured from the forward-bias (FB) to short-circuit (SC) scans under simulated AM1.5 sunlight and corresponding SPO. (D) Statistical results of device parameters for $\mathrm{Cs}_{0.17} \mathrm{FA}_{0.83} \mathrm{~Pb}\left(\mathrm{I}_{0.90} \mathrm{Br}_{0.10}\right)_{3}$ based devices. (E) $J-V$ characteristics for the champion cell with $0.25 \mathrm{~mol} \%[\mathrm{BMP}]^{+}\left[\mathrm{BF}_{4}\right]^{-}$modified $\mathrm{Cs}_{0.17} \mathrm{FA}_{0.83} \mathrm{~Pb}\left(\mathrm{I}_{0.90} \mathrm{Br}_{0.10}\right)_{3}$. Inset: corresponding SPO and current density measured under $\mathrm{SPO}\left(J_{\mathrm{SPO}}\right)$. $(\mathbf{F})$ Modeling of the thickness-dependent subcell $J_{\mathrm{SC}}$ for perovskite-on-silicon tandem cells with perovskites of different band gaps. The evolution of perovskite subcell $J_{\mathrm{SC}}$ is shown in blue, while the corresponding $\mathrm{Si}$ subcell $J_{\mathrm{SC}}$ is shown in red. (G) $J-V$ characteristics of the representative $0.25 \mathrm{~mol} \%[\mathrm{BMP}]^{+}\left[\mathrm{BF}_{4}\right]^{-}$modified and control devices using $\mathrm{Cs}_{0.17} \mathrm{FA}_{0.83} \mathrm{~Pb}\left(\mathrm{I}_{0.77} \mathrm{Br}_{0.23}\right)_{3}$. (H) Corresponding SPO, EQE and integrated $J_{\mathrm{SC}}$ for the devices shown in $(\mathrm{G})$. The integrated $J_{\mathrm{SC}}$ values for the modified and control devices are 18.8 and 19.0 $\mathrm{mA} \cdot \mathrm{cm}^{-2}$, respectively. (I) Statistical results of device parameters for $\mathrm{Cs}_{0.17} \mathrm{FAA}_{0.83} \mathrm{~Pb}\left(\mathrm{I}_{0.77} \mathrm{Br}_{0.23}\right)_{3}$ based devices. 

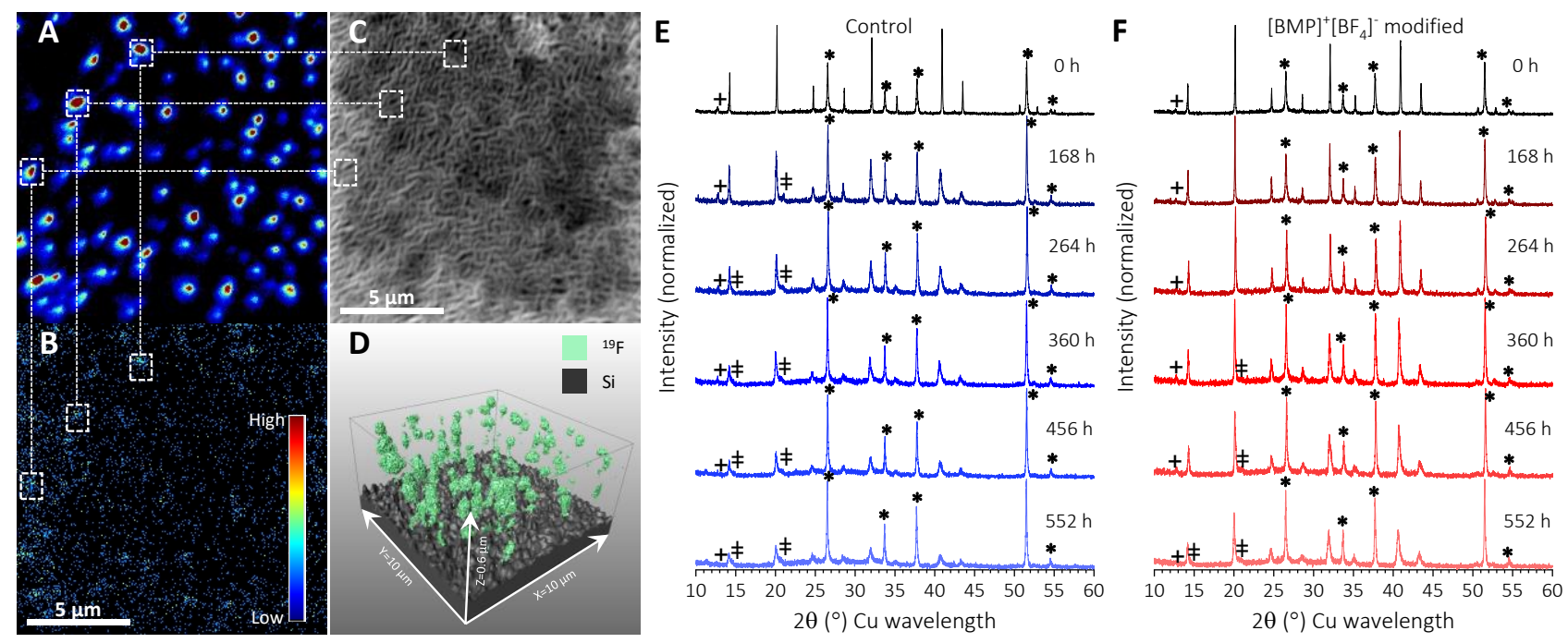

Fig. 2. High-resolution secondary ion mass spectrometry and X-ray diffraction analysis. (A and $\mathbf{B}){ }^{19} \mathrm{~F}^{-}$and ${ }^{11} \mathrm{~B}^{16} \mathrm{O}_{2}{ }^{-}$ion maps for the $\mathrm{F}$ and $\mathrm{B}$ distributions towards the top surface of a $\sim 500$ nm $\mathrm{Cs}_{0.17} \mathrm{FA}_{0.83} \mathrm{~Pb}\left(\mathrm{I}_{0.77} \mathrm{Br}_{0.23}\right)_{3}$ with $0.25 \mathrm{~mol}^{2}[\mathrm{BMP}]^{+}\left[\mathrm{BF}_{4}\right]^{-}$perovskite film. (C) Secondary electron map for the sputtered surface morphology $\sim 60 \mathrm{~nm}$ below the sample surface. The squares denoted in (A-C) are to indicate the corresponding regions of highly localized F and B concentrations. (D) A reconstructed 3D map (stretched in the $\mathrm{Z}$ direction for clarity) showing the distribution of the ${ }^{19} \mathrm{~F}^{-}$signals through the perovskite layer. $(\mathbf{E})$ and $(\mathbf{F})$ show XRD series for the gaining of the unencapsulated control and $0.25 \mathrm{~mol} \% \quad[\mathrm{BMP}]^{+}[\mathrm{BF}]^{-}$modified $\mathrm{Cs}_{0.17} \mathrm{FA}_{0.83} \mathrm{~Pb}\left(\mathrm{I}_{0.77} \mathrm{Br}_{0.23}\right)_{3}$ perovskite films, respectively, prepared on FTO glass substrates. The XRD peaks corresponding to $\mathrm{PbI}_{2}(+)$, FTO (*) and the secondary cubic perovskite phase $(\neq)$ are marked. 
A
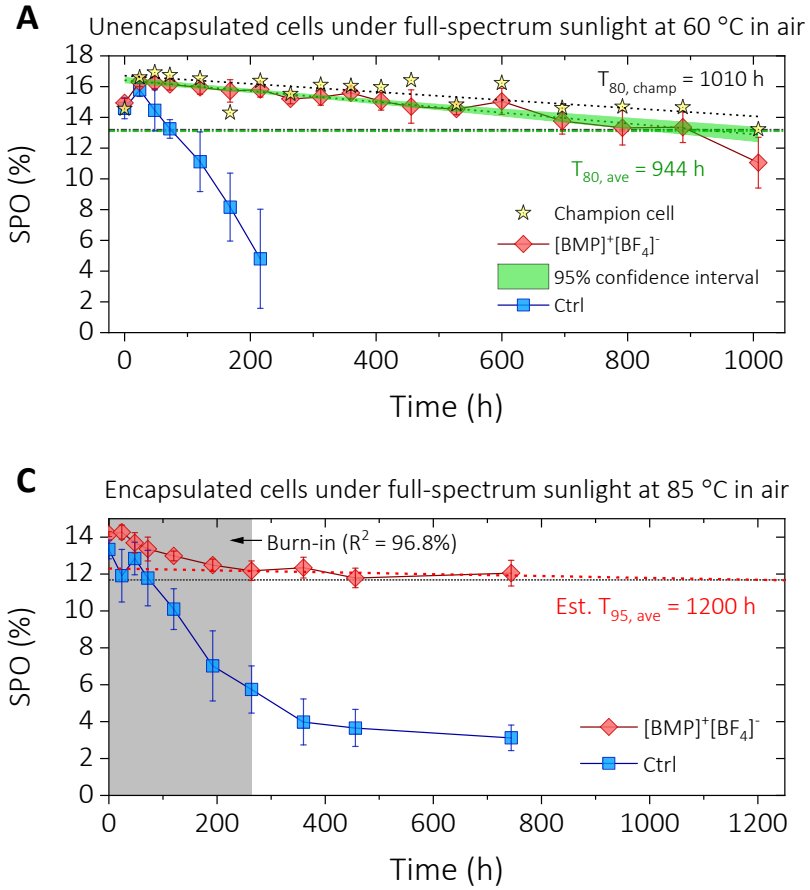

B Unencapsulated cells under full-spectrum sunlight at $60^{\circ} \mathrm{C}$ in air

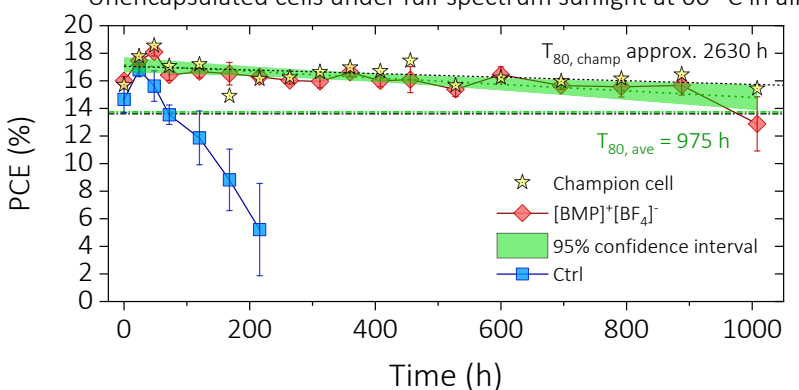

D Encapsulated cells under full-spectrum sunlight at $85^{\circ} \mathrm{C}$ in air

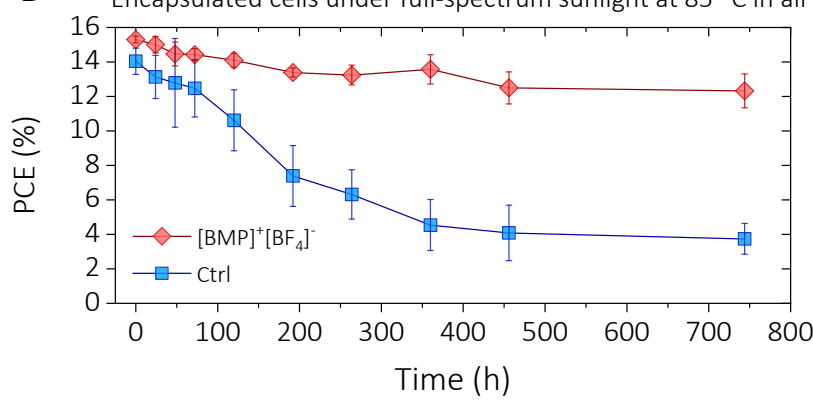

Fig. 3. Long-term operational stability. (A) Evolution of SPOs of unencapsulated $0.25 \mathrm{~mol} \%$ $[\mathrm{BMP}]^{+}\left[\mathrm{BF}_{4}\right]^{-}$modified and control $(\mathrm{Ctrl}) \mathrm{Cs}_{0.17} \mathrm{FA}_{0.83} \mathrm{~Pb}\left(\mathrm{I}_{0.77} \mathrm{Br}_{0.23}\right)_{3}$ perovskite solar cells $(8$ cells for each condition), aged under full-spectrum sunlight at $60^{\circ} \mathrm{C}$ in ambient air. The $95 \%$ confidence interval for the SPOs of the modified devices is shown as the green band. The champion cell with the $[\mathrm{BMP}]^{+}\left[\mathrm{BF}_{4}\right]^{-}$additive is denoted as stars, and the black dotted line is a guide to the eye. The intersections between the data points and the black and green dashed-dotted lines show $\mathrm{T}_{80 \text {, champ }}$

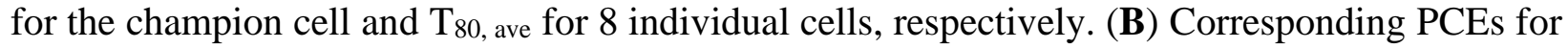
(A). (C) Evolution of SPOs of encapsulated $0.25 \mathrm{~mol} \%[\mathrm{BMP}]^{+}\left[\mathrm{BF}_{4}\right]^{-}$modified and control $\mathrm{Cs}_{0.17} \mathrm{FA}_{0.83} \mathrm{~Pb}\left(\mathrm{I}_{0.77} \mathrm{Br}_{0.23}\right)_{3}$ cells aged under full-spectrum sunlight at $85^{\circ} \mathrm{C}$ in ambient air $(6$ cells for each condition). The early burn-in region $(\sim 264 \mathrm{~h})$ is determined using a linear model (coefficient of determination $\mathrm{R}^{2}=96.8 \%$ ). The intersection between the linear extrapolation for the data (red dashed line) and black dotted line estimated the lifetime for $95 \%$ of the post-burn-in SPO (Est. T95, ave) from 6 individual cells. (D) Corresponding PCEs for (C). In all figures, the error bars denote standard deviations. 

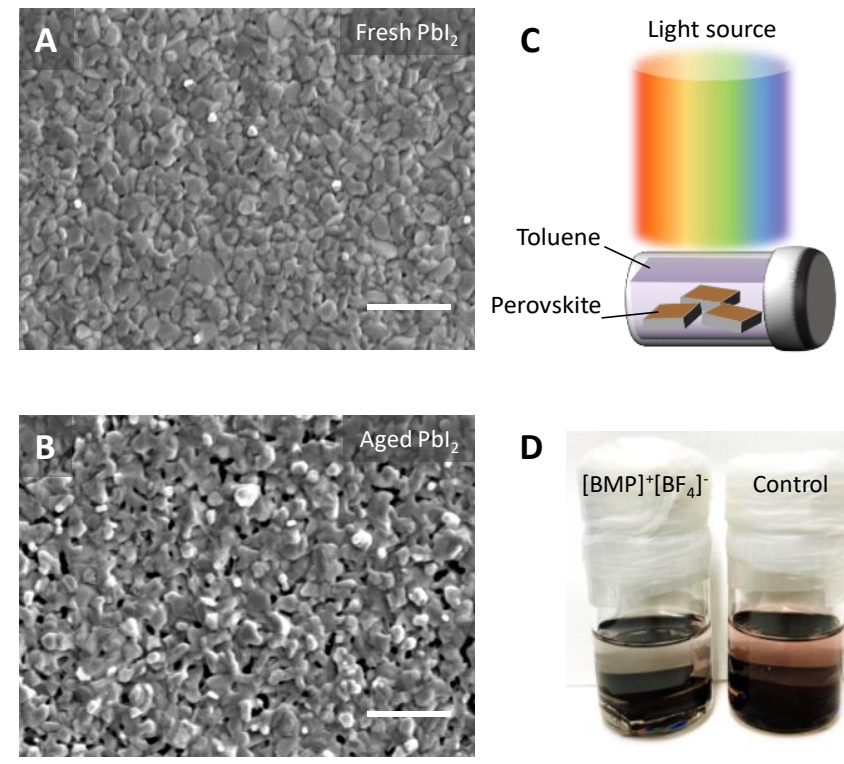

D
$\mathbf{E}$
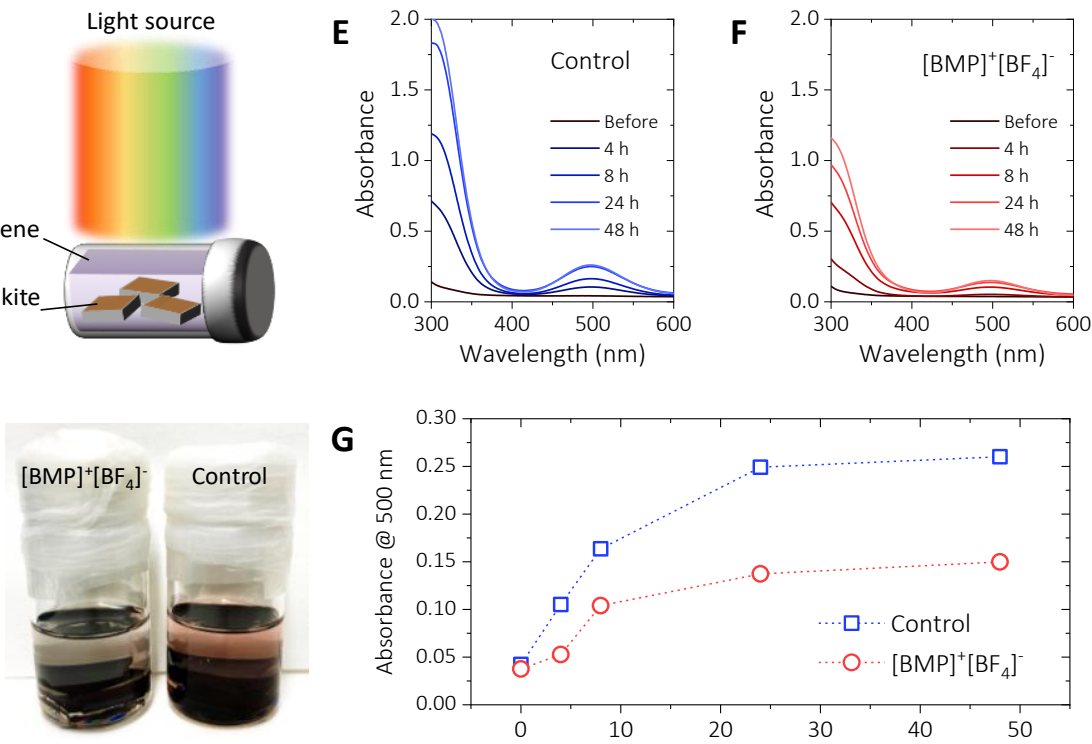

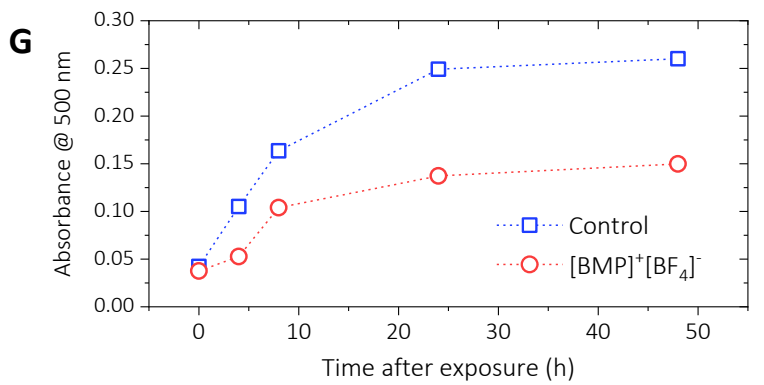

Fig. 4. Iodine-loss analysis of $\mathrm{PbI}_{2}$ and perovskite films. (A and $\mathbf{B}$ ) Top surface SEM images of $\mathrm{PbI}_{2}$ films: (A) fresh and (B) aged under $\sim 0.32$ suns white LED illumination at $85^{\circ} \mathrm{C}$ in a nitrogen filled glove box for 6 hours (scale bar: $1 \mu \mathrm{m}$ ). (C) Schematic of the iodine-loss experimental setup: Vials filled and sealed in nitrogen containing perovskite films fully submerged within toluene were exposed to full spectrum sunlight at $60^{\circ} \mathrm{C}$ in ambient air. (D) Photo of the sealed vials with the control and $0.25 \mathrm{~mol} \%[\mathrm{BMP}]^{+}\left[\mathrm{BF}_{4}\right]^{-}$additive modified $\mathrm{Cs}_{0.17} \mathrm{FA}_{0.83} \mathrm{~Pb}\left(\mathrm{I}_{0.77} \mathrm{Br}_{0.23}\right)_{3}$ perovskite samples, taken after 4-h light and heat exposure. (E and F) $10 \mathrm{UV}$-vis absorbance spectra recorded for the toluene solution taken from the $(\mathrm{E})$ control and $(\mathrm{F})[\mathrm{BMP}]^{+}\left[\mathrm{BF}_{4}\right]^{-}$vials at different aging times. (G) Evolution of absorbance recorded at $500 \mathrm{~nm}$. 


\section{Science MIAAAS}

\section{Supplementary Materials for}

\section{A piperidinium salt stabilizes efficient metal-halide perovskite solar cells}

Yen-Hung Lin*, Nobuya Sakai, Peimei Da, Jiaying Wu, Harry C. Sansom, Alexandra J. Ramadan, Suhas Mahesh, Junliang Liu, Robert D. J. Oliver, Jongchul Lim, Lee Aspitarte, Kshama Sharma, P. K. Madhu, Anna B. Morales-Vilches, Pabitra K. Nayak, Sai Bai, Feng Gao, Chris R. M. Grovenor, Michael B. Johnston, John G. Labram, James R. Durrant, James M. Ball, Bernard Wenger, Bernd Stannowski, Henry J. Snaith*

*Correspondence to: yen-hung.lin@physics.ox.ac.uk, henry.snaith@physics.ox.ac.uk

\section{This PDF file includes:}

Materials and Methods

Supplementary Text

Figs. S1 to S36

Tables S1 to S2

References 


\section{Materials and Methods}

Precursor material preparation

Lead iodide $\left(\mathrm{PbI}_{2}, 99.999 \%\right.$, metals basis), lead bromide $\left(\mathrm{PbBr}_{2}, \geq 98 \%\right)$ and cesium iodide (CsI, 99.99\%) were purchased from Alfa-Aesar. Formamidinium iodide (FAI) was purchased from GreatCell Solar. 1-butyl-1-methylpiperidinium tetrafluoroborate $\left([\mathrm{BMP}]^{+}\left[\mathrm{BF}_{4}\right]^{-}\right.$, 99\%) was purchased from Sigma-Aldrich. [6,6]-phenyl-C $\mathrm{C}_{61}$-butyric acid methyl ester $\left(\mathrm{PC}_{61} \mathrm{BM},>99.5 \%\right)$ was purchased from Solenne BV. Bathocuproine (BCP, 98\%) was purchased from Alfa Aesar. Poly(4-butylphenyl-diphenyl-amine) (polyTPD) was purchased from 1-Material. 2,3,5,6Tetrafluoro-7,7,8,8-tetracyanoquinodimethane (F4-TCNQ) was purchased from Lumtec. Unless stated otherwise, all other materials and solvents were purchased from Sigma-Aldrich. In this work, all the materials were used as received without further purification.

To form the mixed-cation lead mixed-anion perovskite precursor solutions, CsI, FAI, $\mathrm{PbI}_{2}$, and $\mathrm{PbBr}_{2}$ were prepared in the way corresponding to the exact stoichiometry for the hybrid perovskite composition [e.g. $\mathrm{Cs}_{0.17} \mathrm{FA}_{0.83} \mathrm{~Pb}\left(\mathrm{I}_{0.90} \mathrm{Br}_{0.10}\right)_{3}$ and $\mathrm{Cs}_{0.17} \mathrm{FA}_{0.83} \mathrm{~Pb}\left(\mathrm{I}_{0.77} \mathrm{Br}_{0.23}\right)_{3}$ ] in a mixed organic solvent system comprising anhydrous N,N-dimethylformamide (DMF) and anhydrous dimethyl sulfoxide (DMSO) at the volume ratio of DMF:DMSO $=4: 1$. The perovskite precursor concentration used was $1.45 \mathrm{M}$. In parallel, the piperidinium ionic solid $[\mathrm{BMP}]^{+}\left[\mathrm{BF}_{4}\right]^{-}$containing perovskite precursor solutions were prepared by dissolving the same perovskite components as the non-ionic-solid containing perovskite precursor solutions in the DMF/DMSO mixed solvent system with $[\mathrm{BMP}]^{+}\left[\mathrm{BF}_{4}\right]^{-}$in the desired molar ratios with respect to the $\mathrm{Pb}$ content. The perovskite precursor solutions were stirred overnight in a nitrogen-filled glovebox and used without any further treatment. For the hole-transporting material, polyTPD was dissolved in toluene in a concentration of $1 \mathrm{mg} \cdot \mathrm{mL}^{-1}$ along with $20 \mathrm{wt} \%$ of F4-TCNQ. For the electron-transporting $\left(\mathrm{PC}{ }_{61} \mathrm{BM}\right)$ and hole blocking $(\mathrm{BCP})$ materials, $\mathrm{PC}_{61} \mathrm{BM}$ and $\mathrm{BCP}$ were prepared separately by dissolving $\mathrm{PC}_{61} \mathrm{BM}$ and $\mathrm{BCP}$ in a mixed organic solvent system of chlorobenzene $(\mathrm{CB})$ and 1,2dichlorobenzene (DCB) $(\mathrm{CB}: \mathrm{DCB}=3: 1$ in volume) and pure isopropanol (IPA) at a concentration of 20 and $0.5 \mathrm{mg} \cdot \mathrm{mL}^{-1}$, respectively.

\section{Perovskite cell and film fabrication}

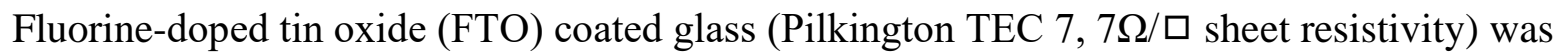
etched with zinc powder and $2 \mathrm{M} \mathrm{HCl}$ to obtain desired transparent electrode patterns. The substrates were cleaned in a series of ultrasonic cleaning baths using various solutions and solvents in the following sequence: 1) deionized water with $2 \% \mathrm{v} / \mathrm{v}$ solution of Decon 90 cleaning detergent; 2) deionized water; 3) acetone and 4) IPA (each step for 5 8 mins). After ultrasonic cleaning, substrates were dried with dry nitrogen and then treated with UV-Ozone for 15 20 mins before use. After the substrate cleaning procedure, F4-TCNQ doped polyTPD was deposited by dispensing the as-prepared organic solution onto a spinning substrate at $2000 \mathrm{rpm}$ for $20 \mathrm{sec}$, followed by thermal annealing at $130^{\circ} \mathrm{C}$ for $5 \mathrm{~min}$ in ambient air. The deposition of the perovskite layers was carried out using a spin coater in a nitrogen-filled glove box with the following processing parameters: starting at $1000 \mathrm{rpm}$ for $5 \mathrm{sec}$ (ramping time of $5 \mathrm{sec}$ from stationary status) and then $5000 \mathrm{rpm}$ (ramping time of $5 \mathrm{sec}$ from $1000 \mathrm{rpm}$ ) for $30 \mathrm{sec}$. Before the end of the spinning process, a solvent-quenching method (46) was used by dropping anisole of $250 \sim 300 \mu \mathrm{L}$ onto the spinning substrates at $40 \mathrm{sec}$ after the start of the spin-coating process. The thermal annealing process $\left(100^{\circ} \mathrm{C}\right.$ for $\left.50 \sim 55 \mathrm{~min}\right)$ was then carried out for the formation of the perovskite layer. The as-prepared $\mathrm{PC}_{61} \mathrm{BM}$ solution was dynamically spun onto the perovskite layers at a speed of $2000 \mathrm{rpm}$ for $20 \mathrm{sec}$. The samples were then annealed at $100^{\circ} \mathrm{C}$ for $3 \sim 5 \mathrm{~min}$. After cooling 
down to room temperature, the as-prepared BCP solution was dynamically spun onto the PCBM layer at a speed of $4000 \mathrm{rpm}$ for $20 \mathrm{sec}$, followed by a brief thermal annealing process at $100^{\circ} \mathrm{C}$ for $\sim 1$ min. Both PCBM and BCP were processed inside the nitrogen-filled glovebox. The hybrid perovskite single-junction solar cells were completed by thermal evaporation of $\mathrm{Cr}(3.5 \mathrm{~nm})$ and Au electrodes $(100 \mathrm{~nm})$ through shadow masks under high vacuum $\left(6 \times 10^{-6}\right.$ torr $)$ using a thermal evaporator (Nano 36, Kurt J. Lesker) placed in ambient environment.

\section{Perovskite solar cell characterization}

The current density and voltage $(\mathrm{J}-\mathrm{V})$ characteristics for perovskite solar cells were measured in air with a Keithley 2400 source meter under AM1.5 sunlight at $98 \sim 102 \mathrm{~mW} \cdot \mathrm{cm}^{-2}$ irradiance generated using an ABET Sun 2000 Class A simulator. The mismatch factor for the test cell, the light source and the National Renewable Energy Laboratories (NREL)-calibrated KG5 filtered silicon reference cell was estimated and applied in order to correctly estimate the equivalent AM1.5 irradiance level. Before the start of the measurement for each set of devices, the intensity of the solar simulator was automatically measured using a KG5 reference cell, and this recorded intensity was used to calculate the precise power conversion efficiency, where power conversion efficiency (PCE) is: (electrical power out/solar light power in) $\times 100 \%$. Unless otherwise stated, all perovskite single-junction devices were masked with a $0.0919 \mathrm{~cm}^{2}$ metal aperture to define the active area and to eliminate edge effects. The $J-V$ curves were taken at a scan rate of $100 \mathrm{mV} \cdot \mathrm{s}^{-1}$ (delay time of $100 \mathrm{~ms}$ ) from $1.3 \mathrm{~V}$ to $-0.1 \mathrm{~V}$ and then back again (from $-0.1 \mathrm{~V}$ to $1.3 \mathrm{~V}$ ). A stabilization time of $1 \mathrm{~s}$ at forward bias of $1.3 \mathrm{~V}$ under illumination was done before scanning. We note that the cells could use multiple, continuous measurements (typically up to five $\mathrm{J}-\mathrm{V}$ scans) in order to reach a peak performance. External quantum efficiency (EQE) measurements were carried out using custom-built Fourier transform photocurrent spectroscopy based on a Bruker Vertex 80v Fourier transform spectrometer. A tungsten-halogen lamp was used as the light source and the intensity was calibrated against a Newport-calibrated reference silicon photodiode.

$\underline{\text { Perovskite solar cell stability test and device characterization }}$

The perovskite solar cells were encapsulated with a cover glass (LT-Cover, Lumtec) and UV adhesive (LT-U001, Lumtec) in a nitrogen-filled glovebox. All the encapsulated devices were aged using an Atlas SUNTEST XLS+ (1,700 W air-cooled Xenon lamp) light-soaking chamber under simulated full-spectrum AM1.5 sunlight with $76 \mathrm{~mW} \cdot \mathrm{cm}^{-2}$ irradiance. For the unencapsulated devices were aged using an Atlas SUNTEST CPS+ light-soaking chamber under simulated fullspectrum AM1.5 sunlight with $77 \mathrm{~mW} \cdot \mathrm{cm}^{-2}$ irradiance. All aging tests were conducted in opencircuit conditions, and to perform $\mathrm{J}-\mathrm{V}$ characterization the samples were taken out from the chamber and tested at different time intervals, following the measurement protocol as described above. No ultraviolet filter was applied during the aging process. The aging chamber for storing the encapsulated samples was air-cooled with the temperature controlled at $85^{\circ} \mathrm{C}$ while the temperature for the chamber where the unencapsulated samples were aged was set to $60^{\circ} \mathrm{C}$. The temperature for both the aging chambers were measured by a black standard temperature control unit. During the aging period the relative humidity in the laboratory was monitored in the range of $\sim 50 \pm 5 \%$.

\section{$\underline{\mathrm{PbI}}_{2}$ film preparation and stability test}

$\mathrm{PbI}_{2}$ films prepared from $1 \mathrm{M} \mathrm{PbI}_{2}$ solution (DMF:DMSO = 4:1) were spun onto FTO glass substrates at $4000 \mathrm{rpm}$ for $30 \mathrm{sec}$ followed by thermal annealing at $100^{\circ} \mathrm{C}$ for $30 \mathrm{~min}$. The entire 
deposition was carried out in $\mathrm{N}_{2}$. A light-emitting diode (LED) luminaire (Intelligent LED Solutions, ILF-GD72-WMWH-SD401-WIR200) positioned above a mirrored box (open at both the top and bottom) was used as the illumination source. The luminaire was supplied with power from a Voltcraft DPPS-60-10 set in constant current mode to provide $2 \mathrm{~A}(\sim 39.7 \mathrm{~V})$ to the LED array. $\mathrm{PbI}_{2}$ films were illuminated by placing them below the luminaire/mirror box assembly in the center of illuminated area on a hotplate (Fisher Scientific, 11-102-50H) set to $85^{\circ} \mathrm{C}$ inside a nitrogen-filled glovebox with $\mathrm{O}_{2}$ and $\mathrm{H}_{2} \mathrm{O}<1 \mathrm{ppm}$. The estimation of the equivalent solar illumination intensity of the LED luminaire is provided in the Supplementary Text.

\section{Photoluminescence characterization}

Steady-state photoluminescence spectra were recorded using an excitation wavelength of 510 $\mathrm{nm}$ and slit widths of $5 \mathrm{~mm}$ on a commercial spectrofluorometer (Horiba, Fluorolog). Timeresolved PL measurements were acquired using a time-correlated single photon counting (TCSPC) setup (FluoTime 300 PicoQuant GmbH). Film samples were photoexcited using a 507-nm laser head (LDH-P-C-510, PicoQuant $\mathrm{GmbH}$ ) pulsed at 0.2 MHz. Perovskite films were prepared on polyTPD coated FTO glass substrates.

High-resolution secondary ion mass spectrometry characterization

To investigate the localisation of $\mathrm{B}$ and $\mathrm{F}$ in these samples we deposited $\sim 500 \mathrm{~nm}$ perovskite films onto $\mathrm{Si} / \mathrm{SiO}_{2}$ substrates with $0.25 \mathrm{~mol} \%[\mathrm{BMP}]^{+}[\mathrm{BF} 4]^{-}$(with to the $\mathrm{Pb}$ content of the perovskite used) and employed high-resolution secondary ion mass spectrometry (NanoSIMS) to perform elemental mapping in a CAMECA NanoSIMS 50 system using a focused $16 \mathrm{keV} \mathrm{Cs}^{+}$ primary beam. The D1 aperture was set to D1-3 (150 $\mu$ m diameter), which provides a primary beam of $\sim 1 \mathrm{pA}$ (beam diameter $\sim 150 \mathrm{~nm}$ ) which was rastered over the selected measurement area. Entrance and aperture slits were chosen to be $40 \times 220 \mu \mathrm{m}(\mathrm{ES}-2)$ and $200 \times 200 \mu \mathrm{m}$ (AS-2) respectively. The raster size was $15 \mu \mathrm{m} \times 15 \mu \mathrm{m}(256 \times 256$ pixels $)$ and the dwell time was $2000 \mu \mathrm{s}$ per pixel. Ion maps were collected simultaneously for ${ }^{12} \mathrm{C}^{-},{ }^{19} \mathrm{~F}^{-},{ }^{28} \mathrm{Si}^{-}$and ${ }^{11} \mathrm{~B}^{16} \mathrm{O}_{2}-$ ion signals, together with the secondary electron signal produced during the sputtering process, which can be used to show both sample morphology and surface topography. These scans were repeated 200 times from the same area, giving a set of stacked images of the distributions of each element, and sputtering to a total depth of $\sim 700 \mathrm{~nm}$ below the sample surface. The typical two-dimensional (2D) SIMS maps in Fig. 2A-C are summed from images \#21 to \#40 to give better signal-to-noise ratios (SNRs). The 'auto-track' feature in ImageJ was used to correct any image drift before the images were summed, and the FEI Avizo software package was then applied for the three-dimensional (3D) visualization shown in Fig. 2D following the methodologies described in Ref. (47). We have plotted depth and line profiles using ImageJ with the OpenMIMS plugin (Harvard) (48) from small regions covering one ${ }^{19} \mathrm{~F}^{-}$hotspot and part of the perovskite matrix to compare the ${ }^{19} \mathrm{~F}^{-}$intensities.

\section{Solid-state nuclear magnetic resonance}

All the solid-state nuclear magnetic resonance (ssNMR) experiments were carried out using a triple-channel $1.3 \mathrm{~mm}$ ssNMR probe on a $700 \mathrm{MHz}$ Bruker AV III spectrometer. All the ${ }^{1} \mathrm{H}$ pulses were at a nutation frequency of $67 \mathrm{kHz}$ with the sample spun at a magic-angle spinning frequency of $55 \mathrm{kHz}$. The number of scans for 1D Bloch-decay experiments was 3200. Standard three-pulse scheme was used for the 2D spin-diffusion experiments. The 2D spectra were acquired with 96 scans for each of the 160 increments corresponding to final $t_{1}$ evolution time of $4 \mathrm{~ms}$, and $100 \mathrm{~ms}$ of mixing time. States-TPPI was used for frequency discrimination in the indirect 
dimension. Data were processed using Topspin 3.5 with an exponential line broadening of $20 \mathrm{~Hz}$ which were edited using inkscape 0.92. The temperature during the experiment was maintained at $298 \mathrm{~K}$.

Transient photovoltage and photocurrent characterization

The illumination was provided by a ring of 12 white light-emitting diodes (LEDs) with a fastswitching metal oxide semiconductor field-effect transistor. The one sun equivalent illumination was calibrated by matching the value of $J_{\mathrm{SC}}$ and $V_{\mathrm{OC}}$ obtained under the AM1.5G solar simulator measurement. The light was switched on for approximately $2 \mathrm{~ms}$ to allow a steady state to be reached, and a much longer time with the light switched off was applied to avoid overheating. The potential bias was applied by a Keithley 2400 source-meter, and the current and the voltage across were measured by a Tektronix TDS3032B oscilloscope with a 1-M $\Omega$ input impedance. Charge extraction was used to determine the average charge carrier densities in devices under different illumination levels and different biases (open circuit and short circuit in this study).

The desired light intensity was provided by a ring of 12 white LEDs the same as above, which is capable of a power up to 5 sun equivalents. The device was held under the initial bias at certain background light and then switched to short circuit and turn off light, and the transient was acquired with a DAQ card connected to a Tektronix TDS3032B oscilloscope. The voltage transients were converted into current transients through Ohm's law, the current transients were then integrated to obtain total charge to calculate charge carrier density in the device. During TPV measurements, the device was held at open circuit condition under different background light intensities controlled by a ring of white LEDs as described before; then a small optical excitation was provided by a pulsed Continuum Minilite Nd:YAG laser at 532nm with a pulse width of smaller than $10 \mathrm{~nm}$. This small excitation produced a small voltage transient decay was then measured by the oscilloscope. The results were fitted with a mono-exponential decay function to obtain the small perturbation carrier lifetime and to estimate the total charge carrier lifetime within the device.

\section{Time-resolved microwave conductivity characterization}

The experimental setup for the time-resolved microwave conductivity (TRMC) measurement can be found in our previous work (49). A microwave-frequency oscillatory electric signal is generated using a Sivers IMA VO4280X/00 voltage-controlled oscillator (VCO). The signal has an approximate power of $16 \mathrm{dBm}$ and a tunable frequency between $8 \mathrm{GHz}$ and $15 \mathrm{GHz}$. The $\mathrm{VCO}$ is powered with an NNS1512 TDK-Lambda constant 12V power supply, and the output frequency is controlled by a Stahl Electronics BSA-Series voltage source. The oscillatory signal is incident on an antenna inside a WR90 copper-alloy waveguide. The microwaves emitted from the antenna pass through an isolator and an attenuator before they are incident on a circulator (Microwave Communication Laboratory Inc. CSW-3). The circulator acts as a unidirectional device in which the incident microwaves pass through a fixed iris $(6.35 \mathrm{~mm}$ diameter) into a sample cavity. The cavity supports a $\mathrm{TE}_{103}$ mode standing wave and consists of an ITO-coated glass window that allows optical access to the sample. The sample is mounted inside the cavity at a maximum of the electric-field component of the standing microwaves, using a 3D-printed PLA sample holder.

Microwaves reflected from the cavity are then incident on the circulator, directed through an isolator, and onto a zero-bias Schottky diode detector (Fairview Microwave SMD0218). The detector outputs a voltage which is linearly proportional to the amplitude of the incident microwaves. The detected voltage signal is amplified by a Femto HAS-X-1-40 high-speed 
amplifier (gain $=\times 100$ ). The amplified detector voltage is measured as a function of time by a Textronix TDS 3032C digital oscilloscope. A Continuum Minilite II pulsed Nd:YaG laser is used to illuminate the sample. The laser pulse has a wavelength of $532 \mathrm{~nm}$, a full width at half-maxima of approximately $5 \mathrm{~ns}$ and a maximum fluence incident on the sample of $\sim 10^{15}$ photons per $\mathrm{cm}^{2}$ per pulse. An external trigger link is employed to trigger the oscilloscope before the laser fires. The photoconductance was evaluated from changes in the detector voltage using standard analysis as described in our previous works (49-51). All the measurements were conducted in air, without encapsulation, in the over-coupled regime. Perovskite films were prepared on quartz substrates.

\section{In-plane transient photoconductivity characterization}

The experimental setup for the in-plane transient photoconductivity (ip-TPC) measurement can be found in our previous work $(52,53)$. A Nd:YAG pulsed laser excitation source pumped at $10 \mathrm{~Hz}$ with FWHM $=3.74 \mathrm{~ns}$ was set to $470 \mathrm{~nm}$ with a range of fluences in order to vary the charge carrier densities of FACs. A bias of $2.96 \mathrm{~V}$ is applied on one of the in-plane electrodes. A variable resistor is connected in series with the samples. The voltage drop on this resistor was monitored through an oscilloscope with a high internal resistance $(1 \mathrm{M} \Omega)$ connected in parallel to determine the change of the potential across the two in-plane Au electrodes. The ip-TPC was calculated using the following equation

$$
\sigma_{\mathrm{TPC}}=\frac{V_{r}}{R_{r} \times\left(V_{\mathrm{appl}}-V_{r}\right)} \times \frac{l}{w \times t}
$$

where $R_{r}$ is resistance for the variable resistor, $V_{r}$ is the potential drop measured across the resistor, $V_{\text {appl }}$ is applied voltage, $l$ is channel length, $w$ is channel width, and $t$ is film thickness. Perovskite films were prepared on glass substrates

\section{$\underline{\text { X-ray diffraction characterization }}$}

The X-ray diffraction (XRD) patterns were measured from perovskite samples deposited onto FTO glass substrates using a $\mathrm{Cu} \mathrm{K \alpha}$ X-ray source and a Panalytical X'PERT Pro X-ray diffractometer. Topas-6 software was used to implement Pawley fits in order to extract lattice parameters, using FTO as an internal standard.

\section{$\underline{\text { X-ray photoemission spectroscopy characterization }}$}

X-ray photoemission spectroscopy measurements were carried out using a Thermo Scientific $\mathrm{K} \alpha$ photoelectron spectrometer using a monochromated Al K $\alpha$ X-ray source at a take-off angle of $90^{\circ}$. The core level XPS spectra were recorded using a pass energy of $20 \mathrm{eV}$ (resolution approximately $0.4 \mathrm{eV}$ ) from an analysis area of $400 \mu \mathrm{m} \times 400 \mu \mathrm{m}$. The spectrometer work function and binding energy scale were calibrated using the Fermi edge and $3 \mathrm{~d}$ peak recorded from a polycrystalline silver (Ag) sample prior to the commencement of the experiments. Fitting procedures to extract peak positions were carried out using CasaXPS, the background of the spectra was fitted using a Shirley lineshape and the peaks were fit using a mixture of Gaussian/Lorentzian (Lorentzian $=20 \%$ ) line shapes. For characterizing perovskite films, the samples were prepared on polyTPD coated FTO glass substrates. 


\section{Ultraviolet-visible spectroscopy characterization}

The ultraviolet-visible (UV-vis) transmission measurements were performed using an Agilent Cary 60 UV-vis spectrophotometer. The samples were prepared on FTO substrates using the same deposition parameters described above.

Optical microscopy characterization

The optical microscopy measurements were performed using a Nikon motorized microscope (Eclipse LV100ND). A UV-375nm LED bulb (BSIL100LEDC) is used for carrying out the PLmode characterization.

Scanning electron microscopy characterization

A Hitachi S-4300 scanning electron microscope was used to acquire cross-sectional images of target samples.

$\underline{\text { Iodine loss characterization }}$

Perovskite films were prepared on FTO glass substrates and deposited using the same protocols as detailed above. For aging, perovskite samples (with a total surface area of $3 \mathrm{~cm} \times 3$ $\mathrm{cm}$ ) were immersed in 10-mL toluene in clear vials and exposed to the same aging environment as for unencapsulated perovskite cells. The iodine loss from perovskites was studied by preparing the aged toluene solution in a quartz cuvette and then measured using the UV-vis spectrophotometer. 


\section{Supplementary Text}

Optical modelling for perovskite-on-silicon tandem subcells

We modelled the optical response of the stack using the generalised transfer matrix method (54). All calculations were done in Python with use of the NumPy and SciPy libraries. Transfer matrix calculations take the complex refractive index spectrum and thickness for each layer as input. The calculation provides us with absorptance of each layer, and the transmittance and reflectance of the stack. We assumed perfect internal quantum efficiency and calculated the short circuit current as the overlap integral of the AM1.5 solar spectrum with the absorptance. To vary the band gap of the perovskite, the extinction coefficient was linearly translated. For each translation, the refractive index was recalculated using the Kramer's Kronig relation (55):

$$
n(\lambda)=1+\frac{2}{\pi} \int_{0}^{\infty} \frac{E^{\prime} k(E)}{E^{\prime 2}-E^{2}} d E^{\prime}
$$

The material stacks and optical data used for each material layer as input for the Transfer Matrix Calculations are the same as though which we used in our previous publication (17), including the device stack which we used for modelling the monolithic perovskite-on-silicon tandem solar cells. For the optical model of the tandem solar cells, we used the optical data from the HTL-perovskite absorber layer-ETL stack in our single-junction perovskite cells. In addition, for the tandem cell simulation we used a $\mathrm{SnO}_{2}$ buffer layer $(5 \mathrm{~nm})$, an ITO layer $(80 \mathrm{~nm})$ and a final antireflection coating, similar to the stack reported by Bush et al. (27).

Charge extraction, transient photocurrent, transient photovoltage and photoluminescent

To understand the effect of [BMP $]^{+}\left[\mathrm{BF}_{4}\right]^{-}$on device performance, particularly on $V_{\mathrm{OC}}$, lightinduced charge carriers, charge carrier lifetime and effective charge carrier diffusion mobility were measured by a series of transient optoelectronic measurements, including charge extraction, transient photocurrent and transient photovoltage. These transient optoelectronic techniques have been widely applied to the study of the recombination and transport kinetics in dye-sensitized solar cells $(56,57)$, organic solar cells $(58-62)$, and perovskite solar cells $(63)$.

Figure S8A shows the light intensity-dependent $V_{\mathrm{OC}}$, and the ideality factors extracted for the control and $0.25 \mathrm{~mol} \%$ [BMP $^{+}[\mathrm{BF} 4]^{-}$modified devices are 2 and 1.55 , respectively. The smaller ideality factor suggests that the $[\mathrm{BMP}]^{+}[\mathrm{BF} 4]^{-}$modified device has less recombination via deeper trap states (64). Regarding charge extraction, Fig. S8B shows the extracted total charge as a function of light-induced $V_{\mathrm{OC}}$. We found that the obtained charge rises exponentially with the lightinduced $V_{\mathrm{OC}}$, with shallow gradients as a function of $V_{\mathrm{OC}}$, indicative of trapped charge carrier distribution $\mathrm{n}$ is significantly larger than thermal energy $k T$. This exponential increase suggests that the photogenerated carriers fill intraband trap states as the quasi-Fermi level splitting increase (65). At smaller light-induced $V_{\mathrm{OC}}$, the charge in the control device is significantly higher than the $[\mathrm{BMP}]^{+}[\mathrm{BF} 4]^{-}$modified device, indicative of a higher density of relatively deeply trapped carriers in the control device, with $[\mathrm{BMP}]^{+}[\mathrm{BF} 4]^{-}$reducing the density of relatively deep traps in the perovskite film.

To shed more light on this point, we performed time-resolved and steady-state photoluminescence (i.e. TRPL and SSPL) on the control and $[\mathrm{BMP}]^{+}[\mathrm{BF} 4]^{-}$modified films made on polyTPD/FTO substrates (Fig. S9). A slower initial TRPL decay and a higher SSPL observed in the $[\mathrm{BMP}]^{+}[\mathrm{BF} 4]^{-}$device also indicate through the addition of $[\mathrm{BMP}]^{+}[\mathrm{BF} 4]^{-}$the trap density in the perovskite film can be effectively reduced. 
The effective charge carrier lifetime measured as a function of the total charge is shown in Fig. S10A. We found that the control device exhibits longer carrier lifetimes than the $[\mathrm{BMP}]^{+}[\mathrm{BF} 4]^{-}$modified device at matched carrier densities, particularly in the low charge density regime. These longer carrier lifetimes are also indicative of a higher trap density for the control device as. In Fig. S10B, the effective diffusion mobility of both devices is similar, with the value of $\sim 10^{-1} \mathrm{~cm}^{2} \cdot \mathrm{V}^{-1} \cdot \mathrm{s}^{-1}$ measured at a short circuit condition.

\section{Evaluation of time-resolved microwave conductivity figure of merit}

Figures S11A and S11B show the time-resolved microwave conductivity (TRMC) transient data (photo-conductance $\Delta G$ as a function of time $t$ ) for the control hybrid perovskite sample [i.e. $\left.\mathrm{Cs}_{0.17} \mathrm{FA}_{0.83} \mathrm{~Pb}\left(\mathrm{I}_{0.77} \mathrm{Br}_{0.23}\right)_{3}\right]$ and the sample with $0.25 \mathrm{~mol} \%[\mathrm{BMP}]^{+}\left[\mathrm{BF}_{4}\right]^{-}$, respectively. The peak observed value of $\Delta G$ (i.e. $\Delta G_{\max }$ ) can then be used to determine the TRMC figure of merit through Eq. S3 (49):

$$
\phi \Sigma \mu_{\mathrm{TRMC}}=\frac{\Delta G_{\max }}{\beta e I_{0} F_{A} M}
$$

Here $\phi \Sigma \mu_{\mathrm{TRMC}}=\phi\left(\mu_{e}+\mu_{h}\right)$, where $\phi$ is the carrier generation efficiency, $\mu_{e}$ and $\mu_{h}$ are the electron and hole mobility in the perovskite sample, respectively. $e$ is the fundamental unit of charge. $I_{0}$ is the fluence of the incident light, and $F_{A}$ is the fractional absorption of photons of the sample at the excitation wavelength (between 0 and 1). $I_{0}$ can be measured by placing a calibrated photodiode / thermopile in the path of the excitation path. $F_{A}$ can be measured using ultravioletvisible spectroscopy. $M$ is a parameter we define as the "masking parameter" and is the fraction (between 0 and 1) of the cross-sectional area of the cavity that is exposed to the incident light. In our case $M=0.25$ in all cases.

Equation S3 assumes that no recombination takes place on the response-time of the measurement. At low fluence this is a reasonable assumption, but at high fluence the carrier density could reach a very high number (66). Under these conditions, bimolecular and Auger recombination can reduce the peak value of $\Delta G$ from what one would expect under ideal conditions (67). This is manifest as a reduction in $\phi \Sigma \mu_{\mathrm{TRMC}}$ as a function of fluence at high fluence. Using a simple model based on recombination during the finite duration of the laser pulse, this behaviour can be modelled. The specific details of the model can be found elsewhere (67).

Time-resolved microwave conductivity and in-plane transient photoconductivity

In order to further investigate the impact of the additive of charge carrier mobility, perovskite films were studied using time-resolved microwave conductivity (TRMC). TRMC was here carried out on isolated thin films on quartz. Figure S12 shows the TRMC figure of merit $\phi \Sigma \mu_{\mathrm{TRMC}}=$ $\phi\left(\mu_{e}+\mu_{h}\right)$, for the control sample and the sample with the additive as function of optical fluence, where $\phi$ is the number of electron hole pairs generated per absorbed photon, and $\mu_{e}$ and $\mu_{h}$ are the average electron and hole mobilities over the sample area, respectively. The parameter $\phi \Sigma \mu$ has the same dimensions as the mobility (e.g. $\mathrm{cm}^{2} \mathrm{~V}^{-1} \mathrm{~s}^{-1}$ ) but carrier-type-specific information remains obscured.

At high optical fluence, a significant amount of bimolecular and Auger recombination will occur during the $\sim 5 \mathrm{~ns}$ laser pulse of the TRMC experiment, resulting in a reduction in peak observable photo-conductance, and hence a reduction in extracted $\phi \Sigma \mu_{\mathrm{TRMC}}$ (as observed in Fig. S12). This is a widely-observed phenomenon in TRMC (68-70), and models have been developed 
to account for it (67). We have applied this model to our experimental data to approximate representative values of $\phi \Sigma \mu_{\text {TRMC }}$ for the films studied here. From these fits we evaluate $\phi \Sigma \mu=$ $0.23 \mathrm{~cm}^{2} \cdot \mathrm{V}^{-1} \cdot \mathrm{s}^{-1}$ for the control sample and $\phi \Sigma \mu_{\mathrm{TRMC}}=0.21 \mathrm{~cm}^{2} \cdot \mathrm{V}^{-1} \cdot \mathrm{s}^{-1}$ for the $[\mathrm{BMP}]^{+}\left[\mathrm{BF}_{4}\right]^{-}$ modified sample.

The results from TRMC hence broadly agree with those obtained from our charge extraction characterization. We note that while for charge extraction the measured mobility is in the out-ofplane direction, TRMC is an area-average local probe of electrical properties of the semiconductor in the plane of the sample (71).

In addition, we have performed in-plane transient photoconductivity (ip-TPC) for both the control and $[\mathrm{BMP}]^{+}\left[\mathrm{BF}_{4}\right]^{-}$samples (Fig. S13). The obtained mobilities $\phi \Sigma \mu_{\mathrm{ip}-\mathrm{TPC}}$ are $0.26 \mathrm{~cm}^{2} \cdot \mathrm{V}^{-}$ ${ }^{1} \cdot \mathrm{s}^{-1}$ and $0.23 \mathrm{~cm}^{2} \cdot \mathrm{V}^{-1} \cdot \mathrm{s}^{-1}$, respectively, as a function of the excitation density across three orders of magnitude (Fig. S13A). We note that these values are in good agreement with those obtained from our TRMC study. For the excitation density below $10^{17} \mathrm{~cm}^{-3}$ the mobility value is nearly constant as the excited charge carriers mostly exist as the free carrier under the equilibrium due to the low binding energy. From the decay profile of photoconductivity measured as a function of time after excitation (Fig. S13B), we found the $[\mathrm{BMP}]^{+}\left[\mathrm{BF}_{4}\right]^{-}$modified sample has a much longer decay. The latter suggests a longer lifetime for the charge carriers in the $[\mathrm{BMP}]^{+}\left[\mathrm{BF}_{4}\right]^{-}$device than the control one.

\section{Solid-state nuclear magnetic resonance}

We examined if there was any direct interaction existing between $[\mathrm{BMP}]^{+}\left[\mathrm{BF}_{4}\right]^{-}$and $\mathrm{Cs}_{0.17} \mathrm{FA}_{0.83} \mathrm{~Pb}\left(\mathrm{I}_{0.77} \mathrm{Br}_{0.23}\right)_{3}$ perovskite through solid-state nuclear magnetic resonance (ssNMR) studies of the modified and control perovskites. The corresponding one-dimensional spectra and the 2D ${ }^{1} \mathrm{H}-{ }^{1} \mathrm{H}$ spin-diffusion (mixing time of $100 \mathrm{~ms}$ ) spectra of the control and modified perovskite are shown in Fig. S15. A $[\mathrm{BMP}]^{+}\left[\mathrm{BF}_{4}\right]^{-}$reference sample was used as the reference. The modified perovskite exhibited similar spectra to the control as most of the signature peaks of $[\mathrm{BMP}]^{+}[\mathrm{BF} 4]^{-}$overlapped with those of $\mathrm{Cs}_{0.17} \mathrm{FA}_{0.83} \mathrm{~Pb}\left(\mathrm{I}_{0.77} \mathrm{Br}_{0.23}\right)_{3}$ (Fig. S15A). We also performed a ${ }^{1} \mathrm{H}-{ }^{1} \mathrm{H} 2 \mathrm{D}$ correlation experiment. Since, the cross-peaks obtained in both samples are similar (Figs. S15B and S15C), this indicates either very weak or even no direct interaction between $[\mathrm{BMP}]^{+}\left[\mathrm{BF}_{4}\right]^{-}$and perovskites.

\section{$\underline{X-r a y}$ photoemission spectroscopy}

We further confirmed our findings from the ssNMR measurement by characterizing the modified and control samples using X-ray photoemission spectroscopy (XPS). Figures S16A and S16B show high-resolution scans of $\mathrm{C} 1 s$ and $\mathrm{N} 1 s$, respectively. When comparing both the modified and control samples, there was barely any change observed in the A-site relevant peaks, i.e. $\mathrm{C}\left(\mathrm{NH}_{2}\right)_{2}\left(288.7 \mathrm{eV}\right.$, Fig. S16A) and $\mathrm{HC}\left(\mathrm{NH}_{2}\right)_{2}(400 \mathrm{eV}$, Fig. S16B). This result again indicated that the interaction between $[\mathrm{BMP}]^{+}[\mathrm{BF} 4]^{-}$and $\mathrm{Cs}_{0.17} \mathrm{FA}_{0.83} \mathrm{~Pb}\left(\mathrm{I}_{0.77} \mathrm{Br}_{0.23}\right)_{3}$ was too weak to determine through the change in the chemical shift. However, because the peaks assigned to HC$\mathrm{N}^{+}\left(286 \mathrm{eV}\right.$, Fig. S16A) and $\mathrm{N}^{+} \mathrm{C}_{10} \mathrm{H}_{22} \mathrm{BF}_{4}(402 \mathrm{eV}$, Fig. S16B) were only found in the modified sample, this observation confirmed the presence of $[\mathrm{BMP}]^{+}[\mathrm{BF} 4]^{-}$at the sample surfaces. These results indicated that it was unlikely that $[\mathrm{BMP}]^{+}[\mathrm{BF} 4]^{-}$grew as part of the perovskite structures and only weakly interacted at the surface of the crystalline material, presumably between the crystalline grains within the film. 
Equivalent solar illumination intensity measurement

The equivalent solar irradiance used to illuminate the $\mathrm{PbI}_{2}$ films is given by the ratio of absorbed irradiance from the AM1.5G solar spectrum to that from the LED luminaire. The absorbed irradiance $\left(\boldsymbol{F}_{\boldsymbol{i}}\right)$ from illumination source $(\boldsymbol{i})$ is given by:

$$
F_{i}=\int_{0}^{\infty} A(\lambda) P_{i}(\lambda) d \lambda
$$

where $\lambda$ is incident wavelength, $\boldsymbol{A}(\lambda)$ is the spectral absorptance of the material, and $\boldsymbol{P}_{i}(\lambda)$ is the spectral irradiance. The equivalent solar irradiance $(\boldsymbol{M})$ is thus:

$$
M=F_{L E D} / F_{A M 1.5 G}
$$

To calculate the approximate equivalent intensity of the illumination source the short-circuit current $\left(\boldsymbol{I}_{\boldsymbol{S C}}\right)$ from a KG3-filtered certified silicon reference diode (Fraunhofer), placed on top of the hotplate (the diode itself was thus $\sim 1 \mathrm{~cm}$ above the surface of the hotplate) under illumination by the luminaire, was measured using a source-measure unit (Keithley Instruments, 2400). The illumination spectrum from the luminaire was measured using a fiber-coupled spectrograph (Ocean Optics MAYA Pro 2000) with a cosine corrector on the light input aperture of the optical fiber. Dispersion in the optical measurement system was corrected using a calibration lamp of known spectral irradiance (Ocean Optics, HL-3P-CAL). The short circuit current density $\left(\boldsymbol{J}_{S C}\right)$ of a solar cell is given by:

$$
J_{S C}=q N \int_{0}^{\infty} E Q E(\lambda) \phi_{i, n o r m}(\lambda) d \lambda
$$

where $\boldsymbol{q}$ is the charge of an electron, $\boldsymbol{E} \boldsymbol{Q E}(\boldsymbol{\lambda})$ is the spectral external quantum efficiency, and $\boldsymbol{\phi}_{i, \text { norm }}$ is the normalized incident photon flux from the illumination source, and $\boldsymbol{N}$ is a factor that scales the normalized photon flux spectrum to physical units. Therefore, using the measured $\boldsymbol{J}_{S C}$ and certified $\boldsymbol{E Q E}$ of the calibration cell as well as the measured $\phi_{i, n o r m}$ from the LED array, it is possible to calculate $\boldsymbol{N}, \boldsymbol{P}_{\boldsymbol{L E D} \boldsymbol{D}}$ in absolute units, as well as $\boldsymbol{F}_{\boldsymbol{L E D}}$ and $\boldsymbol{F}_{\boldsymbol{A M 1 . 5 G}}$ using the measured $\mathrm{PbI}_{2}$ absorptance spectrum (approximated as $1-\boldsymbol{T}$, where $\boldsymbol{T}$ is transmittance). Our setup gave equivalent solar intensity $\approx 0.32$ suns (Fig. S34) when aging $\mathrm{PbI}_{2}$ films in $\mathrm{N}_{2}$. 


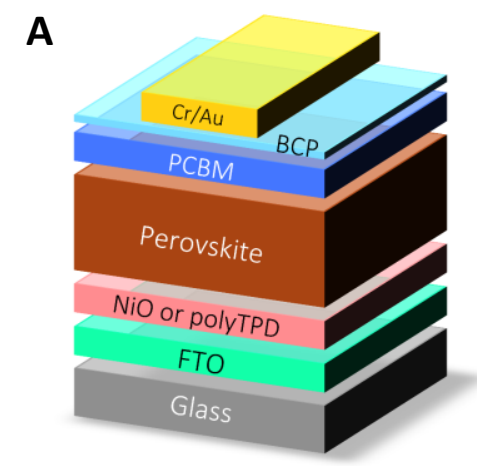

B

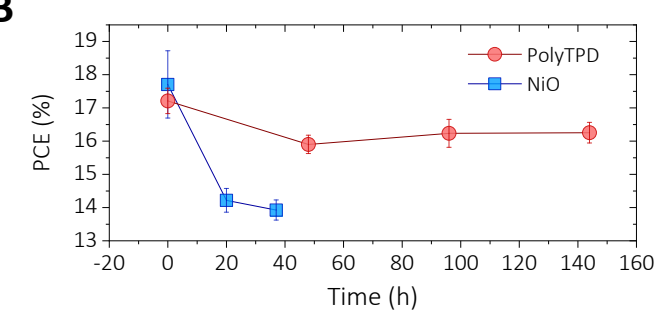

D

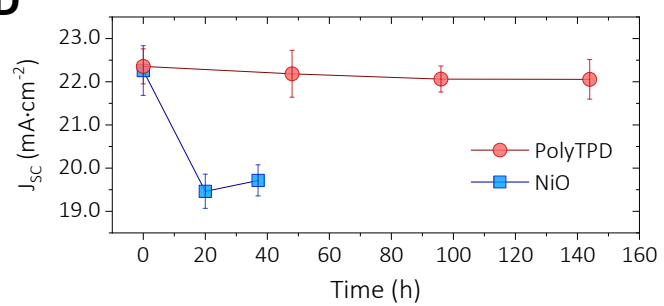

C

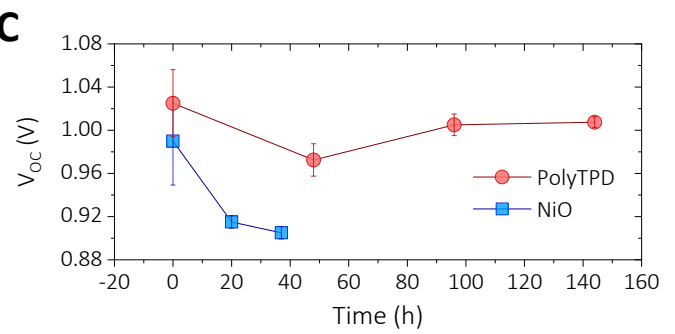

$\mathbf{E}$

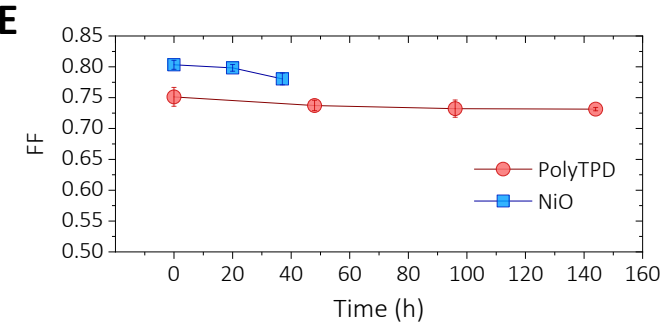

Fig. S1. (A) Schematic of the p-i-n perovskite solar cells using $\mathrm{Cs}_{0.17} \mathrm{FA}_{0.83} \mathrm{~Pb}\left(\mathrm{I}_{0.90} \mathrm{Br}_{0.10}\right)_{3}$ as the light absorber and a hole-transporting layer of polyTPD or NiO. Evolution of the solar cell performance parameters obtained from a set of perovskite solar cells (8 devices), as depicted in (A), using either polyTPD or $\mathrm{NiO}$ as the hole-transporting layer when aged at $85^{\circ} \mathrm{C}$ in nitrogen: (B) PCE; (C) $V_{\mathrm{OC}}$; (D) $J_{\mathrm{SC}}$; (E) FF. The error bars denote standard derivation. 
A

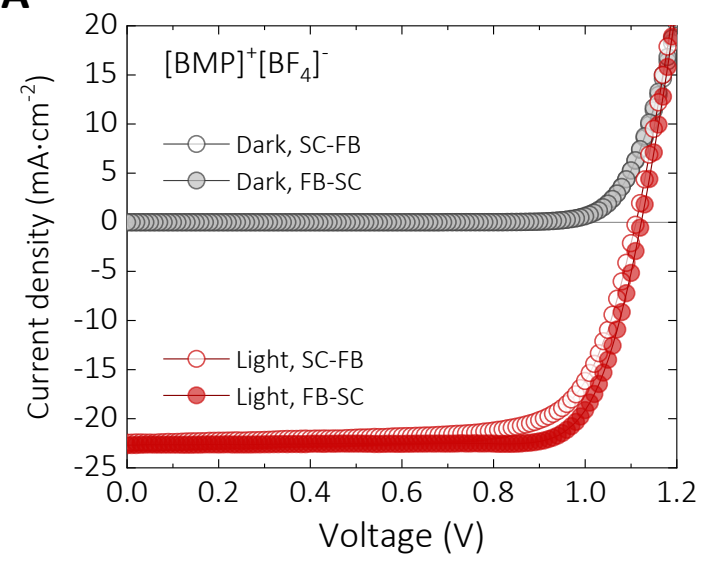

B

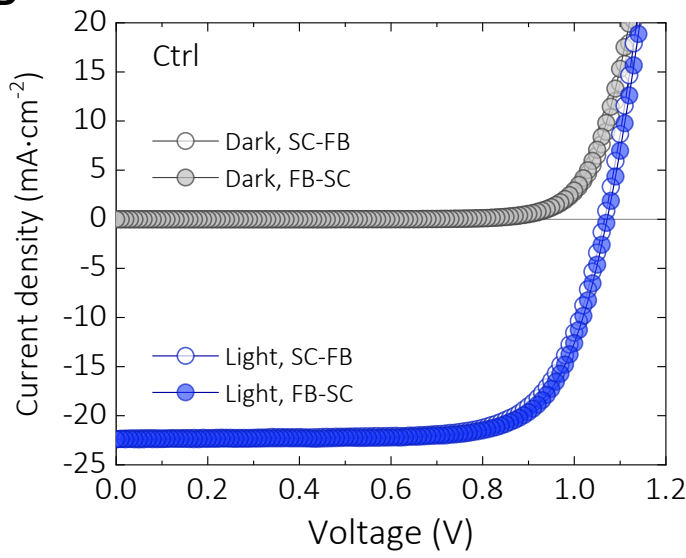

Fig. S2. $J$ - $V$ scans of (A) an optimized $0.25 \mathrm{~mol} \%[\mathrm{BMP}]^{+}\left[\mathrm{BF}_{4}\right]^{-}$p-i-n perovskite solar cell and (B) a control device with a perovskite composition of $\mathrm{Cs}_{0.17} \mathrm{FA}_{0.83} \mathrm{~Pb}\left(\mathrm{I}_{0.90} \mathrm{Br}_{0.10}\right)_{3}$. Reverse and forward scans represent the measurements following the voltage sweeps from flat-band to shortcircuit (FB-SC) and from short-circuit to flat-band (SC-FB), respectively. For the FB-SC scan, the obtained device performance parameters are as follows: (A) $V_{\mathrm{OC}}=1.12 \mathrm{~V}, J_{\mathrm{SC}}=22.7 \mathrm{~mA} \cdot \mathrm{cm}^{-2}$, $\mathrm{FF}=0.80, \mathrm{PCE}=20.3 \%$; (B) $V_{\mathrm{OC}}=1.07 \mathrm{~V}, J_{\mathrm{SC}}=22.4 \mathrm{~mA} \cdot \mathrm{cm}^{-2}, \mathrm{FF}=0.74, \mathrm{PCE}=17.6 \%$. For the SC-FB scan, the obtained device performance parameters are as follows: (A) $V_{\mathrm{OC}}=1.11 \mathrm{~V}, J_{\mathrm{SC}}=$ $22.5 \mathrm{~mA} \cdot \mathrm{cm}^{-2}, \mathrm{FF}=0.73, \mathrm{PCE}=18.1 \%$; (B) $V_{\mathrm{OC}}=1.07 \mathrm{~V}, J_{\mathrm{SC}}=22.4 \mathrm{~mA} \cdot \mathrm{cm}^{-2}, \mathrm{FF}=0.72, \mathrm{PCE}$ $=17.2 \%$. 


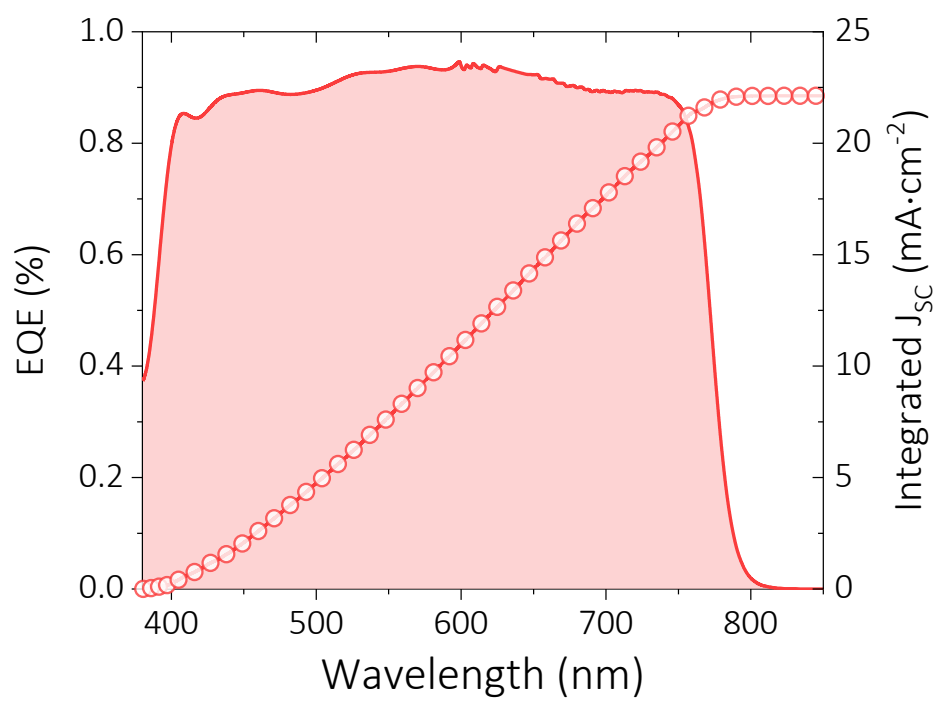

Fig. S3. External quantum efficiency (EQE) spectra (line) and integrated photocurrent (scatters), integrated over the AM1.5 $\left(100 \mathrm{~mW} \cdot \mathrm{cm}^{-2}\right)$ solar spectrum, for the champion $[\mathrm{BMP}]^{+}\left[\mathrm{BF}_{4}\right]^{-}$ perovskite $\mathrm{Cs}_{0.17} \mathrm{FA}_{0.83} \mathrm{~Pb}\left(\mathrm{I}_{0.90} \mathrm{Br}_{0.10}\right)_{3}$ solar cell shown in Fig. 1E. The integrated $J_{\mathrm{SC}}$ values over the measured EQE was $22.1 \mathrm{~mA} \cdot \mathrm{cm}^{-2}$. 


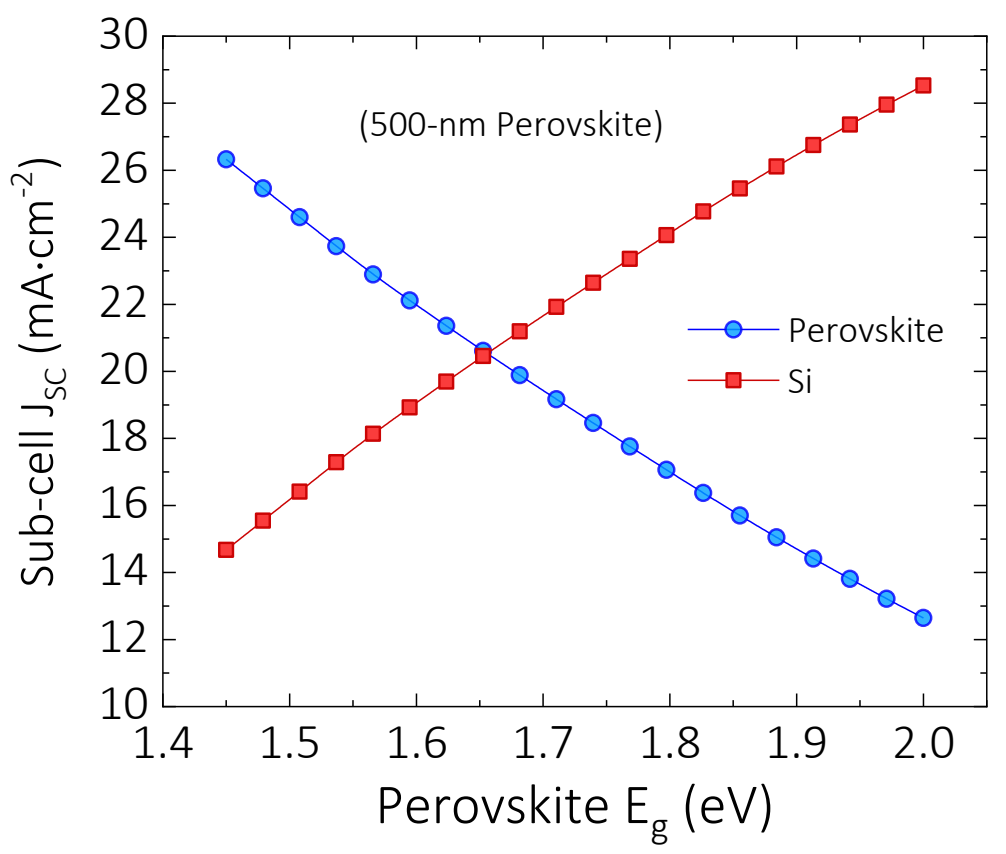

Fig. S4. Simulated subcell current densities $\left(J_{\mathrm{SC}}\right)$ for $500-\mathrm{nm}$ thick perovskite top cells and $\mathrm{Si}$ bottom cells for different perovskite band gap $\left(E_{g}\right)$. Parameters employed for this simulation are adopted from our previous publication (17). Current-matching takes place at a perovskite band gap of $\sim 1.66 \mathrm{eV}$. 


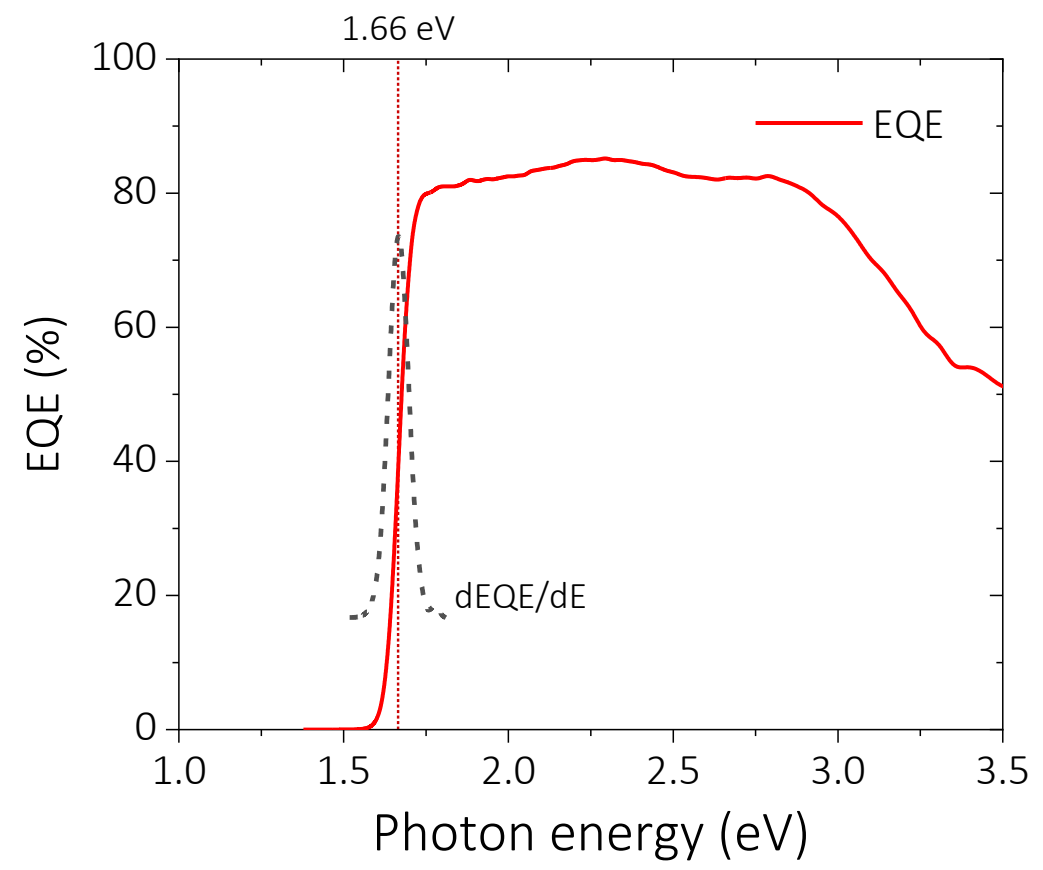

Fig. S5. External quantum efficiency (EQE, red solid line) for the $[B M P]^{+}\left[B F_{4}\right]^{-}$modified perovskite solar cell shown in Fig 1G. A band gap value of $1.66 \mathrm{eV}$ is extracted from the first derivative of the EQE (grey dashed line) as a function of photon energy. 

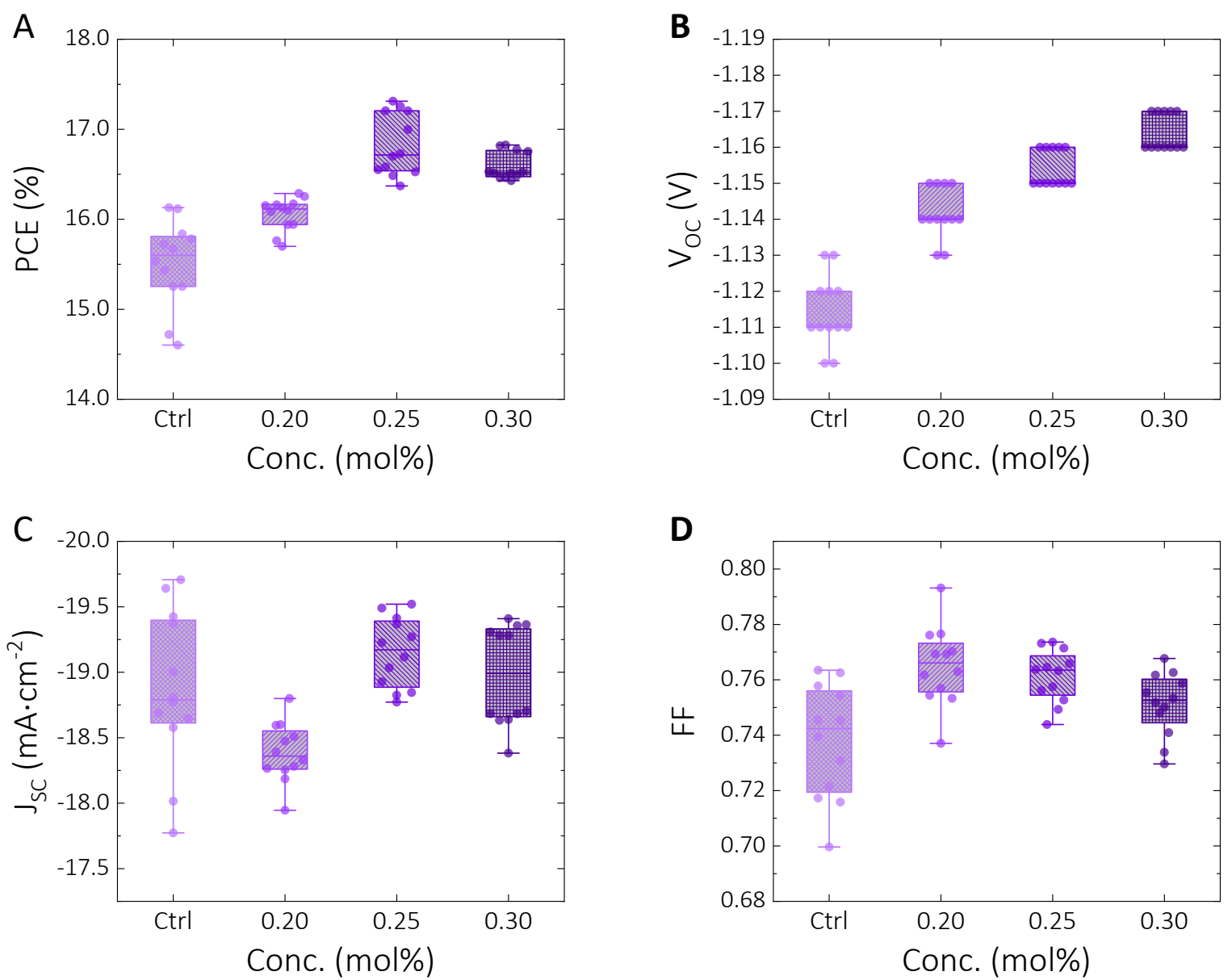

Fig. S6. Statistics of the device performance parameters for solar cells fabricated from perovskite precursors with $[\mathrm{BMP}]^{+}\left[\mathrm{BF}_{4}\right]^{-}$concentrations ranging from 0 mol\% (i.e. the control device, Ctrl) to $0.3 \mathrm{~mol} \%$ (with respect to the Pb concentration). (A) PCE, (B) $V_{\mathrm{OC}},(\mathbf{C}) J_{\mathrm{SC}}$ and (D) FF were determined from the reverse $J-V$ scans (i.e. from flat-band to short-circuit, FB-SC) of 12 cells for each condition. 
A

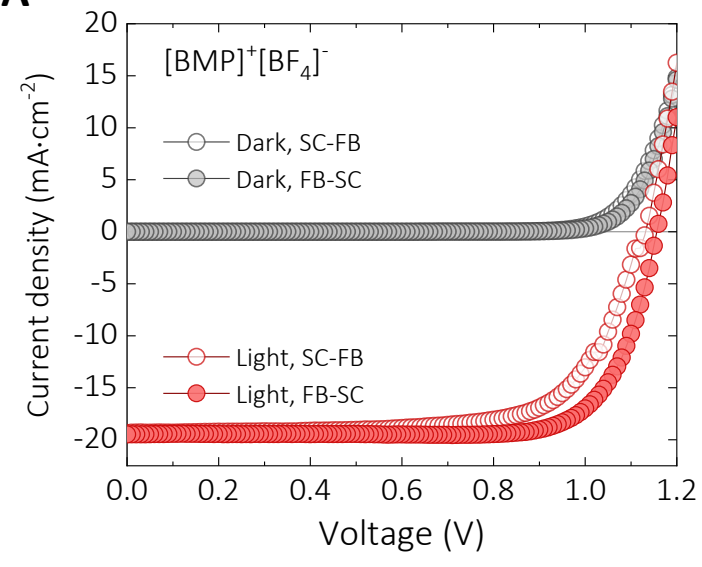

B

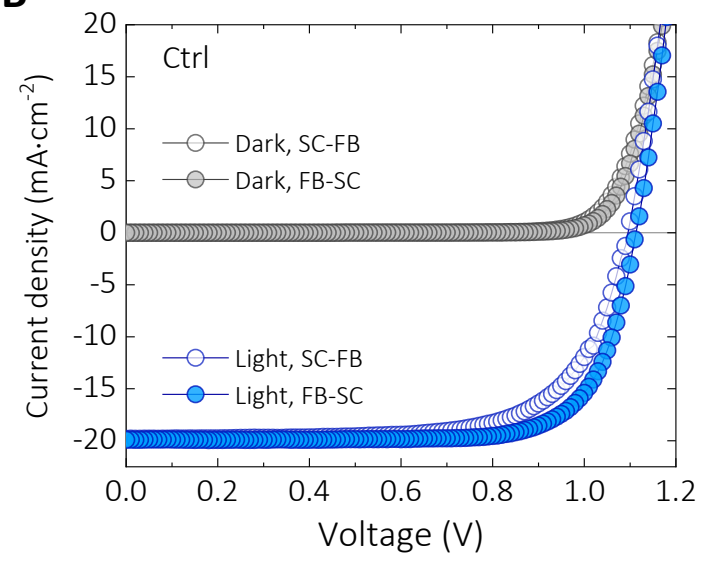

Fig. S7. $J-V$ scans of (A) an optimized $0.25 \mathrm{~mol} \%[\mathrm{BMP}]^{+}\left[\mathrm{BF}_{4}\right]^{-} \mathrm{p}-\mathrm{i}-\mathrm{n}$ perovskite solar cell and (B) a control device with a perovskite composition of $\mathrm{Cs}_{0.17} \mathrm{FA}_{0.83} \mathrm{~Pb}\left(\mathrm{I}_{0.77} \mathrm{Br}_{0.23}\right)_{3}$. Reverse and forward scans represent the measurements following the voltage sweeps from flat-band to shortcircuit (FB-SC) and from short-circuit to flat-band (SC-FB), respectively. For the FB-SC scan, the obtained device performance parameters are as follows: (A) $V_{\mathrm{OC}}=1.16 \mathrm{~V}, J_{\mathrm{SC}}=19.5 \mathrm{~mA} \cdot \mathrm{cm}^{-2}$, $\mathrm{FF}=0.77, \mathrm{PCE}=17.3 \%$; (B) $V_{\mathrm{OC}}=1.11 \mathrm{~V}, J_{\mathrm{SC}}=19.9 \mathrm{~mA} \cdot \mathrm{cm}^{-2}, \mathrm{FF}=0.75, \mathrm{PCE}=16.6 \%$. For the SC-FB scan, the obtained device performance parameters are as follows: (A) $V_{\mathrm{OC}}=1.13 \mathrm{~V}, J_{\mathrm{SC}}=$ $19.4 \mathrm{~mA} \cdot \mathrm{cm}^{-2}, \mathrm{FF}=0.70, \mathrm{PCE}=15.1 \% ;(\mathrm{B}) V_{\mathrm{OC}}=1.10 \mathrm{~V}, J_{\mathrm{SC}}=19.8 \mathrm{~mA} \cdot \mathrm{cm}^{-2}, \mathrm{FF}=0.69, \mathrm{PCE}$ $=14.9 \%$. 

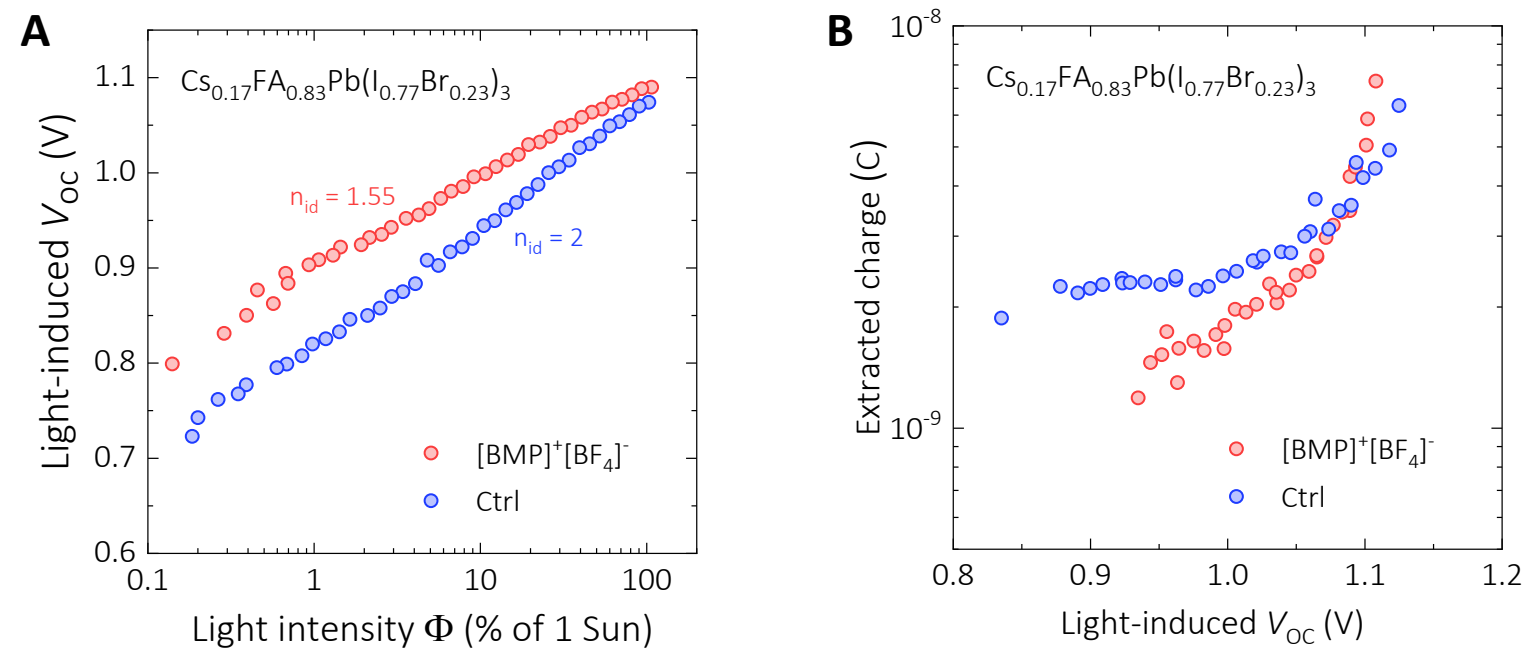

Fig. S8. (A) Light intensity-dependent device $V_{\mathrm{OC}}$. For the control and $[\mathrm{BMP}]^{+}[\mathrm{BF}]^{-}$modified perovskite films, the ideality factors $\left(\mathrm{n}_{\text {id }}\right)$ of 2 and 1.55 are determined, respectively. (B) Total extracted charge as a function of light-induced $V_{O C}$, using a range of background illumination intensities. The $[\mathrm{BMP}]^{+}\left[\mathrm{BF}_{4}\right]^{-}$content is $0.25 \mathrm{~mol} \%$ with respect to the $\mathrm{Pb}$ atom in the perovskite films while the control sample $(\mathrm{Ctrl})$ is $\mathrm{Cs}_{0.17} \mathrm{FA}_{0.83} \mathrm{~Pb}\left(\mathrm{I}_{0.77} \mathrm{Br}_{0.23}\right)_{3}$ without any $[\mathrm{BMP}]^{+}\left[\mathrm{BF}_{4}\right]^{-}$ additive. 

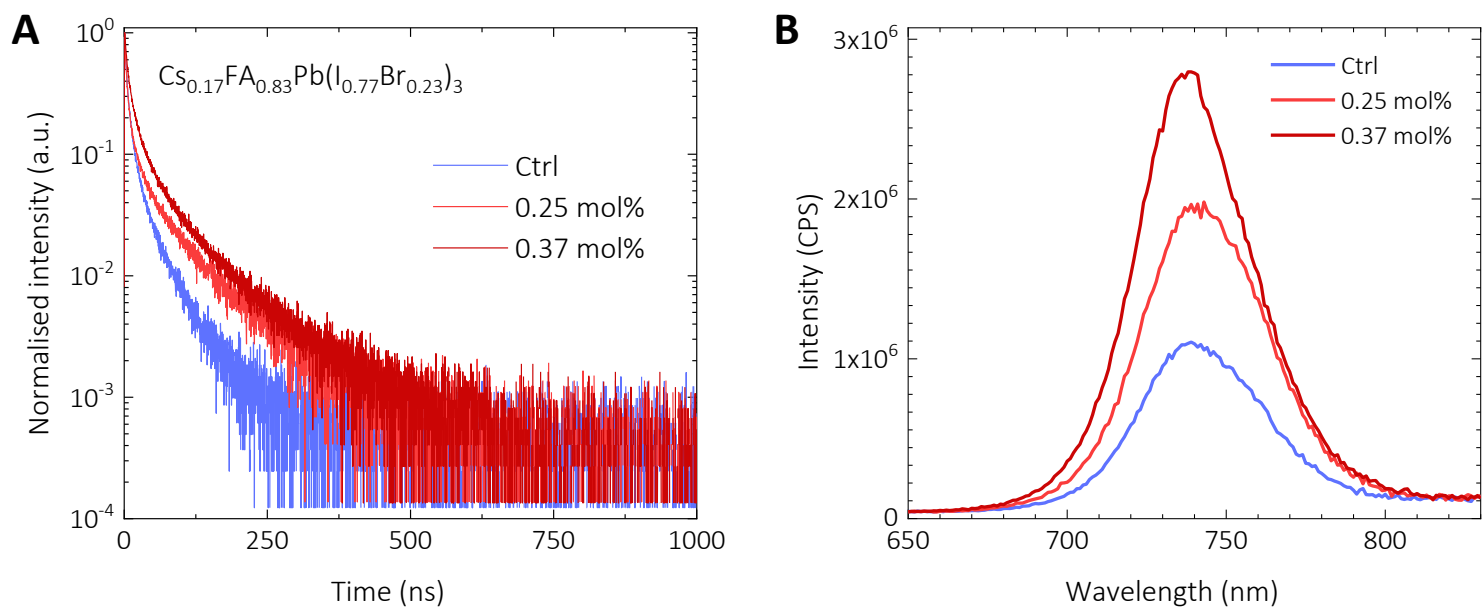

Fig. S9. (A) Time-resolved photoluminescence (TRPL) and (B) steady state photoluminescence (SSPL) results obtained from $\mathrm{Cs}_{0.17} \mathrm{FA}_{0.83} \mathrm{~Pb}\left(\mathrm{I}_{0.77} \mathrm{Br}_{0.23}\right)_{3}$ with and without $[\mathrm{BMP}]^{+}\left[\mathrm{BF}_{4}\right]^{-}$prepared on polyTPD:F4-TCNQ/FTO glass substrates. From the TRPL results, the initial decay of the control device $(\mathrm{Ctrl})$ is faster than the $[\mathrm{BMP}]^{+}\left[\mathrm{BF}_{4}\right]^{-}$, suggesting stronger trapping process and faster recombination. Meanwhile, the SSPL intensity increases when adding more concentrated $[\mathrm{BMP}]^{+}\left[\mathrm{BF}_{4}\right]^{-}$into the perovskite films (concentrations of $[\mathrm{BMP}]^{+}\left[\mathrm{BF}_{4}\right]^{-}$with respect to the $\mathrm{Pb}$ content). 

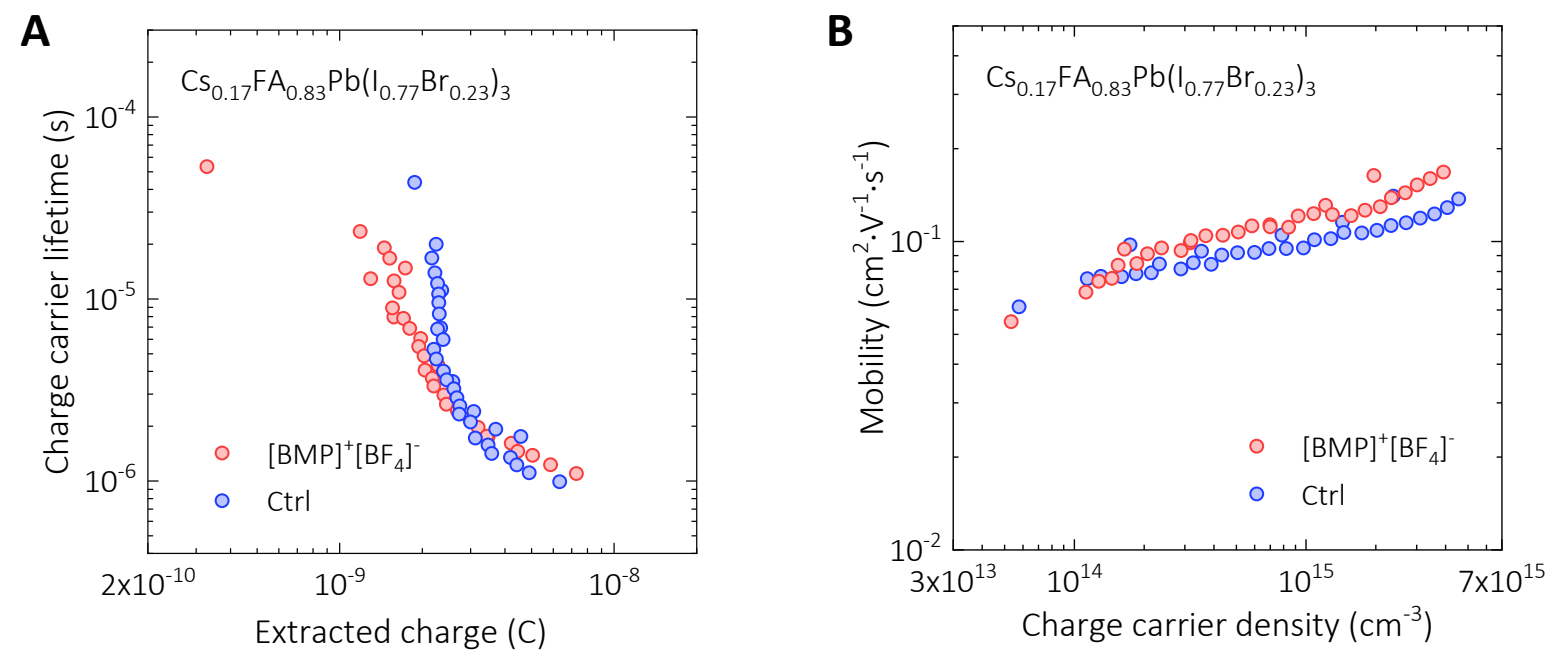

Fig. S10. (A) Charge carrier lifetime (measured at $V_{\mathrm{OC}}$ ) as a function of total extracted charge. (B) Effective diffusion mobilities measured at short circuit conditions. The $[\mathrm{BMP}]^{+}\left[\mathrm{BF}_{4}\right]^{-}$content is $0.25 \mathrm{~mol} \%$ with respect to the $\mathrm{Pb}$ atom in the perovskite films while the control sample (Ctrl) is $\mathrm{Cs}_{0.17} \mathrm{FA}_{0.83} \mathrm{~Pb}\left(\mathrm{I}_{0.77} \mathrm{Br}_{0.23}\right)_{3}$ without any $[\mathrm{BMP}]^{+}\left[\mathrm{BF}_{4}\right]^{-}$additive. 

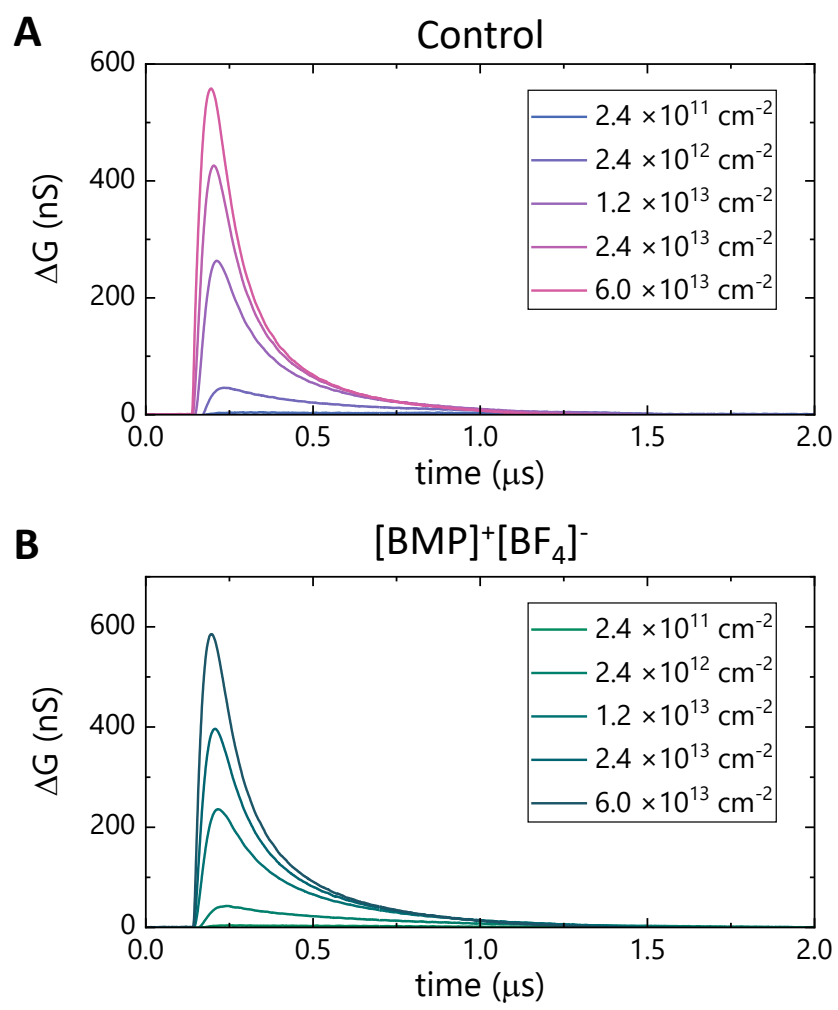

Fig. S11. TRMC transients: photo-conductance $(\Delta \boldsymbol{G})$ as a function of time $(\boldsymbol{t})$ for $(\mathbf{A})$ control sample in a composition of $\mathrm{Cs}_{0.17} \mathrm{FA}_{0.83} \mathrm{~Pb}\left(\mathrm{I}_{0.77} \mathrm{Br}_{0.23}\right)_{3}$, and $(\mathbf{B})$ the same perovskite composition with $0.25 \mathrm{~mol} \%[\mathrm{BMP}]^{+}\left[\mathrm{BF}_{4}\right]^{-}$, for various incident optical fluences. All measurements were carried out in air at room temperature. 


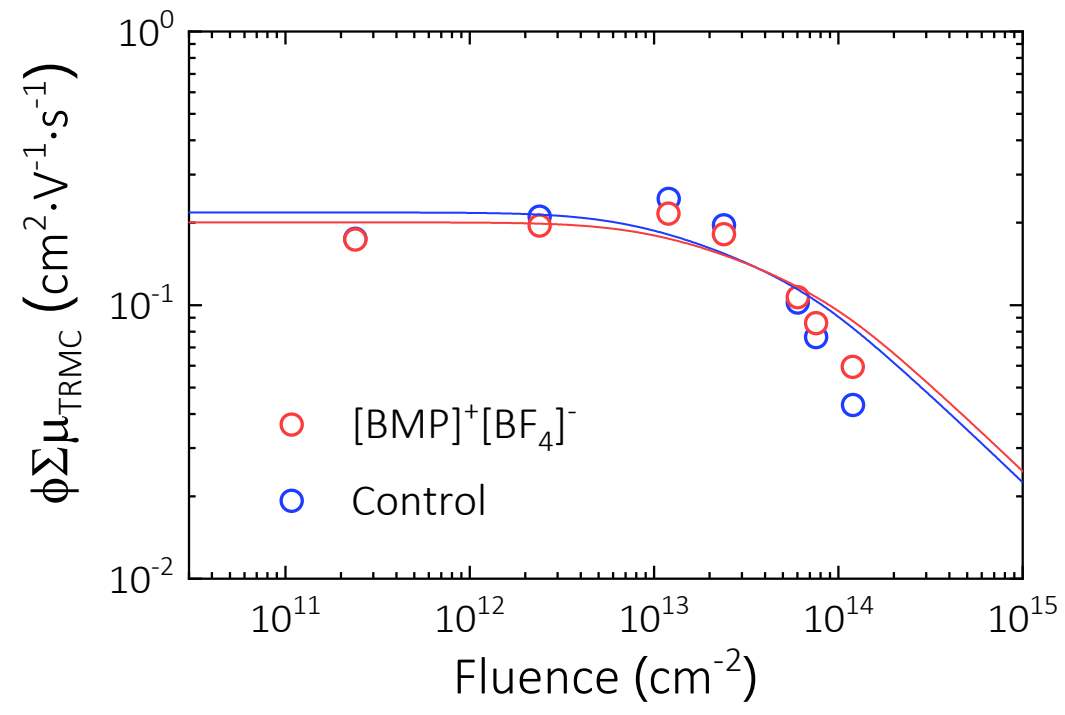

Fig. S12. Time-resolved microwave conductivity (TRMC) figure of merit: $\boldsymbol{\phi} \boldsymbol{\Sigma} \boldsymbol{\mu}_{\text {TRMC }}$ as a function of laser fluence for the $0.25 \mathrm{~mol} \%[\mathrm{BMP}]^{+}\left[\mathrm{BF}_{4}\right]^{-}$modified and control $\mathrm{Cs}_{0.17} \mathrm{FA}_{0.83} \mathrm{~Pb}\left(\mathrm{I}_{0.77} \mathrm{Br}_{0.23}\right)_{3}$ perovskite samples. The points are experimental values and the lines are straight line fits to a numerical model that accounts for bimolecular and Auger recombination during the laser pulse. All measurements were carried out in air at room temperature. 
A

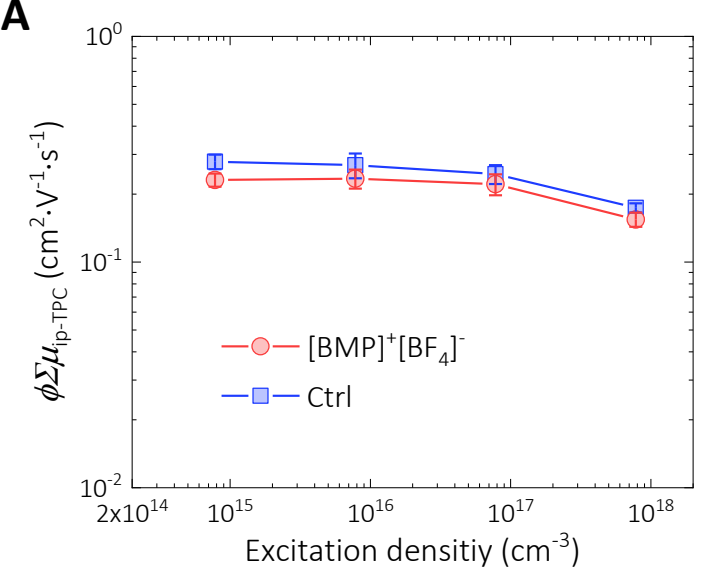

B

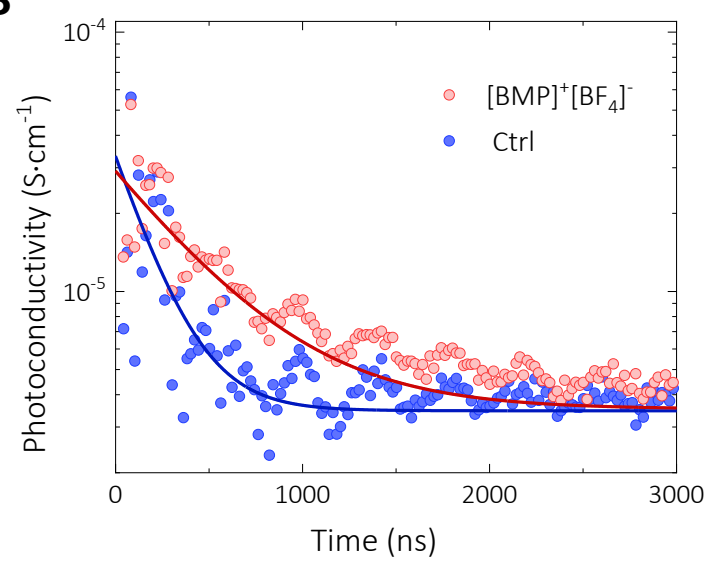

Fig. S13. (A) Sum of charge carrier mobilities $\phi \Sigma \mu_{\text {ip-TPC }}$ of electrons and holes for the 0.25 mol\% $[\mathrm{BMP}]^{+}\left[\mathrm{BF}_{4}\right]^{-}$modified (red circle) and control (blue square) $\mathrm{Cs}_{0.17} \mathrm{FA}_{0.83} \mathrm{~Pb}\left(\mathrm{I}_{0.77} \mathrm{Br}_{0.23}\right)_{3}$ perovskite samples obtained from in-plane transient photoconductivity under different excitation densities. The lines are guide for the eye while the error bars represent standard derivation. (B) Decay profile of photoconductivity measured as a function of time after pulse laser excitation. The data is fitted with a mono-exponential decay function (solid lines). 

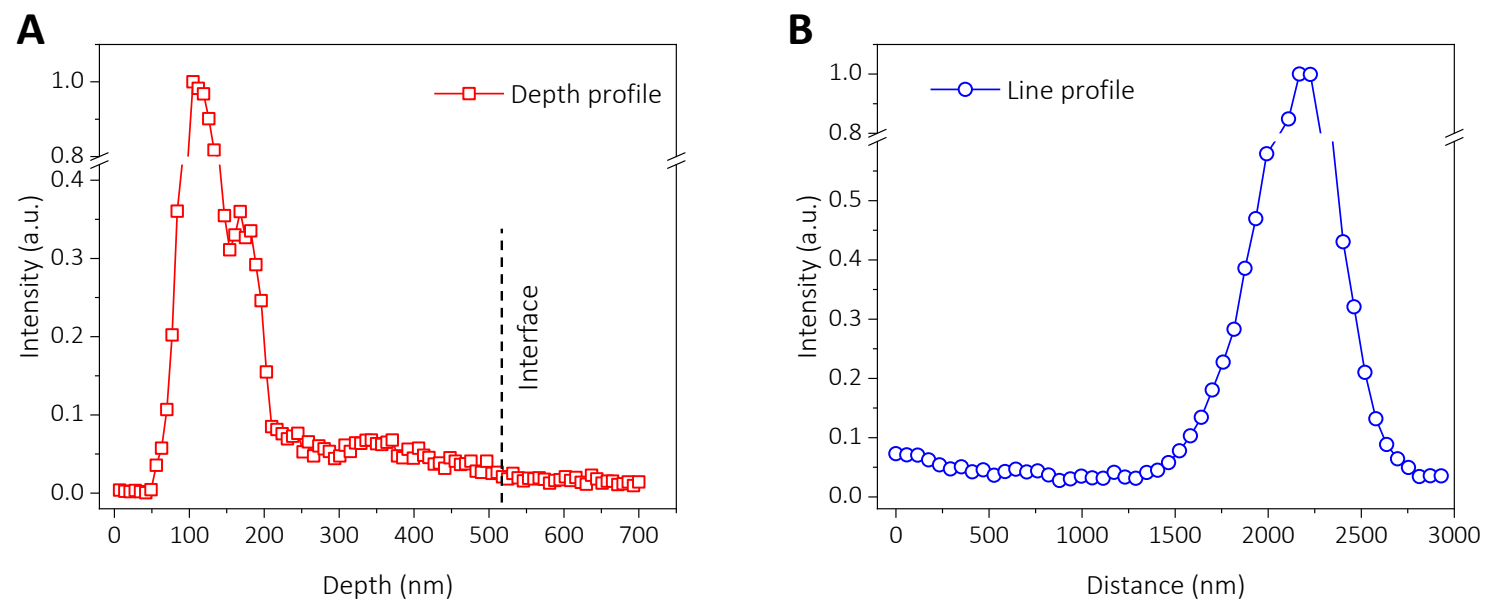

Fig. S14. (A) A typical depth profile acquired from a region $(1.2 \mu \mathrm{m} \times 1.2 \mu \mathrm{m})$ covering one ${ }^{19} \mathrm{~F}^{-}$ hotspot through the perovskite film thickness (see Figs. 2A and 2D for corresponding information). (B) A line profile acquired from a region covering a ${ }^{19} \mathrm{~F}^{-}$hotspot and nearby perovskite. 
A

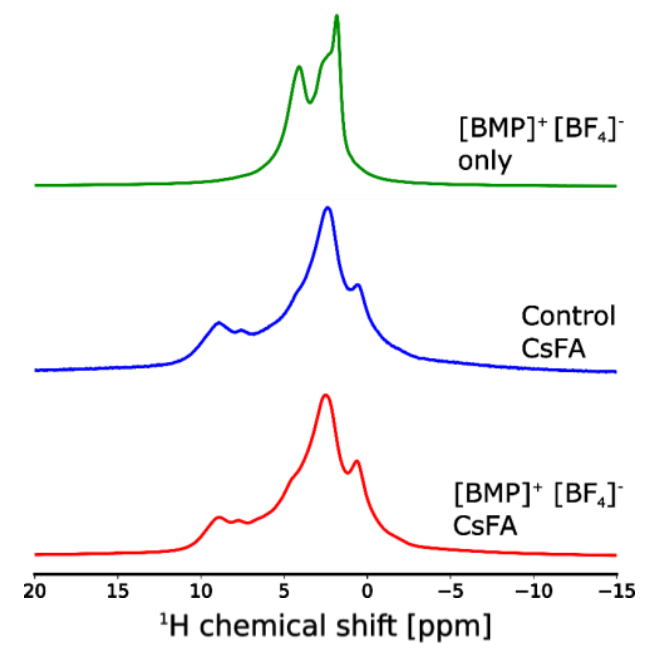

B
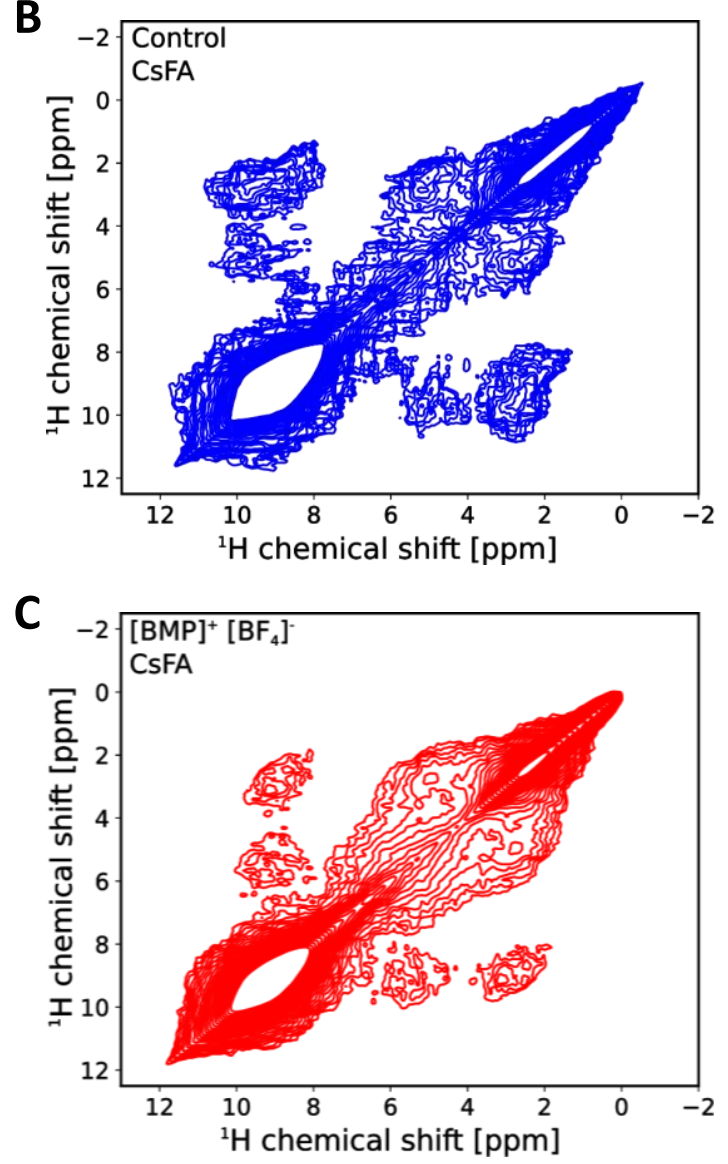

Fig. S15. Solid-state nuclear magnetic resonance characterization of the control and $[\mathrm{BMP}]^{+}\left[\mathrm{BF}_{4}\right]^{-}$ modified $\mathrm{Cs}_{0.17} \mathrm{FA}_{0.83} \mathrm{~Pb}\left(\mathrm{I}_{0.77} \mathrm{Br}_{0.23}\right)_{3}(\mathrm{CsFA})$ films: (A) $1 \mathrm{D}^{1} \mathrm{H} \mathrm{NMR}$ for $[\mathrm{BMP}]^{+}\left[\mathrm{BF}_{4}\right]^{-}$only (green line); control Cs/FA (blue line); $[\mathrm{BMP}]^{+}\left[\mathrm{BF}_{4}\right]^{-} \mathrm{Cs} / \mathrm{FA}$ (red line) while (B) and (C) show ${ }^{1} \mathrm{H}^{-}{ }^{1} \mathrm{H} 2 \mathrm{D}$ correlation for control $\mathrm{Cs} / \mathrm{FA}$ and $[\mathrm{BMP}]^{+}\left[\mathrm{BF}_{4}\right]^{-}$modified $\mathrm{Cs} / \mathrm{FA}$, respectively. 

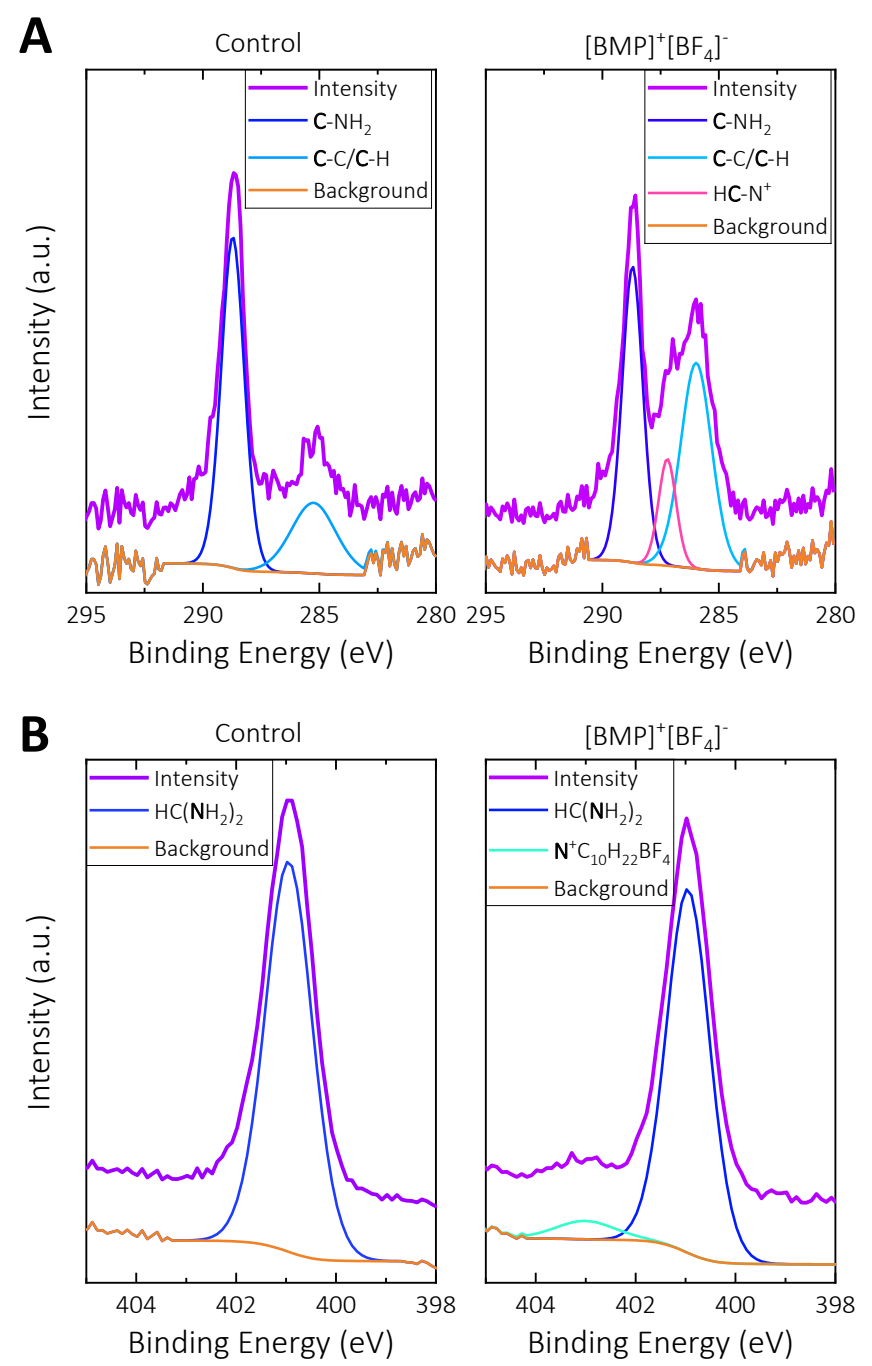

Fig. S16. Comparison of X-ray photoelectron spectroscopy $\mathrm{C} 1 \mathrm{~s}$ and $\mathrm{N} 1 \mathrm{~s}$ spectra of $\mathrm{Cs}_{0.17} \mathrm{FA}_{0.83} \mathrm{~Pb}\left(\mathrm{I}_{0.77} \mathrm{Br}_{0.23}\right)_{3}$ with $0.25 \mathrm{~mol} \%[\mathrm{BMP}]^{+}\left[\mathrm{BF}_{4}\right]^{-}$. perovskite films measured after aging under full spectrum sunlight at $60^{\circ} \mathrm{C}$ in ambient air: (A) $\mathrm{C} 1 s$ and (B) $\mathrm{N} 1 s$ regions with $0.25 \mathrm{~mol} \%$ $[\mathrm{BMP}]^{+}\left[\mathrm{BF}_{4}\right]^{-}$additive and without (control). 
A

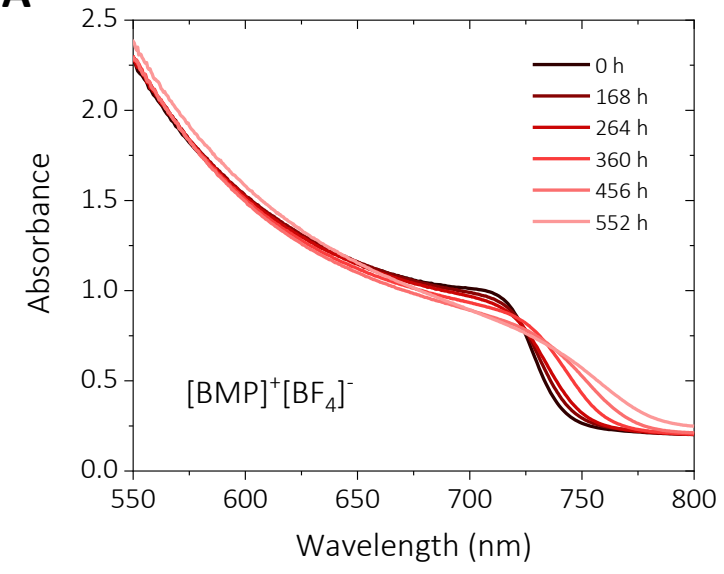

B

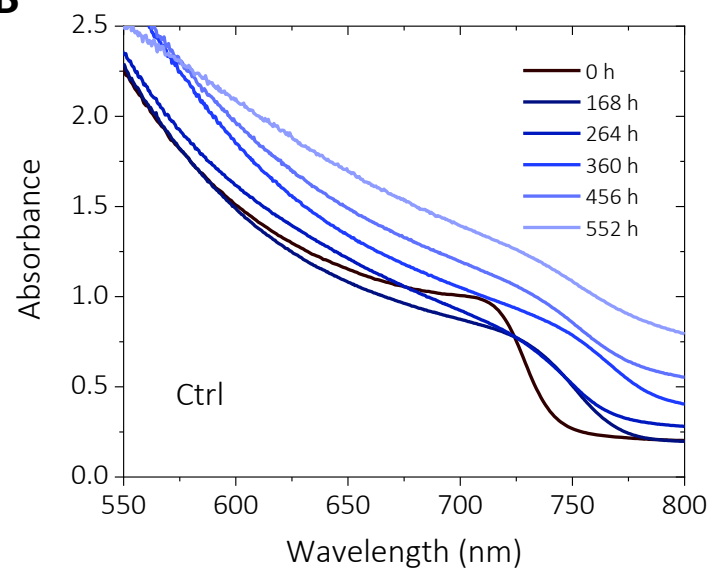

Fig. S17. Evolution of ultraviolet-visible absorbance spectra of $\mathrm{Cs}_{0.17} \mathrm{FA}_{0.83} \mathrm{~Pb}\left(\mathrm{I}_{0.77} \mathrm{Br}_{0.23}\right)_{3}$ perovskite films measured after aged under full spectrum sunlight at $60^{\circ} \mathrm{C}$ in ambient air: (A) with $0.25 \mathrm{~mol} \%[\mathrm{BMP}]^{+}\left[\mathrm{BF}_{4}\right]^{-}$additive; $(\mathbf{B})$ control. 

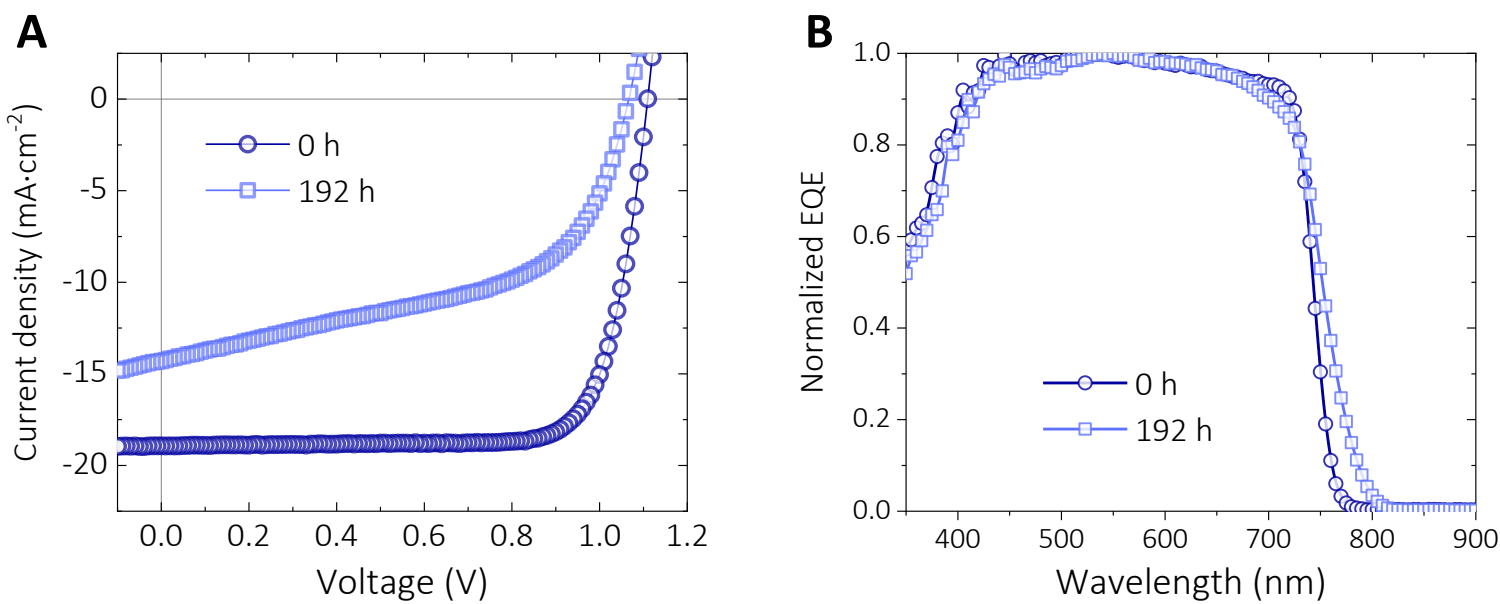

Fig. S18. (A) Reverse $J$ - $V$ characteristics and (B) Normalized EQEs of the p-i-n perovskite solar cell using $\mathrm{Cs}_{0.17} \mathrm{FA}_{0.83} \mathrm{~Pb}\left(\mathrm{I}_{0.77} \mathrm{Br}_{0.23}\right)_{3}$ (without any ionic additive) measured before and after aged for $192 \mathrm{~h}$ under full spectrum sunlight at $60^{\circ} \mathrm{C}$ in ambient air. 


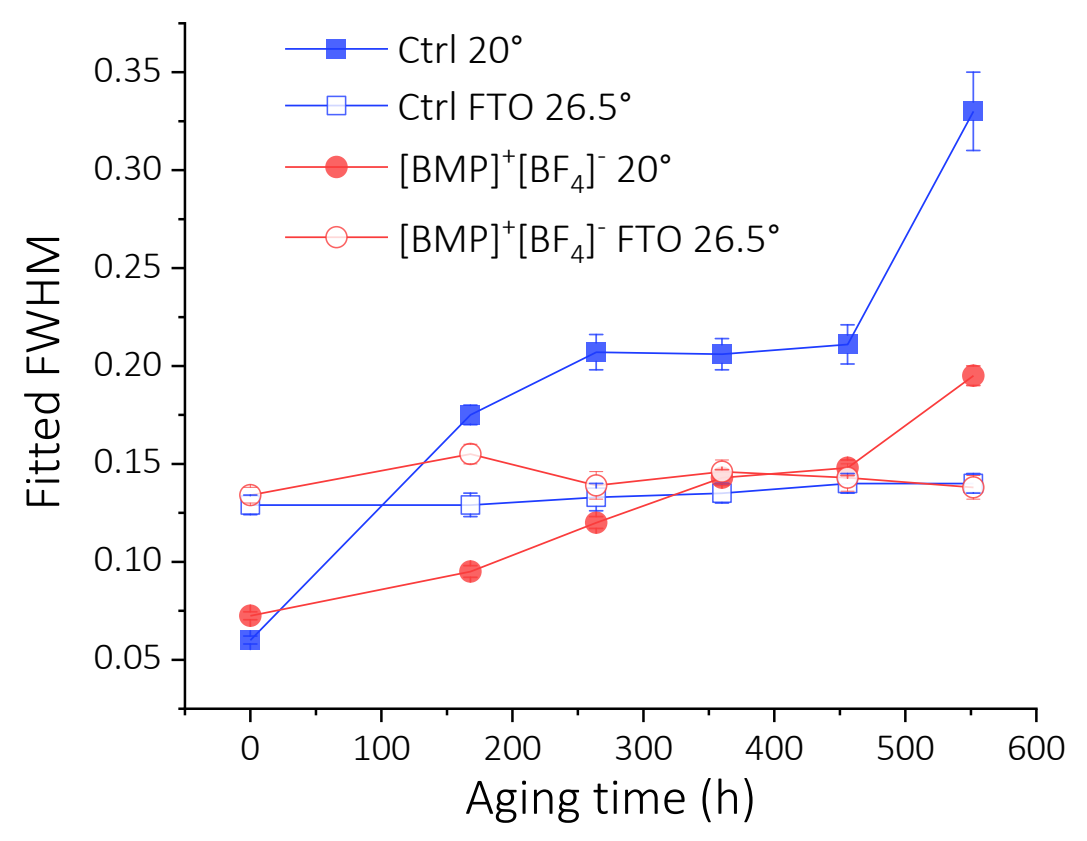

Fig. S19. The full width at half maximum (FWHM) were obtained by fitting peaks using the CMPR software. The peaks at around 20.2 and 26.5 degrees were used as representative peaks for the perovskite and FTO glass, respectively. The FTO glass peaks were used as an internal standard. 

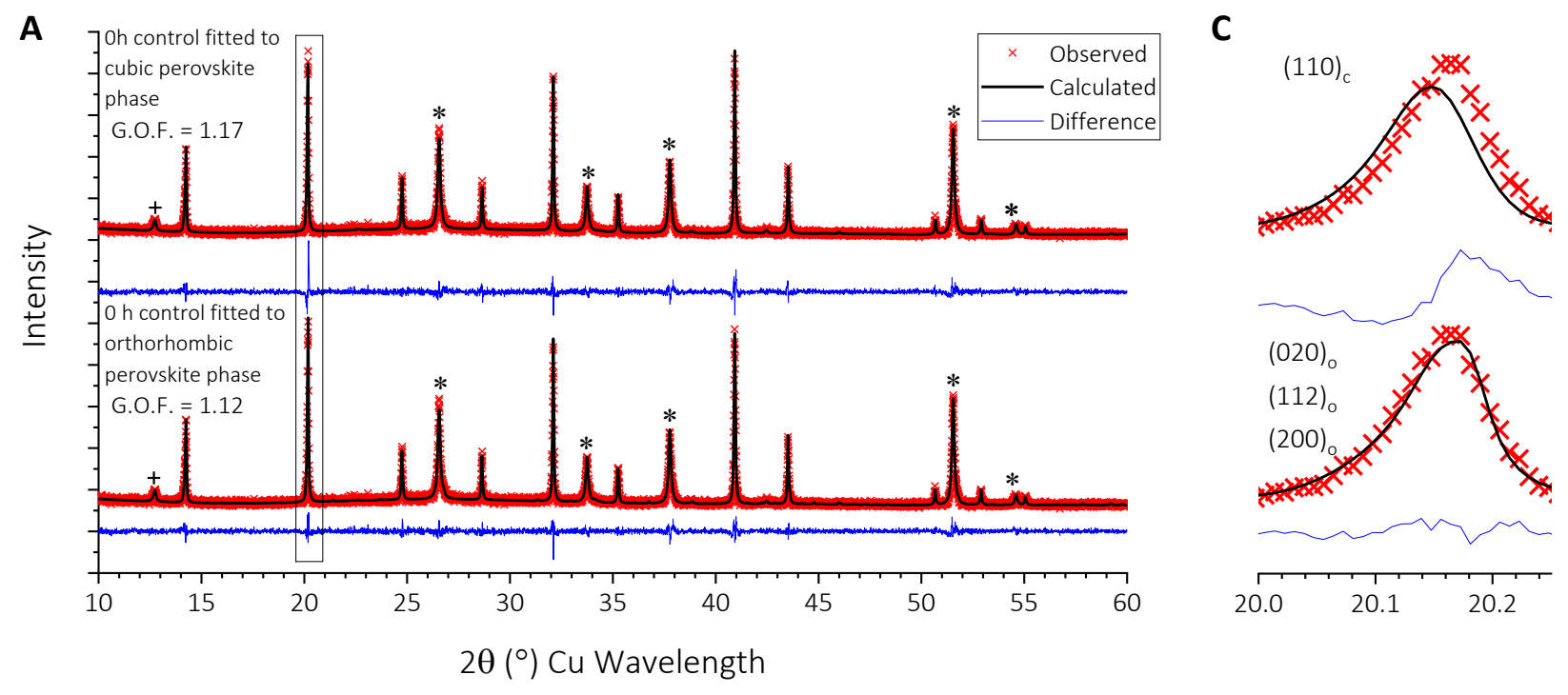

B

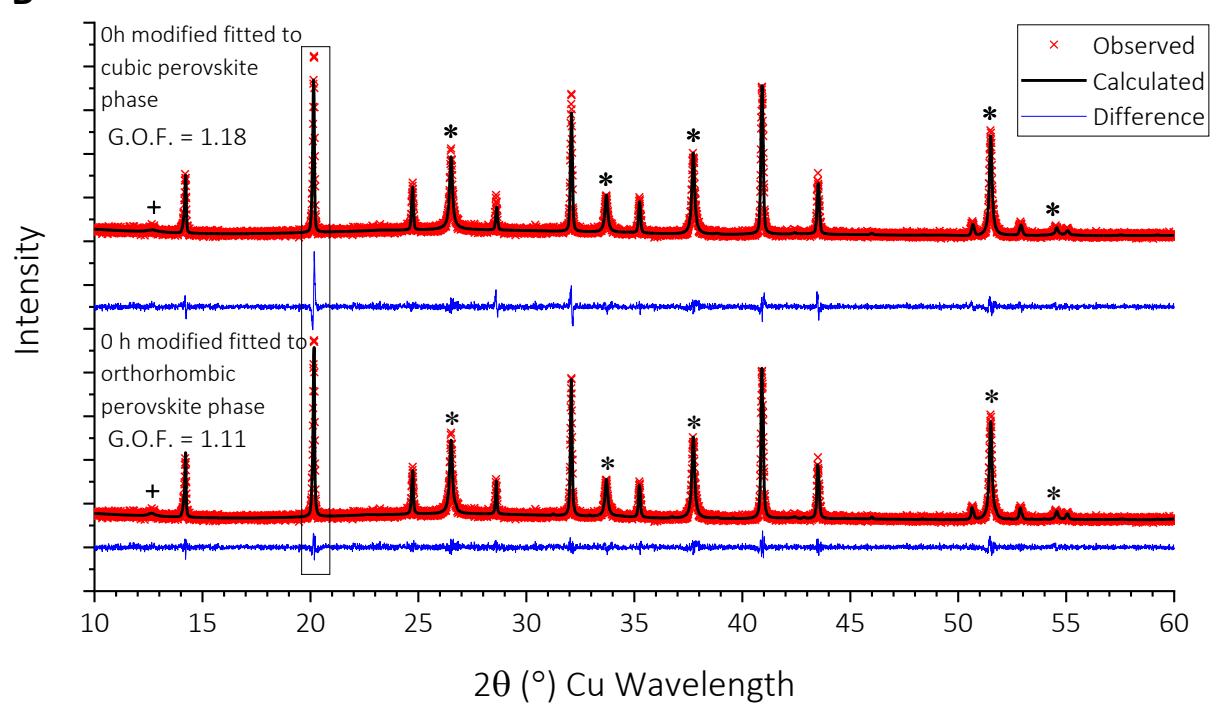

D

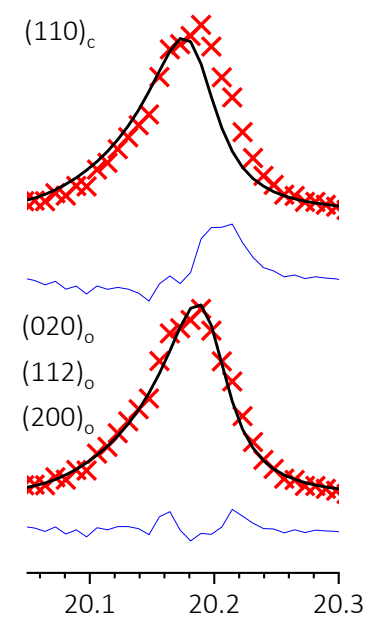

Fig. S20. Pawley fittings of the unencapsulated $(\mathbf{A})$ control and $(\mathbf{B}) 0.25 \mathrm{~mol} \%[\mathrm{BMP}]^{+}\left[\mathrm{BF}_{4}\right]^{-}$ modified $\mathrm{Cs}_{0.17} \mathrm{FA}_{0.83} \mathrm{~Pb}\left(\mathrm{I}_{0.77} \mathrm{Br}_{0.23}\right)_{3}$ perovskite films before aging. The XRD peaks are marked by + for $\mathrm{PbI}_{2}$ and * for FTO. Highlighted by the box, and shown in (C) for the control film, and (D) for the modified film, is the peak corresponding to the $(110)_{c}$ peak in the cubic case, or $(020)_{\mathrm{o}},(112)_{\mathrm{o}},(200)_{\mathrm{o}}$ peak in the orthorhombic case. This is the peak which mostly clearly did not fit when fitting to the cubic unit cell, and required an orthorhombic cell to fit well. Using the orthorhombic cell increased the overall goodness of fit (G.O.F) from 1.17 to 1.12 for the control film, and from 1.18 to 1.11 for the treated film. 

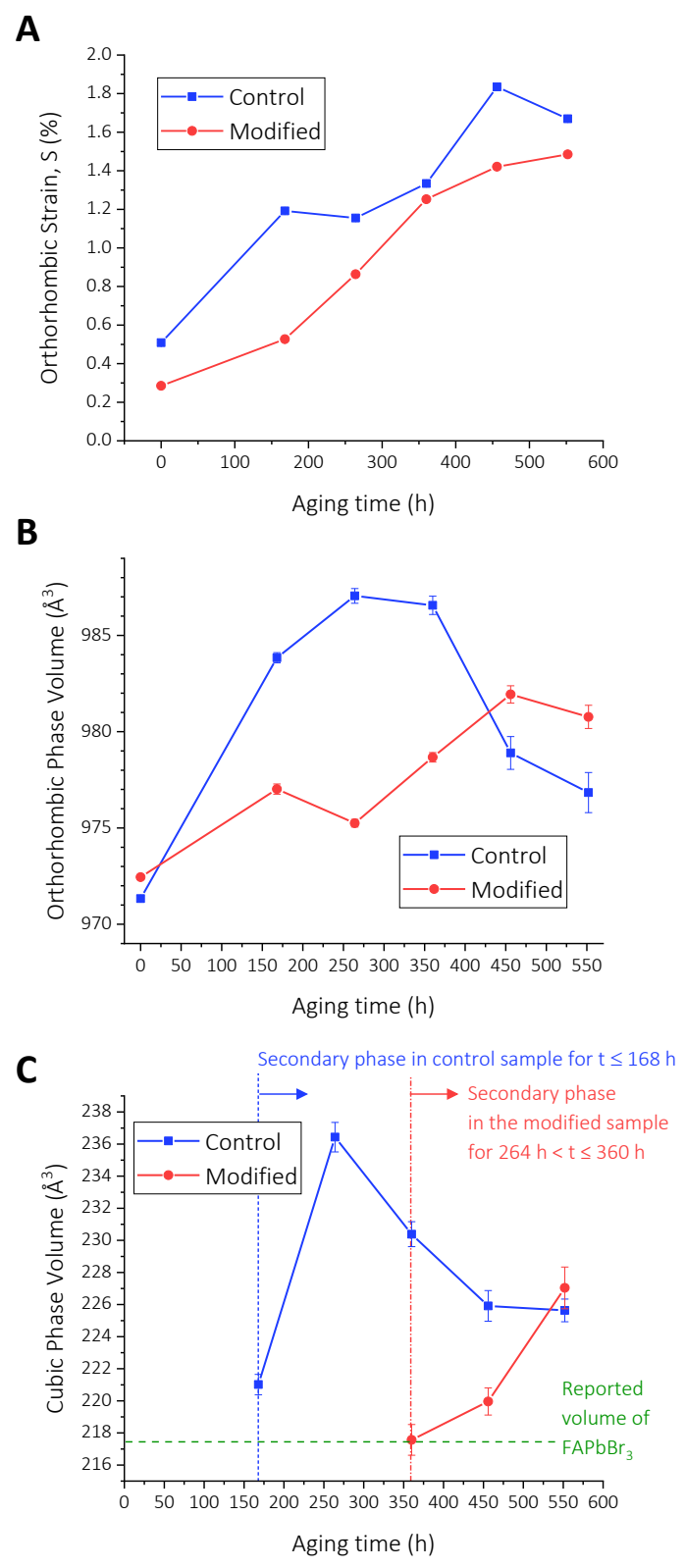

Fig. S21. (A) The orthorhombic strain of the main orthorhombic perovskite phase for the unencapsulated control and $0.25 \mathrm{~mol} \%[\mathrm{BMP}]^{+}\left[\mathrm{BF}_{4}\right]^{-}$modified $\mathrm{Cs}_{0.17} \mathrm{FA}_{0.83} \mathrm{~Pb}\left(\mathrm{I}_{0.77} \mathrm{Br}_{0.23}\right)_{3}$ mixedcation mixed-anion perovskite films, using the refined lattice parameters to calculate: $\boldsymbol{S}(\%)=$ $\sqrt{(\sqrt{2} a-\sqrt{2} b)^{2}+(\sqrt{2} b-c)^{2}+(\sqrt{2} a-c)^{2}}$. (B) The refined volume of the main orthorhombic perovskite phase over the aging time, showing a rapid increase and then decrease in the control sample, and a more gradual increase for the modified sample. (C) The refined volume of the second cubic perovskite phase, first seen at $168 \mathrm{~h}$ in the control and $360 \mathrm{~h}$ in the modified sample. When the cubic phase is first seen in the treated sample, it has lattice parameters of $\mathrm{FAPbBr}_{3}(20)$. 
A

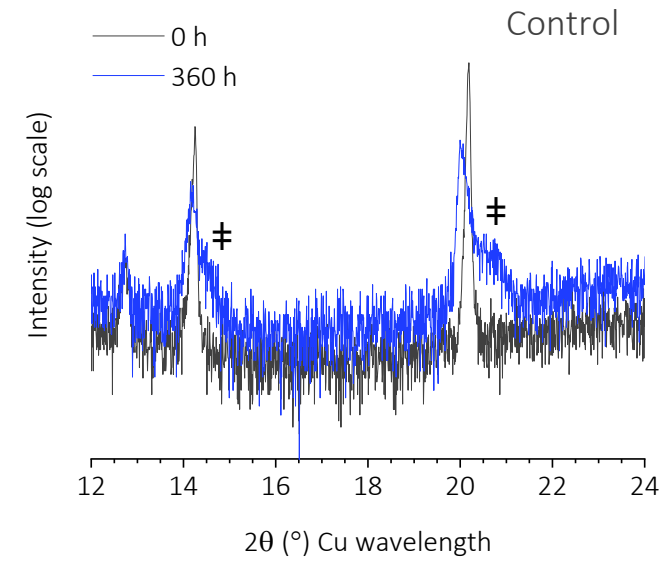

B

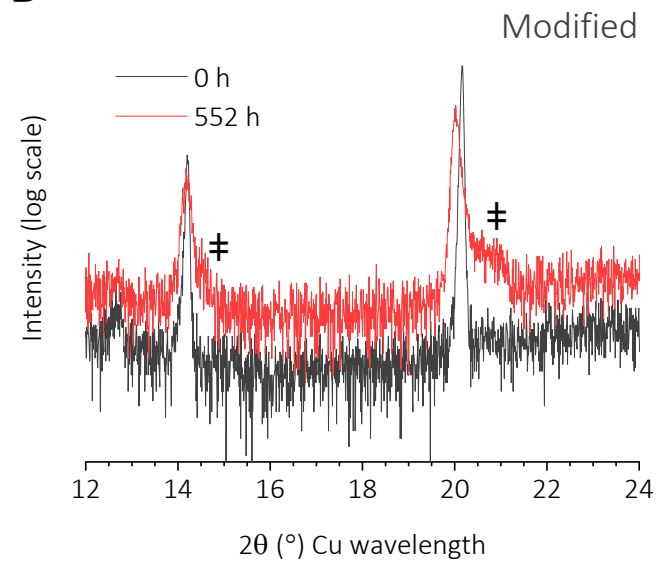

Fig. S22. (A) and (B), respectively show the XRD peaks corresponding to the secondary phase for the control and $0.25 \mathrm{~mol} \%$ [BMP $]^{+}\left[\mathrm{BF}_{4}\right]^{-}$modified $\mathrm{Cs}_{0.17} \mathrm{FA}_{0.83} \mathrm{~Pb}\left(\mathrm{I}_{0.77} \mathrm{Br}_{0.23}\right)_{3}$ perovskite films before and after aging. 
A

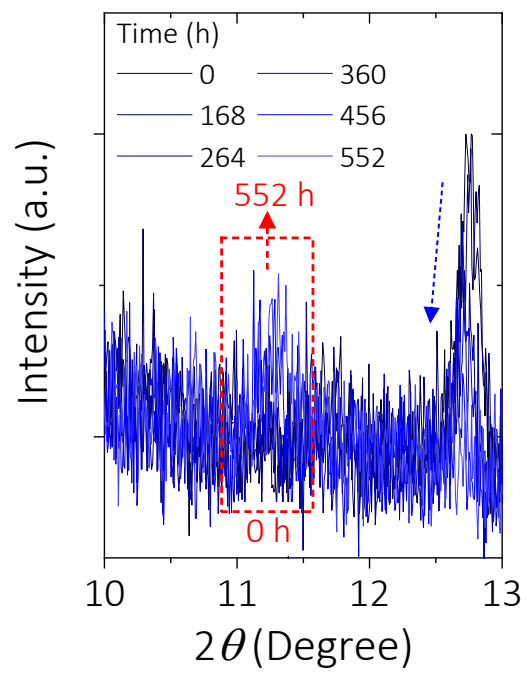

B

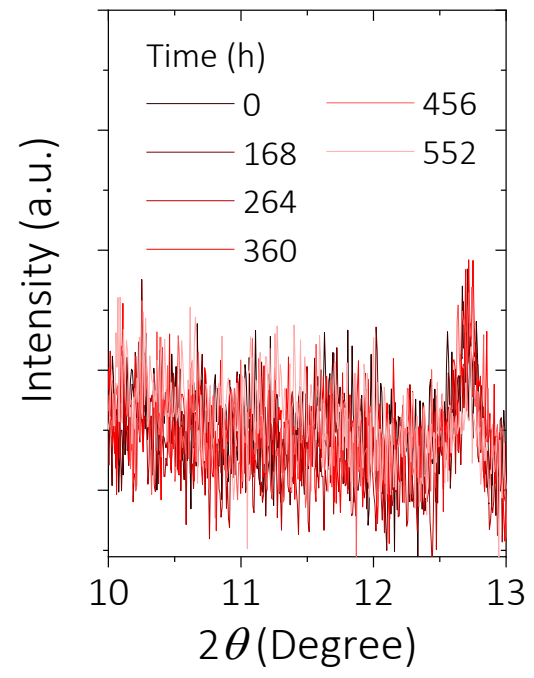

Fig. S23. (A) and (B) present the high-angle XRD data corresponding to the control and $0.25 \mathrm{~mol} \%$ $[\mathrm{BMP}]^{+}\left[\mathrm{BF}_{4}\right]^{-}$modified $\mathrm{Cs}_{0.17} \mathrm{FA}_{0.83} \mathrm{~Pb}\left(\mathrm{I}_{0.77} \mathrm{Br}_{0.23}\right)_{3}$ perovskite films, respectively. 

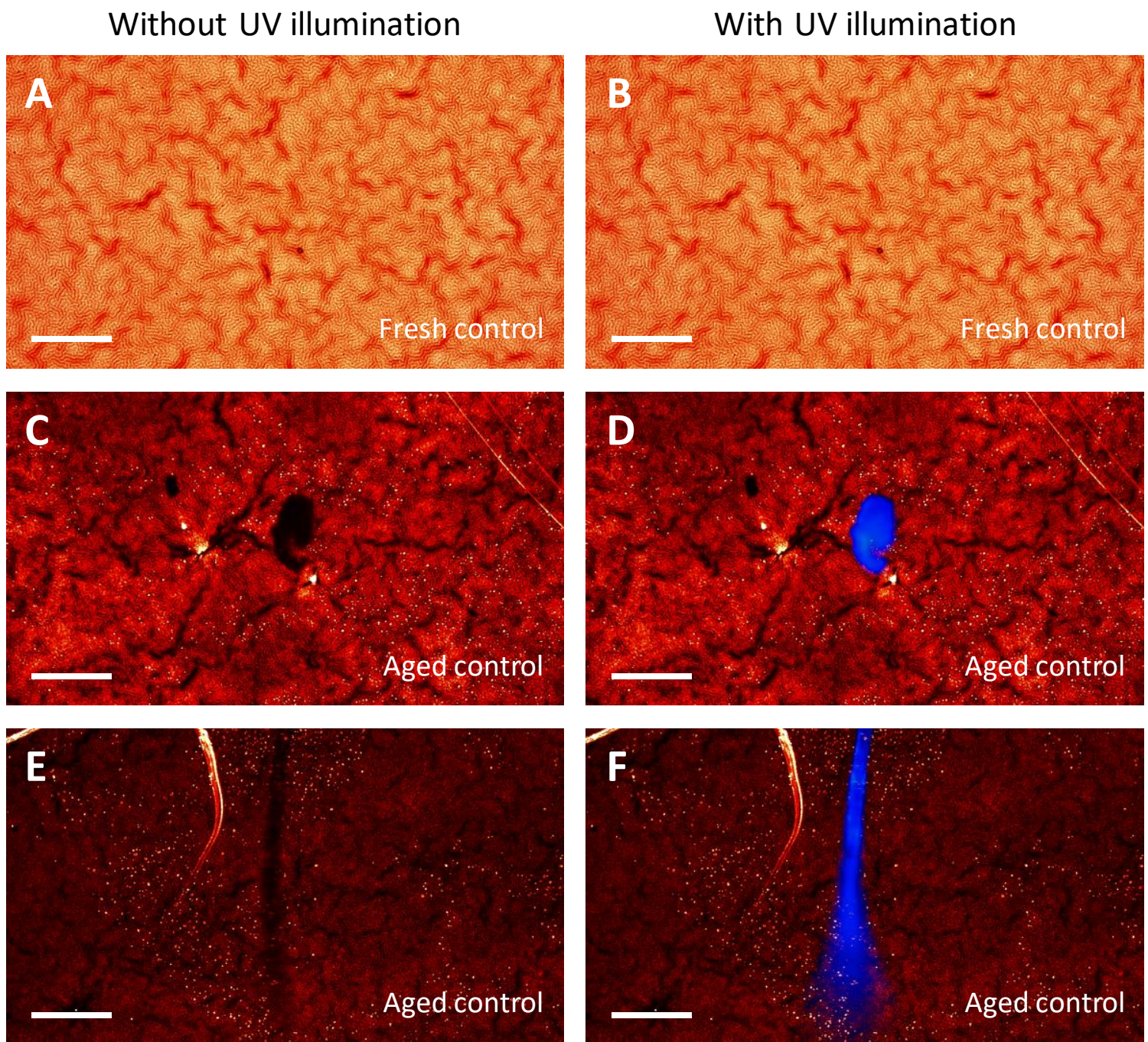

Fig. S24. Optical microscopy $(\mathrm{OM})$ measurements on (A and $\mathbf{B})$ fresh $\mathrm{Cs}_{0.17} \mathrm{FA}_{0.83} \mathrm{~Pb}\left(\mathrm{I}_{0.77} \mathrm{Br}_{0.23}\right)_{3}$ perovskite films and (C-F) after aged under full spectrum sunlight at $60^{\circ} \mathrm{C}$ in ambient air for 500 hours. (A, $\mathbf{C}$ and $\mathbf{E}$ ) are the OM images taken only under back illumination using a halogen lamp while (B, D and F) are taken under both the backlit halogen lamp and a frontlit 375-nm UV light source. Scale bar: $100 \mu \mathrm{m}$. 

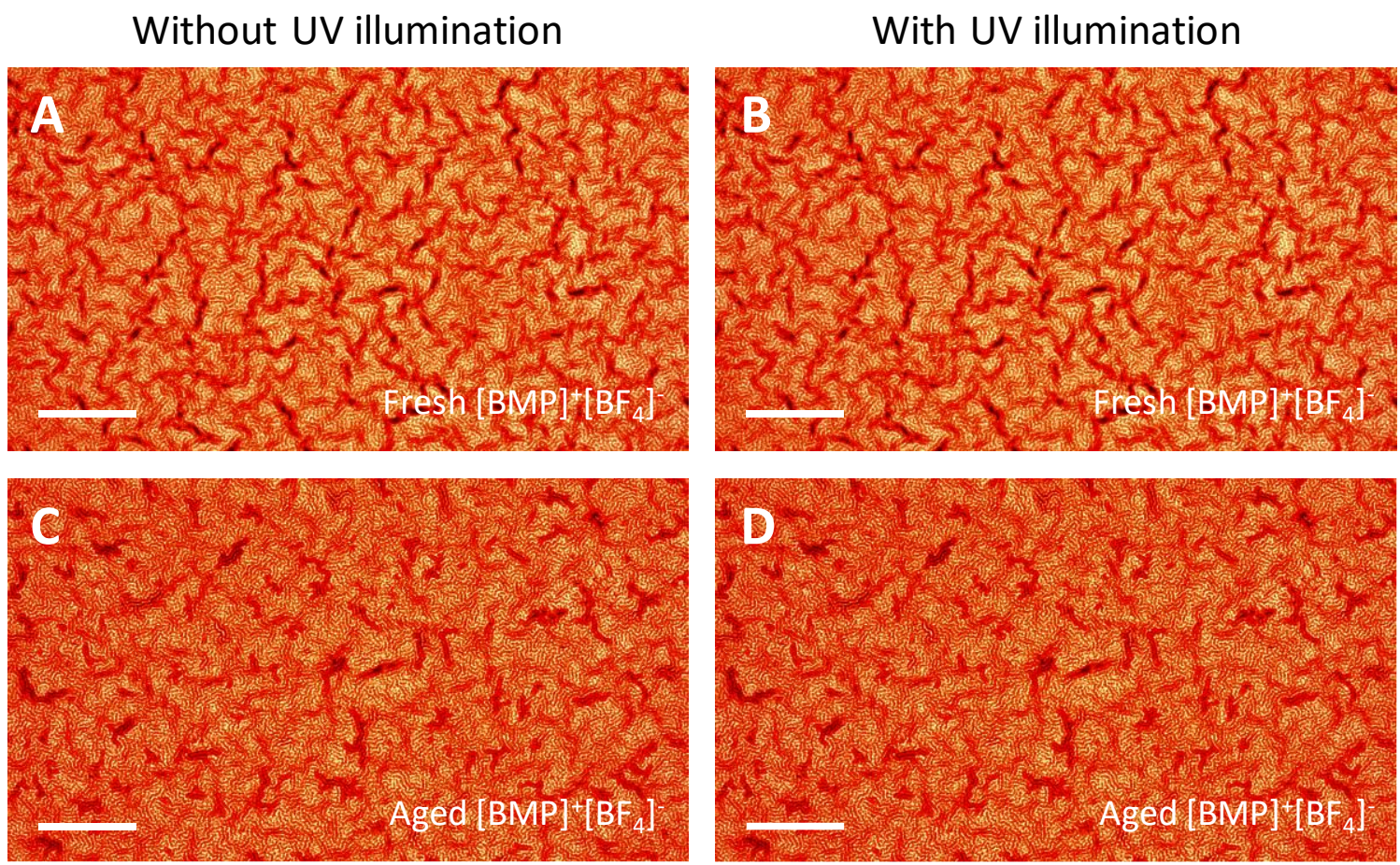

Fig. S25. Optical microscopy $(\mathrm{OM})$ measurements on $(\mathbf{A}$ and $\mathbf{B})$ fresh $0.25 \mathrm{~mol} \%[\mathrm{BMP}]^{+}\left[\mathrm{BF}_{4}\right]^{-}$ modified $\mathrm{Cs}_{0.17} \mathrm{FA}_{0.83} \mathrm{~Pb}\left(\mathrm{I}_{0.77} \mathrm{Br}_{0.23}\right)_{3}$ perovskite films and $(\mathbf{C}$ and $\mathbf{D})$ after aged under full spectrum sunlight at $60^{\circ} \mathrm{C}$ in ambient air for more than 500 hours. (A and $\mathbf{C}$ ) are the OM images taken only under back illumination using a halogen lamp while (B and $\mathbf{D})$ are taken under both the backlit halogen lamp and a frontlit 375-nm UV light source. Scale bar: $100 \mu \mathrm{m}$. 

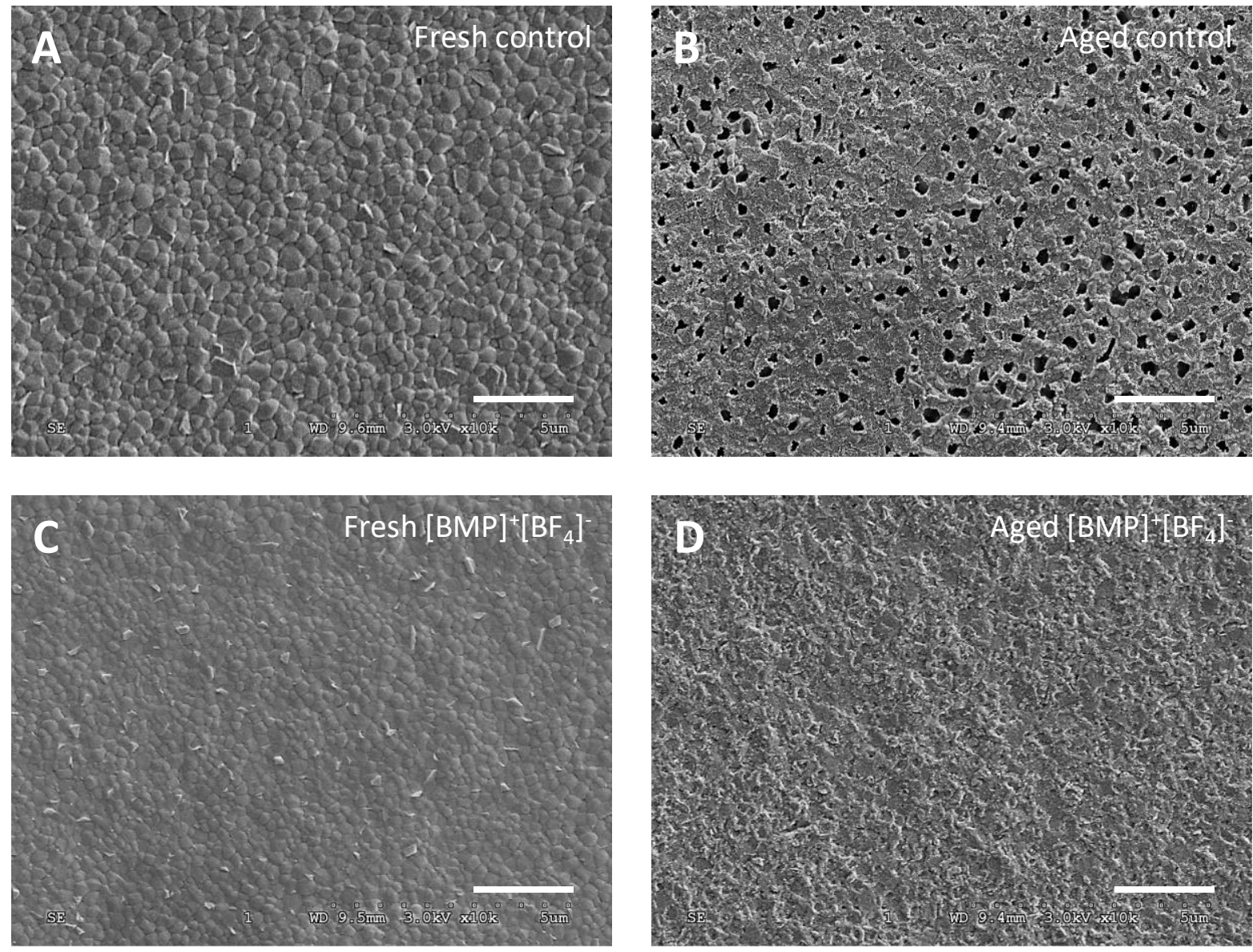

Fig. S26. Corresponding top surface SEM images of the fresh and aged control and $[\mathrm{BMP}]^{+}\left[\mathrm{BF}_{4}\right]^{-}$ modified films shown in Figs. S24 and S25: (A) fresh control; (B) aged control; (C) fresh modified; (D) aged modified. Scale bar: $2 \mu \mathrm{m}$. 


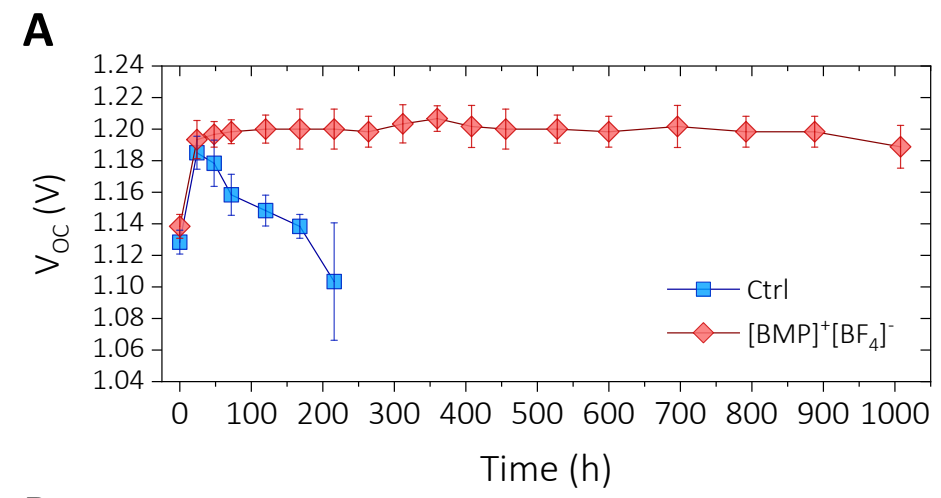

B

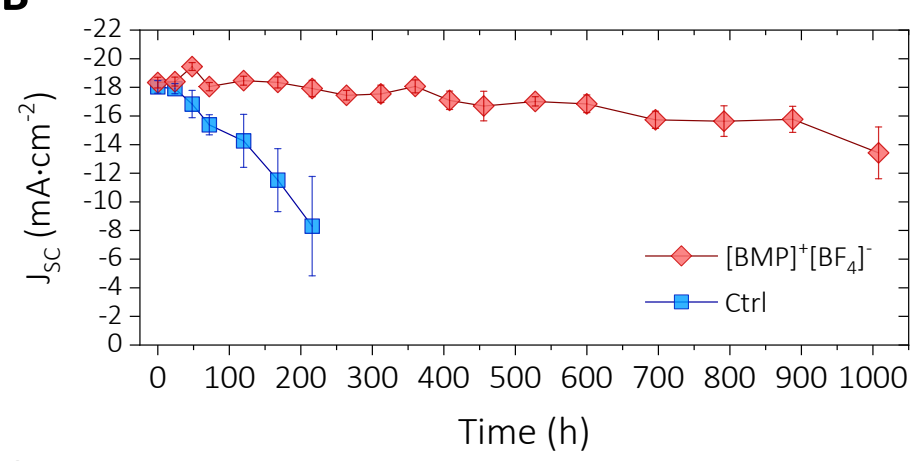

C

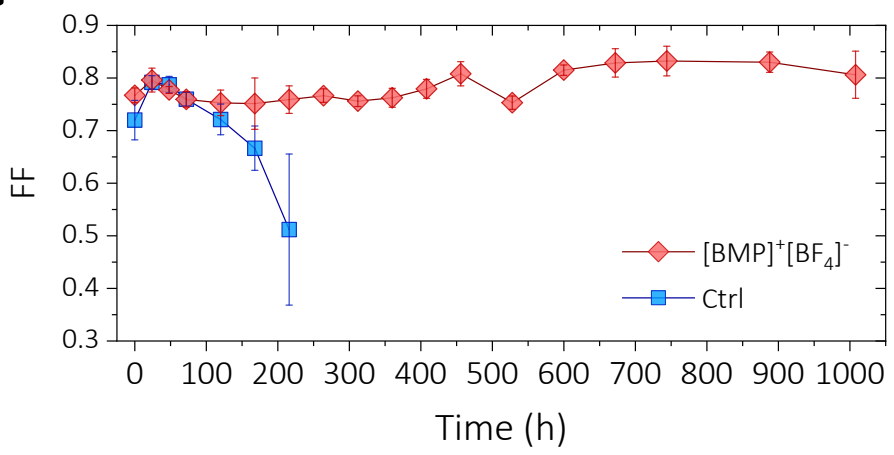

Fig. S27. Evolution of device parameters for unencapsulated $\mathrm{Cs}_{0.17} \mathrm{FA}_{0.83} \mathrm{~Pb}\left(\mathrm{I}_{0.77} \mathrm{Br}_{0.23}\right)_{3}$ perovskite solar cells under full-spectrum sunlight at $60^{\circ} \mathrm{C}$ : (A) $V_{\mathrm{OC}} ;(\mathbf{B}) J_{\mathrm{SC}} ;(\mathbf{C}) \mathrm{FF}$. 

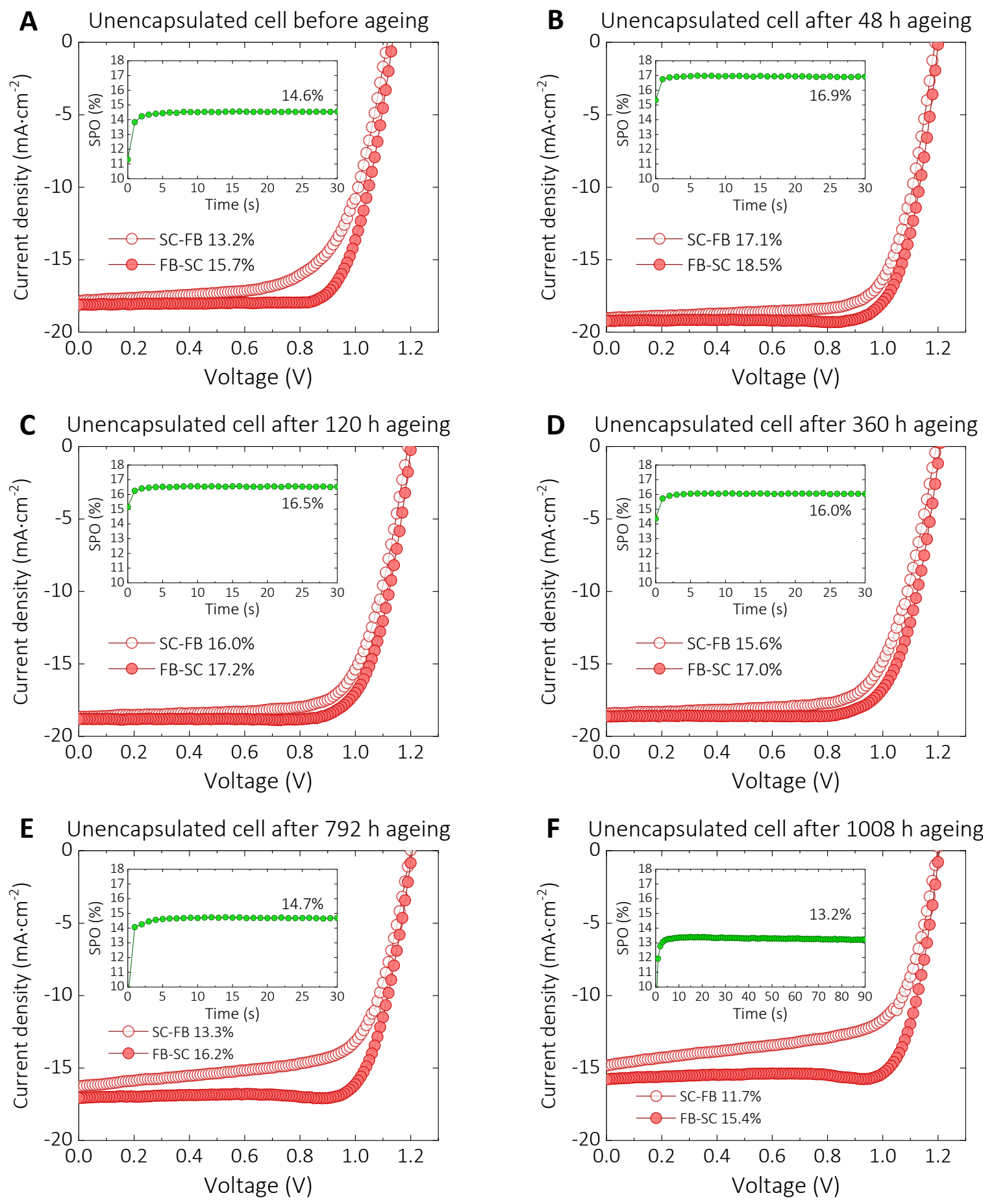

Fig. S28. Evolution of current density-voltage $(J-V)$ characteristics and static-state power output (SPO) curves for the most stable $0.25 \mathrm{~mol} \%[\mathrm{BMP}]^{+}\left[\mathrm{BF}_{4}\right]^{-}$modified $\mathrm{Cs}_{0.17} \mathrm{FA}_{0.83} \mathrm{~Pb}\left(\mathrm{I}_{0.77} \mathrm{Br}_{0.23}\right)_{3}$ perovskite solar cell (unencapsulated) under full-spectrum sunlight at $60^{\circ} \mathrm{C}$ : (A) before aging; (B) 48 h; (C) 120 h; (D) 360 h; (E) 792 h; (F) 1008 h. 


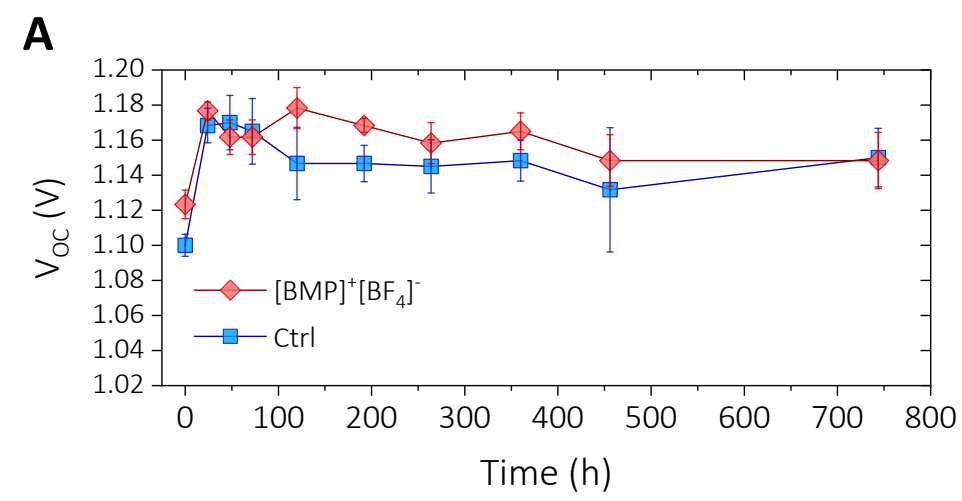

B

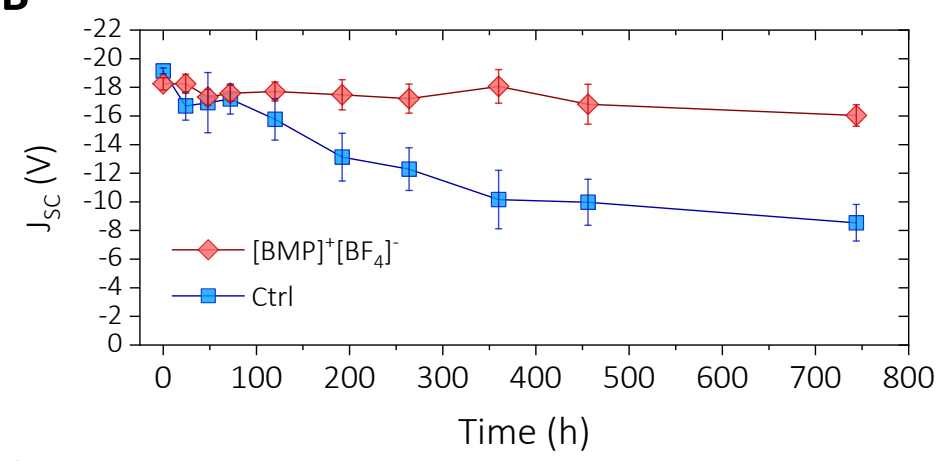

C

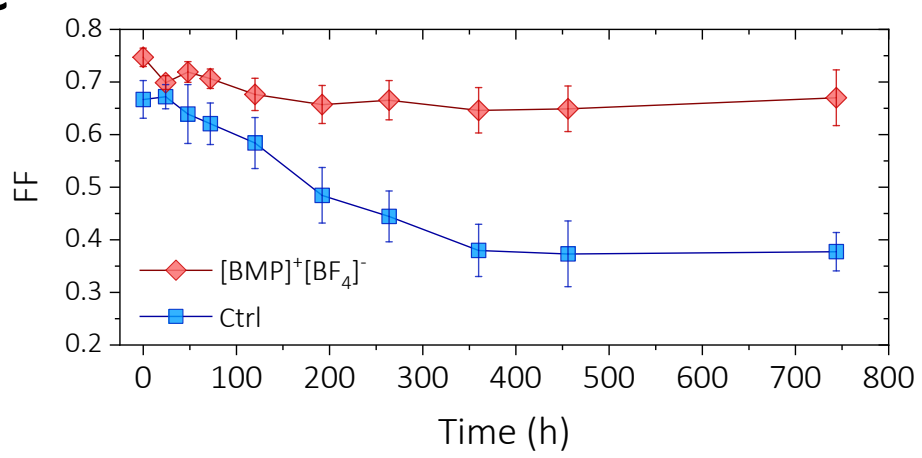

Fig. S29. Evolution of device parameters for encapsulated $\mathrm{Cs}_{0.17} \mathrm{FA}_{0.83} \mathrm{~Pb}\left(\mathrm{I}_{0.77} \mathrm{Br}_{0.23}\right)_{3}$ perovskite solar cells under full-spectrum sunlight at $85^{\circ} \mathrm{C}$ : (A) $V_{\mathrm{OC}} ;(\mathbf{B}) J_{\mathrm{SC}} ;(\mathbf{C}) \mathrm{FF}$. 

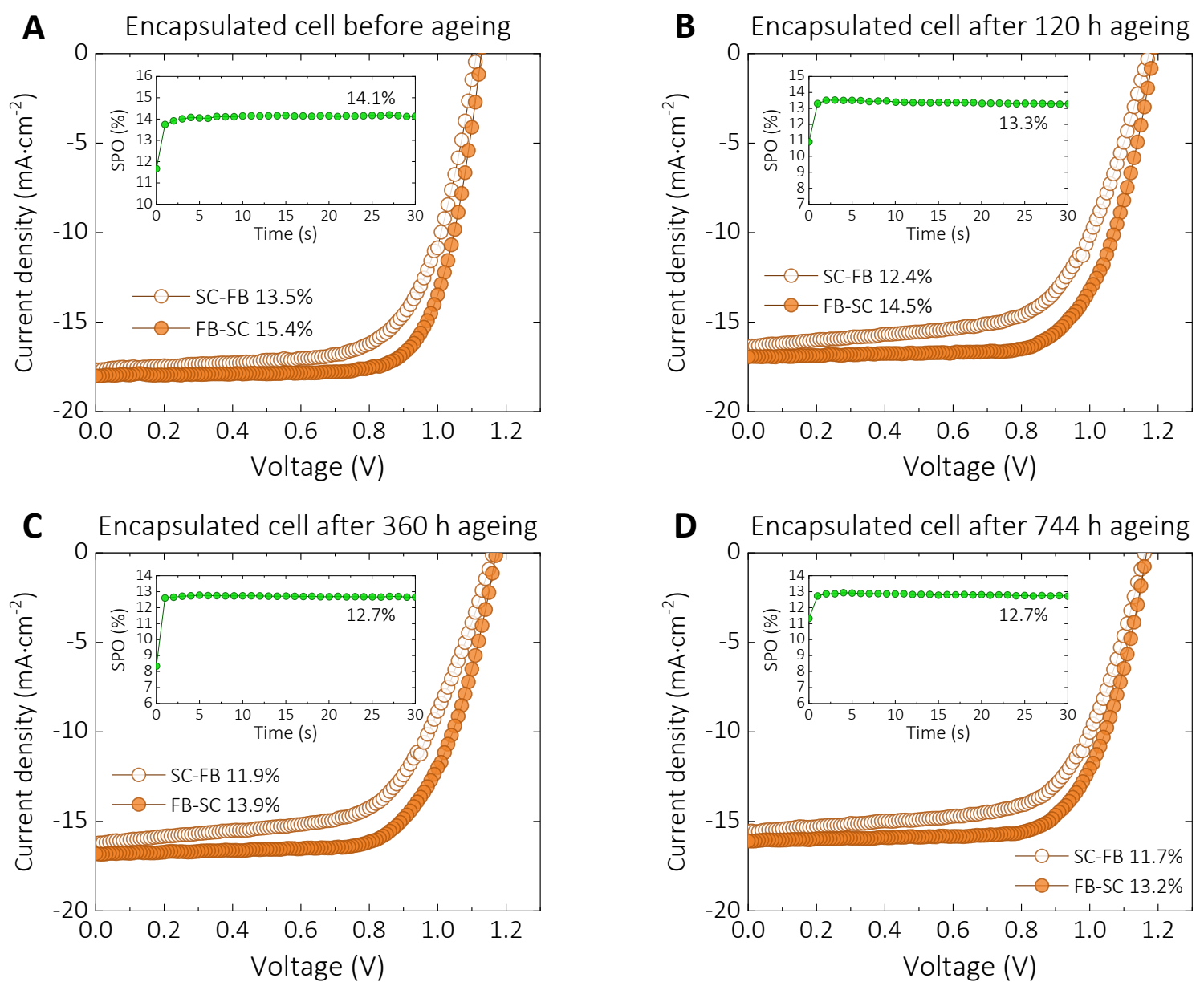

Fig. S30. Evolution of current density-voltage $(J-V)$ characteristics and static-state power output (SPO) curves for the most stable $0.25 \mathrm{~mol} \%[\mathrm{BMP}]^{+}\left[\mathrm{BF}_{4}\right]^{-}$modified $\left.\mathrm{Cs}_{0.17} \mathrm{FA}_{0.83} \mathrm{~Pb}_{\left(\mathrm{I}_{0.77}\right.} \mathrm{Br}_{0.23}\right)_{3}$ perovskite solar cell (encapsulated) under full-spectrum sunlight at $85^{\circ} \mathrm{C}$ : $(\mathbf{A})$ before aging; $(\mathbf{B})$ $120 \mathrm{~h}$; (C) $360 \mathrm{~h}$; (D) $744 \mathrm{~h}$. 

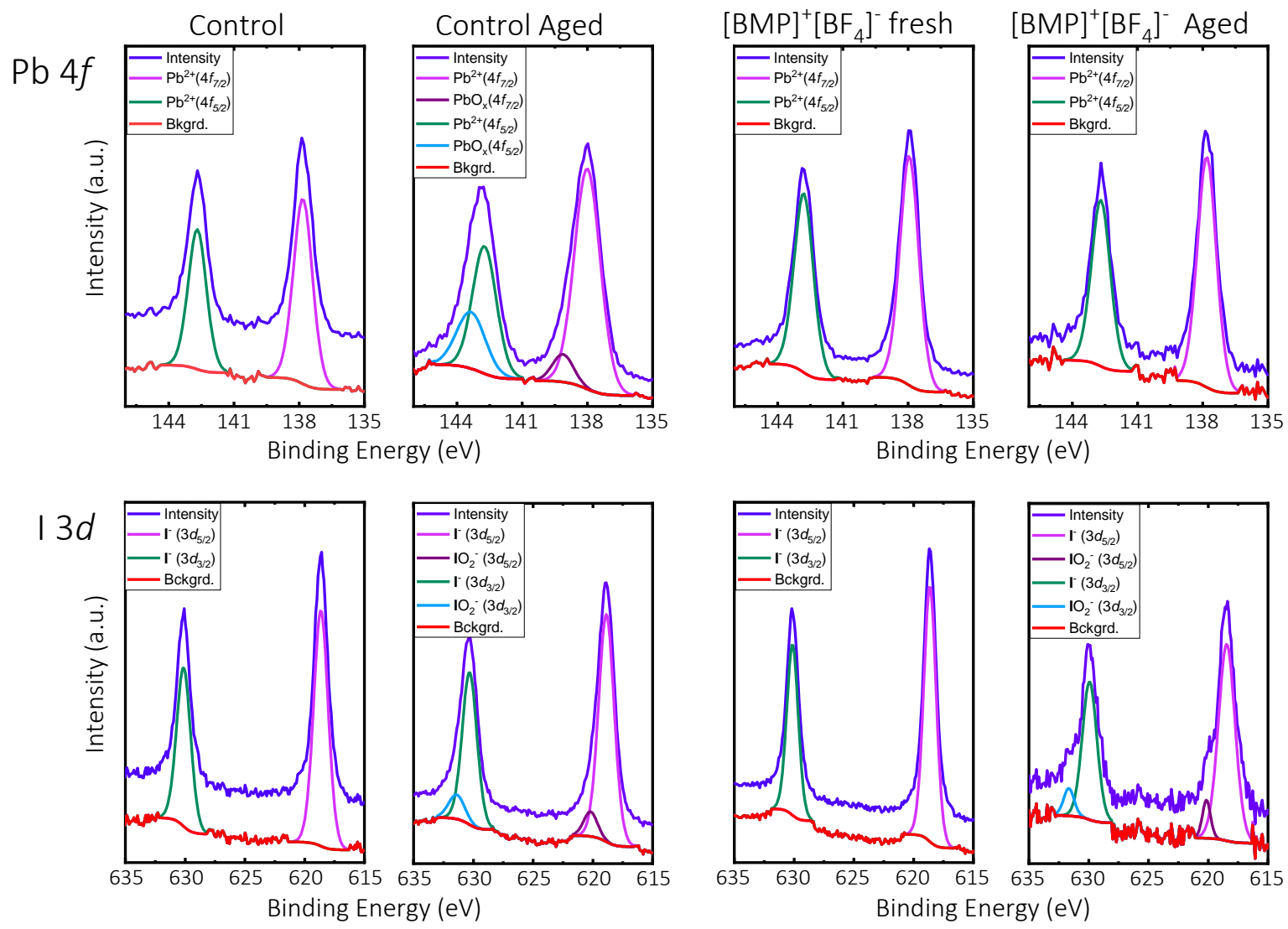

Fig. S31. X-ray photoemission spectra of the $\mathrm{Pb} 4 f$ and I $3 d$ core levels for the fresh and aged control devices (control) and those treated with $[\mathrm{BMP}]^{+}\left[\mathrm{BF}_{4}\right]^{-}$. 

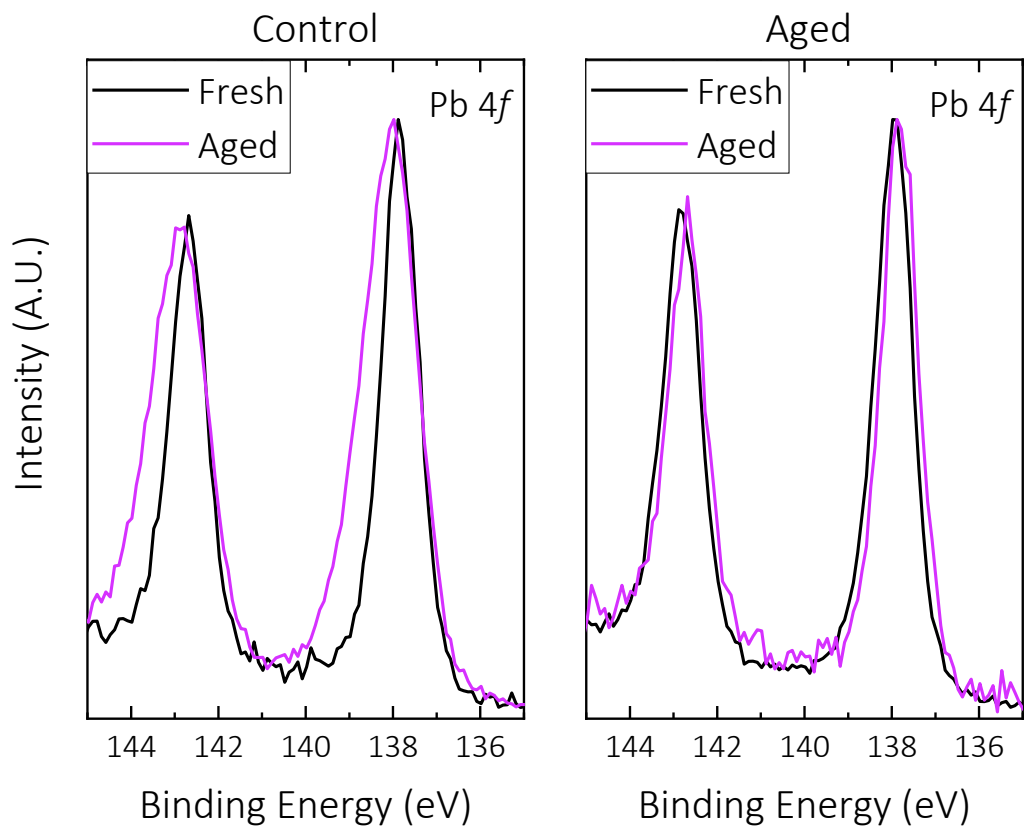

Fig. S32. Direct comparison of $\mathrm{Pb} 4 f$ core level spectra. The peaks corresponding to the aged control devices show a clear broadening in comparison to the fresh devices. This broadening is due to the emergence of $\mathrm{PbO}_{\mathrm{x}}$ in the perovskite layer as a result of aging. Conversely no such broadening is seen in the devices with $[\mathrm{BMP}]^{+}\left[\mathrm{BF}_{4}\right]^{-}$. 

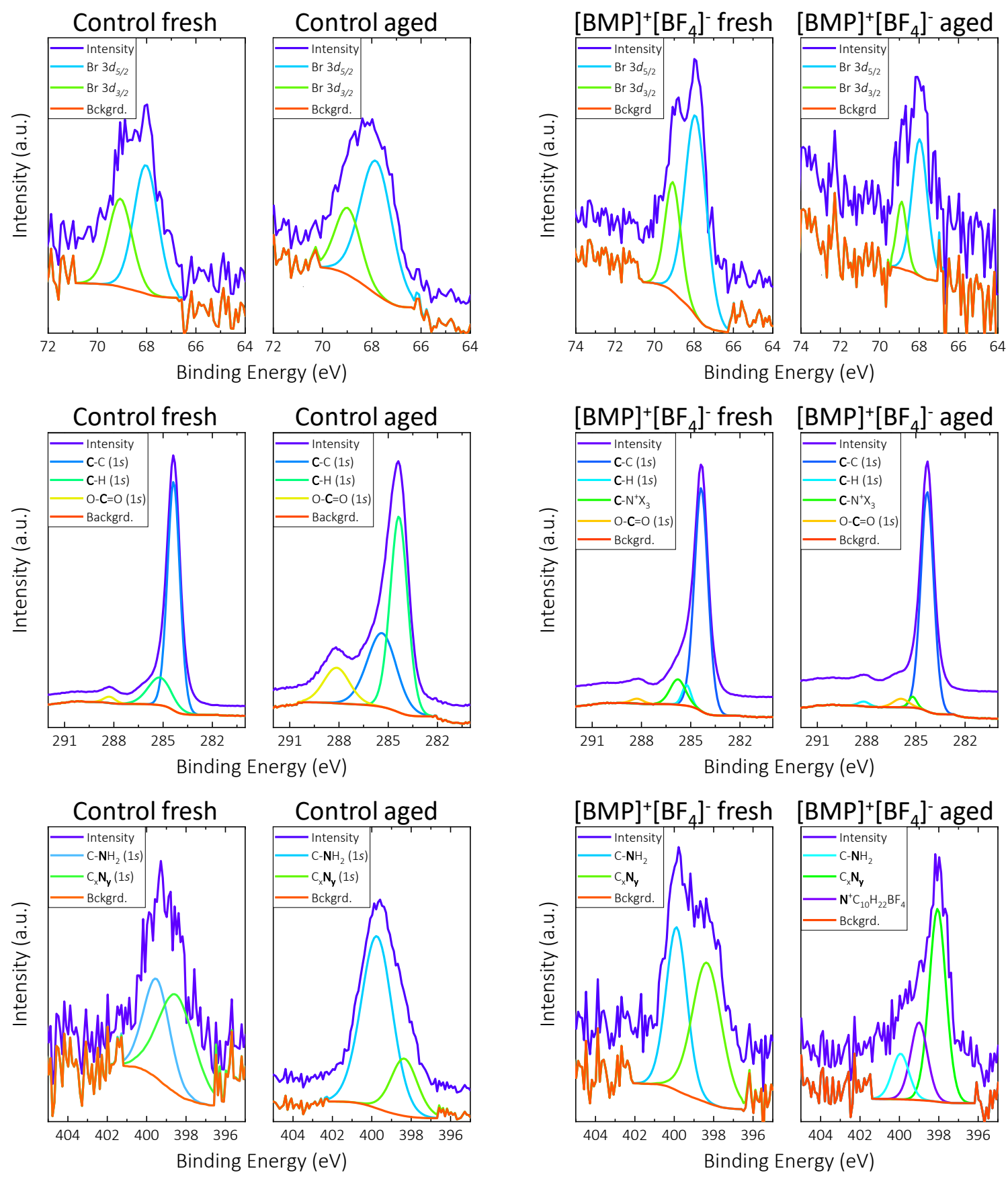

Fig. S33. Full peak fittings for X-ray photoemission spectra of $\mathrm{Br} 3 d, \mathrm{C} 1 s$ and $\mathrm{N} 1 s$ core levels. 
A

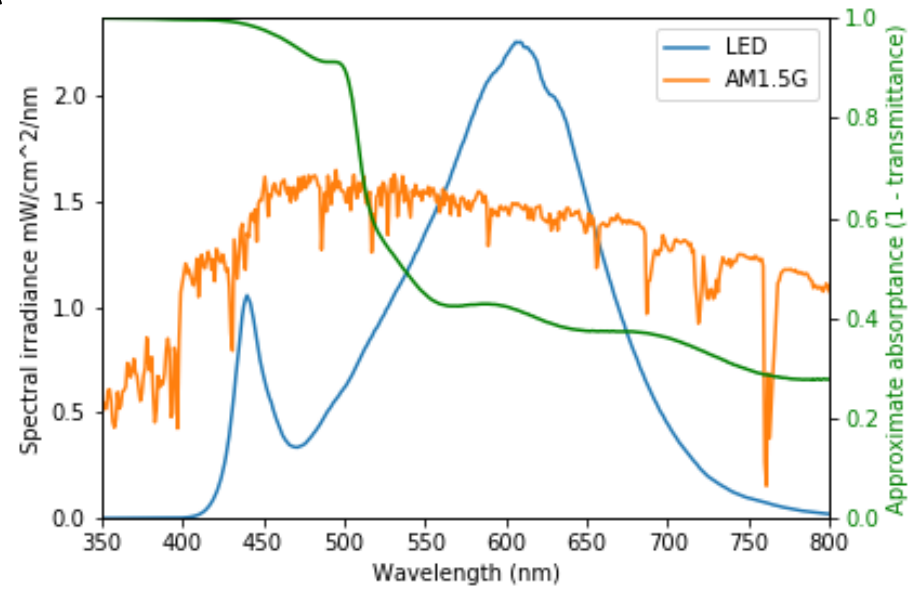

B

$\mathrm{Oh}$

$3 \mathrm{~h}$

$6 \mathrm{~h}$

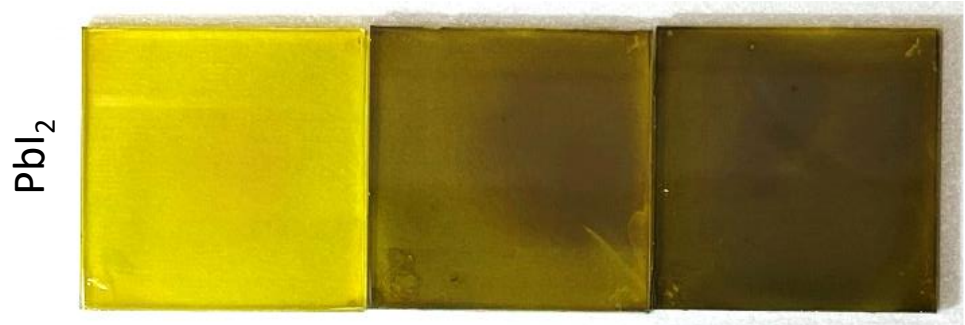

Fig. S34. (A) Spectral irradiance of LED (blue) and AM1.5 (orange), and $\mathrm{PbI}_{2}$ absorptance (green) for equivalent solar intensity calculation. (B) Evolution of appearance of $\mathrm{PbI}_{2}$ films measured after aged under $\sim 0.32$ suns white LED illumination at $85^{\circ} \mathrm{C}$ in a nitrogen filled glove box. 


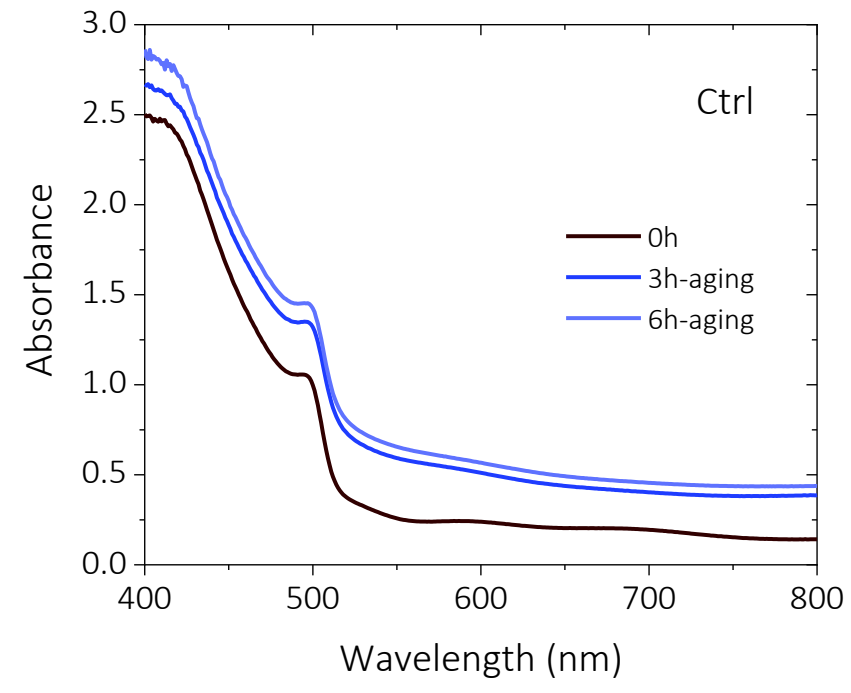

Fig. S35. Evolution of corresponding UV-vis absorbance spectra of $\mathrm{PbI}_{2}$ films shown in Fig. $\mathbf{S 3 4}$ measured before and after aging. 


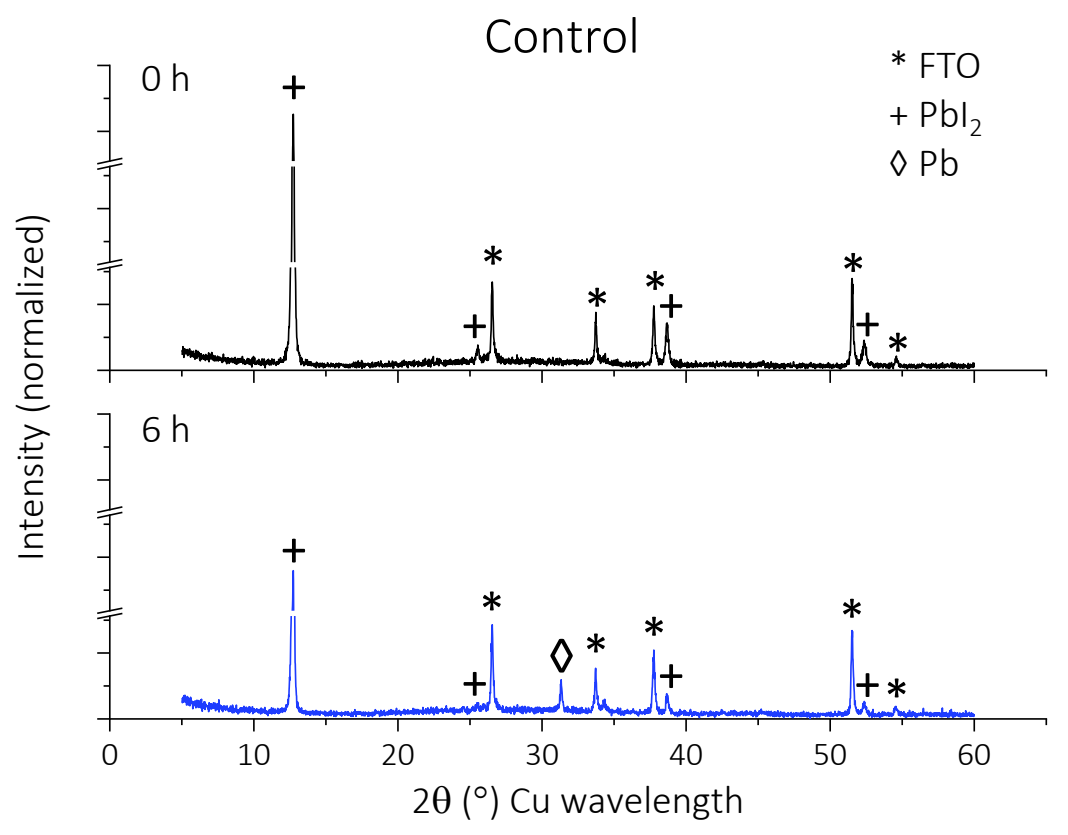

Fig. S36. Corresponding XRD data of $\mathrm{PbI}_{2}$ films shown in Fig. S34 measured before and after aging. The XRD peaks corresponding to $\mathrm{PbI}_{2}(+), \mathrm{FTO}\left(^{*}\right)$ and $\mathrm{Pb}(\diamond)$ are marked (44). 
Table S1. Comparison of $\mathrm{Pb}$-based solar cell operational stability with the representative literature works. For unencapsulated cells, $\mathrm{T}_{80, \mathrm{SPO}} \mathrm{MPP}$ (or $\mathrm{T}_{80}$, PCE when $\mathrm{T}_{80}, \mathrm{SPO} / \mathrm{MPP}$ is not available) is listed, while T95, SPO/MPP (or T95, PCE when T95, SPO/MPP is not available) is listed for encapsulated cells (30). When performance is given in absolute values, the value of the SPO, MPP or PCE at the $\mathrm{T}_{80}$ or $\mathrm{T}_{95}$ is given.

\begin{tabular}{|c|c|c|c|c|}
\hline Perovskite compositions & Device architecture & Aging conditions & $\begin{array}{c}\text { Lifetime \& } \\
\text { SPO/MPP/PCE @ } \mathrm{T}_{80 / 95} \\
\end{array}$ & Ref. \\
\hline $\mathrm{Cs}_{0.17} \mathrm{FA}_{0.83} \mathrm{~Pb}\left(\mathrm{I}_{0.77} \mathrm{Br}_{0.23}\right)_{3}$ & $\begin{array}{c}\text { FTO/polyTPD/pero/ } \\
\text { PCBM/BCP/Cr/Au } \\
\text { (unencapsulated) }\end{array}$ & $\begin{array}{l}\text { Xenon lamp, } \\
\text { open-circuit, } \mathbf{6 0}{ }^{\circ} \mathrm{C}, \\
\text { RH } \sim \mathbf{5 0 \%} \text {, air }\end{array}$ & $\begin{aligned} \mathbf{T}_{80, \text { Champ-SPO }} & =1010 \mathrm{~h}^{\dagger} \\
\text { SPO @ } \mathbf{T}_{80} & =\mathbf{1 3 . 2 \%} \\
\mathbf{T}_{80, \text { Champ-PCE }} & =2630 \mathrm{~h}^{\dagger} \\
\text { PCE @ } \mathbf{T}_{80} & =\mathbf{1 3 . 6 \%}\end{aligned}$ & $\begin{array}{l}\text { This } \\
\text { work }\end{array}$ \\
\hline $\mathrm{Cs}_{0.17} \mathrm{FA}_{0.83} \mathrm{~Pb}\left(\mathrm{I}_{0.77} \mathrm{Br}_{0.23}\right)_{3}$ & $\begin{array}{c}\text { FTO/polyTPD/pero/ } \\
\text { PCBM/BCP/Cr/Au } \\
\text { (encapsulated) }\end{array}$ & $\begin{array}{c}\text { Xenon lamp, } \\
\text { open-circuit, } 85^{\circ} \mathrm{C}, \\
\mathrm{RH} \sim \mathbf{5 0 \%} \text {, air }\end{array}$ & $\begin{array}{l}T_{95} \text {, Ave-SPO }=1200 h^{+} \\
\text {SPO @ } T_{95}=11.8 \%\end{array}$ & $\begin{array}{l}\text { This } \\
\text { work }\end{array}$ \\
\hline $\mathrm{Cs}_{0.05}\left(\mathrm{FA}_{0.83} \mathrm{MA}_{0.17}\right)_{0.95} \mathrm{~Pb}\left(\mathrm{I}_{0.9} \mathrm{Br}_{0.1}\right)_{3}$ & $\begin{array}{c}\mathrm{FTO} / \mathrm{NiO} / \text { pero/PCBM} / \\
\mathrm{BCP} / \mathrm{Cr}_{2} \mathrm{O}_{3} / \mathrm{Cr} / \mathrm{Au} \\
\text { (unencapsulated) }\end{array}$ & $\begin{array}{c}\text { Xenon lamp, } \\
\text { open-circuit, } 60^{\circ} \mathrm{C} \text {, } \\
\text { RH } 40 \sim 50 \% \text {, air }\end{array}$ & $\begin{aligned} \mathrm{T}_{80, \text { Champ-PCE }} & =100 \mathrm{~h}^{\dagger} \\
\text { PCE @ } \mathrm{T}_{80} & =\sim 15 \%\end{aligned}$ & $(14)$ \\
\hline $\mathrm{Cs}_{0.05}\left(\mathrm{FA}_{0.83} \mathrm{MA}_{0.17}\right)_{0.95} \mathrm{~Pb}\left(\mathrm{I}_{0.9} \mathrm{Br}_{0.1}\right)_{3}$ & $\begin{array}{c}\mathrm{FTO} / \mathrm{NiO} / \text { pero/PCBM} / \\
\mathrm{BCP} / \mathrm{Cr}_{2} \mathrm{O}_{3} / \mathrm{Cr} / \mathrm{Au} \\
\text { (encapsulated) }\end{array}$ & $\begin{array}{c}\text { Xenon lamp, } \\
\text { open-circuit, } 70 \sim 75^{\circ} \mathrm{C}, \\
\text { RH } 40 \sim 50 \% \text {, air }\end{array}$ & $\begin{array}{l}\mathrm{T}_{95} \text {, Ave-SPO }=360 \mathrm{~h}^{\ddagger} \\
\mathrm{SPO} @ \mathrm{~T}_{95}=\sim 18 \%\end{array}$ & $(14)$ \\
\hline $\mathrm{Cs}_{0.05} \mathrm{FA}_{0.81} \mathrm{MA}_{0.14} \mathrm{PbI}_{2.55} \mathrm{Br}_{0.45}$ & $\begin{array}{c}\text { ITO/PTAA/pero/ } \\
\mathrm{PbSO}_{4} / \mathrm{C}_{60} / \mathrm{BCP} / \mathrm{Cu} \\
\text { (encapsulated) }\end{array}$ & $\begin{array}{c}\text { Plasma lamp, } \\
\text { MPP, } 65^{\circ} \mathrm{C} \text {, } \\
\text { RH } 60 \pm 10 \% \text {, air }\end{array}$ & $\begin{aligned} \mathrm{T}_{95} \text {, Champ-PCE } & =1200 \mathrm{~h} \\
\mathrm{PCE} @ \mathrm{~T}_{95} & =\sim 18 \%\end{aligned}$ & $(72)$ \\
\hline $\mathrm{Cs}_{0.17} \mathrm{FA}_{0.83} \mathrm{~Pb}\left(\mathrm{Br}_{0.17} \mathrm{I}_{0.83}\right)_{3}$ & $\begin{array}{l}\mathrm{ITO} / \mathrm{NiO} / \mathrm{pero} / \mathrm{LiF} / \\
\mathrm{PCBM} / \mathrm{SnO}_{2} / \mathrm{ZTO} / \\
\mathrm{ITO} / \mathrm{Ag} / \mathrm{LiF} \\
\text { (ITO acting as the } \\
\text { encapsulation layer) }\end{array}$ & $\begin{array}{l}\text { Plasma lamp, } \\
\text { MPP, } 35^{\circ} \mathrm{C}, \\
\text { RH } 40 \% \text {, air }\end{array}$ & $\begin{aligned} \mathrm{T}_{95} \text {, Champ-MPP } & =625 \mathrm{~h}^{\dagger} \\
\mathrm{MPP} @ \mathrm{~T}_{95} & =\sim 14 \%\end{aligned}$ & $(27)$ \\
\hline $\mathrm{Cs}_{0.05}\left(\mathrm{FA}_{0.92} \mathrm{MA}_{0.08}\right)_{0.95} \mathrm{~Pb}\left(\mathrm{I}_{0.92} \mathrm{Br}_{0.08}\right)_{3}$ & $\begin{array}{l}\text { ITO/PTAA/pero/ } \\
\text { PCBM/C } 60 / \mathrm{BCP} / \mathrm{Cu} \\
\text { (encapsulated \& } \mathrm{N}_{2} \text { ) }\end{array}$ & $\begin{array}{l}\text { AM1.5 with UV filter } \\
\text { (420-nm cut-off), } \\
\text { MPP, } 40^{\circ} \mathrm{C}, \mathrm{N}_{2}\end{array}$ & $\begin{array}{l}\text { T95, Champ-PCE unknown } \\
\text { No degradation for } 1000 \mathrm{~h}\end{array}$ & $(73)$ \\
\hline $\mathrm{Cs}_{0.05}\left(\mathrm{FA}_{0.92} \mathrm{MA}_{0.08}\right)_{0.95} \mathrm{~Pb}\left(\mathrm{I}_{0.92} \mathrm{Br}_{0.08}\right)_{3}$ & $\begin{array}{c}\text { ITO/PTAA/pero/ } \\
\text { PCBM/C } 60 / \mathrm{BCP} / \mathrm{Cu} \\
\text { (encapsulated \& } \mathrm{N}_{2} \text { ) }\end{array}$ & $\begin{array}{c}\text { Dark (no light), } \\
\text { open-circuit, } 85^{\circ} \mathrm{C}, \mathrm{N}_{2}\end{array}$ & $\begin{array}{l}\mathrm{T}_{95, \text { Champ-PCE }}=510 \mathrm{~h} \\
\mathrm{PCE} @ \mathrm{~T}_{95}=\sim 17 \%\end{array}$ & $(73)$ \\
\hline$\left(\mathrm{FAPbI}_{3}\right)_{0.95}\left(\mathrm{MAPbBr}_{3}\right)_{0.05}$ & $\begin{array}{c}\mathrm{FTO} / \mathrm{d}-\mathrm{TiO}_{2} / \\
\mathrm{mp}-\mathrm{TiO}_{2} / \text { pero/WBH} / \\
\mathrm{P} 3 \mathrm{HT} / \mathrm{Au} \\
\text { (encapsulated) }\end{array}$ & $\begin{array}{l}\text { White LED, } \\
\text { MPP, } 25^{\circ} \mathrm{C} \text {, } \\
\text { RH } 30 \% \text {, air }\end{array}$ & $\begin{array}{l}\mathrm{T}_{95, \text { Champ-PCE }}=1370 \mathrm{~h} \\
\text { Actual PCE unknown }\end{array}$ & $(74)$ \\
\hline$(\mathrm{FA}, \mathrm{MA}, \mathrm{Cs}) \mathrm{Pb}(\mathrm{I}, \mathrm{Br})_{3}(\mathrm{Cl})$ & $\begin{array}{c}\mathrm{ITO} / \mathrm{SnO}_{2} / \text { pero/ } \\
\text { spiro-OMeTAD/Au } \\
\text { (encapsulation } \\
\text { information unknown) }\end{array}$ & $\begin{array}{l}\text { Continuous } 1 \text {-sun } \\
\text { equivalent illumination, } \\
\text { room temperature }\end{array}$ & $\begin{array}{c}\mathrm{T}_{95, \text { Champ-MPP }}=310 \mathrm{~h}^{\dagger} \\
\text { Actual MPP/PCE unknown }\end{array}$ & $(75)$ \\
\hline$\left(\mathrm{FA}_{0.79} \mathrm{MA}_{0.16} \mathrm{Cs}_{0.05}\right)_{0.97} \mathrm{~Pb}\left(\mathrm{I}_{0.84} \mathrm{Br}_{0.16}\right)_{2.97}$ & $\begin{array}{c}\mathrm{FTO} / \mathrm{SnO}_{2} / \text { pero/EH44/ } \\
\mathrm{MoO}_{\mathrm{x}} / \mathrm{Al} \\
\text { (unencapsulated) } \\
\end{array}$ & $\begin{array}{l}\text { Plasma lamp, } \\
\text { resistive load, } \sim 30^{\circ} \mathrm{C}, \\
\mathrm{RH} 10 \sim 20 \% \text {, air }\end{array}$ & $\begin{aligned} \mathrm{T}_{80, \text { Champ-PCE }} & =2400 \mathrm{~h}^{\dagger} \\
\text { PCE @ } \mathrm{T}_{80} & =\sim 10 \%\end{aligned}$ & $(12)$ \\
\hline$\left(\mathrm{FA}_{0.79} \mathrm{MA}_{0.16} \mathrm{Cs}_{0.05}\right)_{0.97} \mathrm{~Pb}\left(\mathrm{I}_{0.84} \mathrm{Br}_{0.16}\right)_{2.97}$ & $\begin{array}{c}\mathrm{FTO} / \mathrm{SnO}_{2} / \text { pero/EH44/ } \\
\mathrm{MoO}_{\mathrm{x}} / \mathrm{Al} \\
\text { (unencapsulated) }\end{array}$ & $\begin{array}{l}\text { Plasma lamp, } \\
\text { resistive load, } \sim 70^{\circ} \mathrm{C}, \\
\mathrm{RH} 50 \% \text {, air }\end{array}$ & $\begin{aligned} \mathrm{T}_{80, \text { Ave-PCE }} & =30 \mathrm{~h} \\
\mathrm{PCE} @ \mathrm{~T}_{80} & =\sim 13 \%\end{aligned}$ & $(12)$ \\
\hline $\mathrm{BA}_{0.09}\left(\mathrm{FA}_{0.83} \mathrm{Css}_{0.17}\right)_{0.91} \mathrm{~Pb}\left(\mathrm{I}_{0.6} \mathrm{Br}_{0.4}\right)_{3}$ & $\begin{array}{c}\mathrm{FTO} / \mathrm{SnO}_{2} / \mathrm{PCBM} / \\
\text { pero/spiro-OMeTAD/ } \\
\mathrm{Au} \\
\text { (unencapsulated) }\end{array}$ & $\begin{array}{c}\text { Xenon lamp, } \\
\text { open-circuit, } 50 \sim 60^{\circ} \mathrm{C}, \\
\text { RH } \sim 45 \% \text {, air }\end{array}$ & $\begin{aligned} \mathrm{T}_{80, \text { Champ-SPO }} & =805 \mathrm{~h}^{\ddagger} \\
\mathrm{SPO} @ \mathrm{~T}_{80} & =\sim 10 \%\end{aligned}$ & $(76)$ \\
\hline $\mathrm{BA}_{0.09}\left(\mathrm{FA}_{0.83} \mathrm{Cs}_{0.17}\right)_{0.91} \mathrm{~Pb}\left(\mathrm{I}_{0.6} \mathrm{Br}_{0.4}\right)_{3}$ & $\begin{array}{c}\mathrm{FTO} / \mathrm{SnO}_{2} / \mathrm{PCBM} / \\
\text { pero/spiro-OMeTAD/ } \\
\mathrm{Au} \\
\text { (encapsulated) }\end{array}$ & $\begin{array}{c}\text { Xenon lamp, } \\
\text { open-circuit, } 50 \sim 60^{\circ} \mathrm{C}, \\
\text { RH } \sim 45 \% \text {, air }\end{array}$ & $\begin{aligned} \mathrm{T}_{95} \text { Champ-SPO } & =460 \mathrm{~h}^{\ddagger} \\
\mathrm{SPO} @ \mathrm{~T}_{95} & =\sim 14 \%\end{aligned}$ & $(76)$ \\
\hline$(\mathrm{FA}, \mathrm{MA}, \mathrm{Cs}, \mathrm{Rb}) \mathrm{Pb}(\mathrm{I}, \mathrm{Br})_{3}$ & $\begin{array}{c}\mathrm{FTO} / \mathrm{c}-\mathrm{TiO}_{2} / \mathrm{mp}-\mathrm{TiO}_{2} / \\
\text { pero/PTAA} / \mathrm{Au} \\
\left(\mathrm{N}_{2}\right)\end{array}$ & $\begin{array}{l}\text { White LED, } \\
\text { MPP, } 85^{\circ} \mathrm{C}, \mathrm{N}_{2}\end{array}$ & $\begin{array}{l}\mathrm{T}_{95, \text { Champ-MPP }}=500 \mathrm{~h} \\
\text { MPP @ } \mathrm{T}_{95}=\sim 13 \% \\
\mathrm{~T}_{95, \text { Champ-PCE }}=250 \mathrm{~h} \\
\text { PCE @ } \mathrm{T}_{95}=\sim 16 \%\end{array}$ & $(77)$ \\
\hline
\end{tabular}

$\dagger$ Light-soaking; + Post-burn-in. 
Table S2. Peak positions and full assignments for high resolution XPS of all fresh and aged devices $(32,78-80)$.

\begin{tabular}{|c|c|c|c|c|c|}
\hline & $\operatorname{Br} 3 d_{5 / 2}(\mathrm{eV})$ & $\begin{array}{l}\operatorname{Pb~} 4 f_{7 / 2} \\
(\mathrm{eV})\end{array}$ & I $3 d_{5 / 2}(\mathrm{eV})$ & $\mathrm{C} 1 s(\mathrm{eV})$ & $\mathrm{N} 1 s(\mathrm{eV})$ \\
\hline $\begin{array}{l}\text { Control } \\
\text { (fresh) }\end{array}$ & $68.0\left(\mathbf{B r}^{+}\right)$ & $\begin{array}{l}137.8 \\
\left(\mathbf{P b}^{2+}\right)\end{array}$ & $618.6\left(\mathbf{I}^{-}\right)$ & $\begin{array}{l}284.4(\mathbf{C}-\mathrm{C}) \\
285.2(\mathbf{C}-\mathrm{H}) \\
288.3\end{array}$ & $\begin{array}{l}398.4\left(\mathrm{C}_{\mathrm{x}} \mathbf{N}_{\mathbf{y}}\right) \\
399.5\left(\mathrm{C}-\mathrm{NH}_{2}\right)\end{array}$ \\
\hline $\begin{array}{l}\text { Control } \\
\text { (aged) }\end{array}$ & $67.8\left(\mathbf{B r}^{+}\right)$ & $\begin{array}{l}138.0 \\
\left(\mathbf{P b}^{2+}\right) \\
139.1 \\
\left(\mathbf{P b O}_{\mathbf{x}}\right)\end{array}$ & $\begin{array}{l}618.9\left(\mathbf{I}^{-}\right) \\
620.2\left(\mathbf{I O}_{2}^{-}\right) /\left(\mathbf{I C H}_{3}\right)\end{array}$ & $\begin{array}{l}284.3(\mathbf{C}-\mathrm{C}) \\
285.4(\mathbf{C}-\mathrm{H}) \\
288.1(\mathrm{O}-\mathrm{C}=\mathrm{O})\end{array}$ & $\begin{array}{l}398.4\left(\mathrm{C}_{\mathrm{x}} \mathbf{N}_{\mathbf{y}}\right) \\
399.7\left(\mathrm{C}-\mathrm{NH}_{2}\right)\end{array}$ \\
\hline $\begin{array}{l}\text { Treated } \\
\text { (fresh) }\end{array}$ & $67.9\left(\mathbf{B r}^{+}\right)$ & $\begin{array}{l}137.9 \\
\left(\mathbf{P b}^{2+}\right)\end{array}$ & $618.6\left(\mathbf{I}^{-}\right)$ & $\begin{array}{l}284.4(\mathbf{C}-\mathrm{C}) \\
285.2(\mathbf{C}-\mathrm{H}) \\
285.8\left(\mathbf{C}-\mathrm{N}^{+} \mathrm{X}_{3}\right) \\
288.3(\mathrm{O}-\mathbf{C}=\mathrm{O})\end{array}$ & $\begin{array}{l}398.3\left(\mathbf{C}_{\mathrm{x}} \mathbf{N}_{\mathbf{y}}\right) \\
399.9\left(\mathrm{C}-\mathbf{N H}_{2}\right)\end{array}$ \\
\hline $\begin{array}{l}\text { Treated } \\
\text { (aged) }\end{array}$ & $68.0\left(\mathbf{B r}^{+}\right)$ & $\begin{array}{l}137.8 \\
\left(\mathbf{P b}^{2+}\right)\end{array}$ & $\begin{array}{l}618.4\left(\mathbf{I}^{-}\right) \\
620.1\left(\mathbf{I O}_{2}^{-}\right) /\left(\mathbf{I C H}_{3}\right)\end{array}$ & $\begin{array}{l}284.3(\mathbf{C}-\mathrm{C}) \\
285.2(\mathbf{C}-\mathrm{H}) \\
285.9\left(\mathbf{C}-\mathrm{N}^{+} \mathrm{X}_{3}\right) \\
288.2(\mathrm{O}-\mathbf{C}=\mathrm{O})\end{array}$ & $\begin{array}{l}398.3\left(\mathrm{C}_{\mathbf{x}} \mathbf{N}_{\mathbf{y}}\right) \\
399.0\left(\mathbf{N}^{+} \mathrm{C}_{10} \mathrm{H}_{22} \mathrm{BF}_{4}\right) \\
399.9\left(\mathbf{C}-\mathbf{N H}_{2}\right)\end{array}$ \\
\hline
\end{tabular}




\section{References}

46. N. J. Jeon et al., Solvent engineering for high-performance inorganic-organic hybrid perovskite solar cells. Nat. Mater. 13, 897-903 (2014).

47. K. X. Li et al., 3D-characterization of deuterium distributions in zirconium oxide scale using high-resolution SIMS. Appl. Surf. Sci. 464, 311-320 (2019).

48. C. Poczatek, Z. Kaufman, C. Lechene, OpenMIMS ImageJ Plugin Guide. Harvard Medical School (Boston, Massachusetts, USA), (2009).

49. A. Crovetto et al., Shining Light on Sulfide Perovskites: LaYS3 Material Properties and Solar Cells. Chem. Mater. 31, 3359-3369 (2019).

50. J. G. Labram et al., Charge transport in a two-dimensional hybrid metal halide thiocyanate compound. J. Mater. Chem. C 5, 5930-5938 (2017).

51. T. J. Savenije, A. J. Ferguson, N. Kopidakis, G. Rumbles, Revealing the Dynamics of Charge Carriers in Polymer:Fullerene Blends Using Photoinduced Time-Resolved Microwave Conductivity. J. Phys. Chem. C 117, 24085-24103 (2013).

52. D. G. Georgiadou et al., High Responsivity and Response Speed Single-Layer Mixed-Cation Lead Mixed-Halide Perovskite Photodetectors Based on Nanogap Electrodes Manufactured on Large-Area Rigid and Flexible Substrates. Adv. Funct. Mater. 29, 1901371 (2019).

53. J. Lim et al., Elucidating the long-range charge carrier mobility in metal halide perovskite thin films. Energy. Environ. Sci. 12, 169-176 (2019).

54. C. C. Katsidis, D. I. Siapkas, General transfer-matrix method for optical multilayer systems with coherent, partially coherent, and incoherent interference. Appl. Opt. 41, 3978-3987 (2002).

55. K. Ohta, H. Ishida, Comparison Among Several Numerical Integration Methods for Kramers-Kronig Transformation. Appl. Spectrosc. 42, 952-957 (1988).

56. B. C. O'Regan, J. R. Durrant, P. M. Sommeling, N. J. Bakker, Influence of the TiCl4 Treatment on Nanocrystalline TiO2 Films in Dye-Sensitized Solar Cells. 2. Charge Density, Band Edge Shifts, and Quantification of Recombination Losses at Short Circuit. J. Phys. Chem. C 111, 14001-14010 (2007).

57. B. O'regan, S. Scully, A. Mayer, E. Palomares, J. Durrant, The effect of Al2O3 barrier layers in $\mathrm{TiO} 2 /$ dye/CuSCN photovoltaic cells explored by recombination and DOS characterization using transient photovoltage measurements. J. Phys. Chem. B 109, 4616-4623 (2005).

58. C. Shuttle et al., Charge extraction analysis of charge carrier densities in a polythiophene/fullerene solar cell: Analysis of the origin of the device dark current. Appl. Phys. Lett. 93, 183501 (2008).

59. C. G. Shuttle et al., Experimental determination of the rate law for charge carrier decay in a polythiophene: Fullerene solar cell. Appl. Phys. Lett. 92, 80 (2008).

60. D. Credgington, J. R. Durrant, Insights from transient optoelectronic analyses on the opencircuit voltage of organic solar cells. J. Phys. Chem. Lett. 3, 1465-1478 (2012).

61. F. Deledalle, P. Shakya Tuladhar, J. Nelson, J. R. Durrant, T. Kirchartz, Understanding the apparent charge density dependence of mobility and lifetime in organic bulk heterojunction solar cells. J. Phys. Chem. C 118, 8837-8842 (2014).

62. C. G. Shuttle, R. Hamilton, J. Nelson, B. C. O'Regan, J. R. Durrant, Measurement of chargedensity dependence of carrier mobility in an organic semiconductor blend. Adv. Funct. Mater. 20, 698-702 (2010). 
63. S. Wheeler et al., Transient optoelectronic analysis of the impact of material energetics and recombination kinetics on the open-circuit voltage of hybrid perovskite solar cells. J. Phys. Chem. C 121, 13496-13506 (2017).

64. C. Van Berkel, M. Powell, A. Franklin, I. French, Quality factor in a-Si: H nip and pin diodes. J. Appl. Phys. 73, 5264-5268 (1993).

65. T. Kirchartz, B. E. Pieters, J. Kirkpatrick, U. Rau, J. Nelson, Recombination via tail states in polythiophene: fullerene solar cells. Phys. Rev. B 83, 115209 (2011).

66. I. Levine et al., Can we use time-resolved measurements to get steady-state transport data for halide perovskites? J. Appl. Phys. 124, 103103 (2018).

67. J. G. Labram, M. L. Chabinyc, Recombination at high carrier density in methylammonium lead iodide studied using time-resolved microwave conductivity. J. Appl. Phys. 122, 065501 (2017).

68. H. Oga, A. Saeki, Y. Ogomi, S. Hayase, S. Seki, Improved Understanding of the Electronic and Energetic Landscapes of Perovskite Solar Cells: High Local Charge Carrier Mobility, Reduced Recombination, and Extremely Shallow Traps. J. Am. Chem. Soc. 136, 1381813825 (2014).

69. T. J. Savenije, J. E. Kroeze, M. M. Wienk, J. M. Kroon, J. M. Warman, Mobility and decay kinetics of charge carriers in photoexcited PCBM/PPV blends. Phys. Rev. B 69, 155205 (2004).

70. E. M. Hutter, M. C. Gélvez-Rueda, D. Bartesaghi, F. C. Grozema, T. J. Savenije, Band-Like Charge Transport in Cs2AgBiBr6 and Mixed Antimony-Bismuth Cs2AgBi1-x Sb x Br6 Halide Double Perovskites. ACS Omega 3, 11655-11662 (2018).

71. O. G. Reid et al., Quantitative analysis of time-resolved microwave conductivity data. J. Phys. D Appl. Phys. 50, 493002 (2017).

72. S. Yang et al., Stabilizing halide perovskite surfaces for solar cell operation with widebandgap lead oxysalts. Science 365, 473-478 (2019).

73. X. Zheng et al., Managing grains and interfaces via ligand anchoring enables $22.3 \%$ efficiency inverted perovskite solar cells. Nat. Energy, (2020).

74. E. H. Jung et al., Efficient, stable and scalable perovskite solar cells using poly(3hexylthiophene). Nature 567, 511-515 (2019).

75. L. Wang et al., A Eu<sup $>3+</$ sup $>-$ Eu $<$ sup $>2+</$ sup $>$ ion redox shuttle imparts operational durability to Pb-I perovskite solar cells. Science 363, 265-270 (2019).

76. Z. Wang et al., Efficient ambient-air-stable solar cells with 2D-3D heterostructured butylammonium-caesium-formamidinium lead halide perovskites. Nat. Energy 6, 17135 (2017).

77. M. Saliba et al., Incorporation of rubidium cations into perovskite solar cells improves photovoltaic performance. Science 354, 206-209 (2016).

78. A. J. Ramadan et al., Unravelling the Improved Electronic and Structural Properties of Methylammonium Lead Iodide Deposited from Acetonitrile. Chem. Mater. 30, 7737-7743 (2018).

79. A. J. Ramadan, L. A. Rochford, S. Fearn, H. J. Snaith, Processing Solvent-Dependent Electronic and Structural Properties of Cesium Lead Triiodide Thin Films. J. Phys. Chem. Lett. 8, 4172-4176 (2017).

80. K. S. Kim, T. J. Oleary, N. Winograd, X-Ray Photoelectron Spectra of Lead Oxides. Anal. Chem. 45, 2214-2218 (1973). 